\title{
WestVirginiaUniversity
}

THE RESEARCH REPOSITORY @ WVU

Graduate Theses, Dissertations, and Problem Reports

2020

\section{The Costume Design Process for The Phantom Tollbooth}

Chloe Elizabeth Cappuccilli

West Virginia University, cec0034@mix.wvu.edu

Follow this and additional works at: https://researchrepository.wvu.edu/etd

Part of the Other Theatre and Performance Studies Commons

\section{Recommended Citation}

Cappuccilli, Chloe Elizabeth, "The Costume Design Process for The Phantom Tollbooth" (2020). Graduate Theses, Dissertations, and Problem Reports. 7536.

https://researchrepository.wvu.edu/etd/7536

This Thesis is protected by copyright and/or related rights. It has been brought to you by the The Research Repository @ WVU with permission from the rights-holder(s). You are free to use this Thesis in any way that is permitted by the copyright and related rights legislation that applies to your use. For other uses you must obtain permission from the rights-holder(s) directly, unless additional rights are indicated by a Creative Commons license in the record and/ or on the work itself. This Thesis has been accepted for inclusion in WVU Graduate Theses, Dissertations, and Problem Reports collection by an authorized administrator of The Research Repository @ WVU. For more information, please contact researchrepository@mail.wvu.edu. 
Graduate Theses, Dissertations, and Problem Reports

2020

The Costume Design Process for The Phantom Tollbooth

Chloe Elizabeth Cappuccilli

Follow this and additional works at: https://researchrepository.wvu.edu/etd

Part of the Other Theatre and Performance Studies Commons 


\title{
The Costume Design Process for The Phantom Tollbooth
}

\section{Chloe Cappuccilli}

\author{
Thesis submitted \\ To the College of Creative Arts \\ At West Virginia University \\ Partial fulfilment of the requirements for the degree of \\ Master of Fine Arts in: \\ Design and Technical Theatre: Costume Design and Technology \\ Mary McClung, MFA, Chair \\ Radhica Ganapathy, PhD \\ Tiffany Delligatti, MFA
}

West Virginia University School of Theatre \& Dance

Morgantown, West Virginia

2020

Keywords: Costume Design, Theatre, Theater, Children's Theatre, Child Psychology, Norton Juster, Phantom Tollbooth, children.

Copyright 2020 Chloe Cappuccilli 


\section{ABSTRACT \\ The Costume Design Process for The Phantom Tollbooth Chloe Cappuccilli}

This thesis will give an account of the costume design process for The Phantom Tollbooth at West Virginia University. Specifically, the responsibilities of the role of Costume Designer, from initial meetings to final production. This document will include research about child psychology that inspired the primary design process, specifically the influence of children's dreams, and their relationship to toys. This information was utilized to create designs explicitly for children's theatre audiences. I will present and evaluate the costume designs, including the design evolution until the final production. Detailing the process of costume construction while working with a costume shop. Visual aides are provided throughout including research, color renderings, and production photos. 


\section{ACKNOWLEDGEMENTS}

Thank you to the costume shop staff, students, and professors. Every day I was surrounded by people willing to put their time and energy into helping my designs be realized. It was a privilege to have every helping hand for this production. This show had a hefty list of requirements, and I am incredibly grateful for all the effort and time given to it.

To Professor Leland Blair, Professor Robert Klingelhoefer, and Professor Alan McEwen, thank you for your collaboration as director and design team. This show required a lot of imagination and extreme ideas, I felt very lucky to have collaborators who never denied an idea prematurely. This show through all of our ideas was allowed to flourish and I am thankful to have shared this process with all of you.

Thank you to Jacob Currence, my ideal coworker and friend, you were the perfect support team through this process. I did not deserve all the late hours and helping hands you gave me, but I honestly would not have had a show without your help.

To my family, thank you for challenging me and teaching me to question everything, I pursue higher education because of the values you instilled in me. Thank you for always being my parachute and never telling me I should not take the leap.

Thank you to Oscar and Felix, you will never understand how much happiness and stress relief you give me, but I am grateful for it every day. 


\section{TABLE OF CONTENTS}

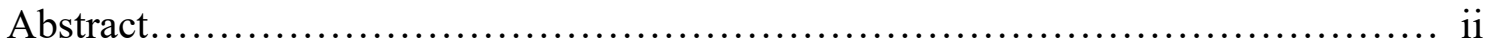

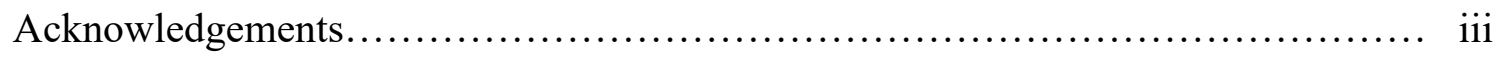

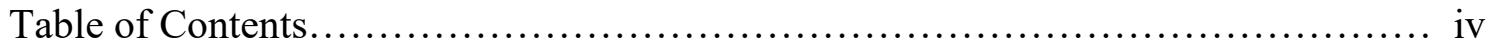

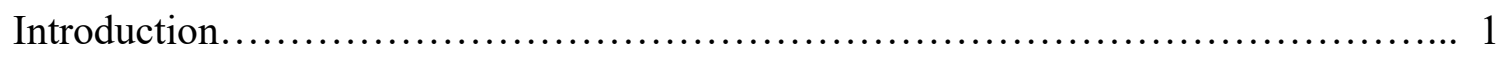

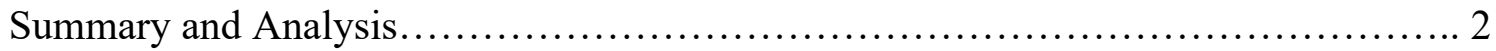

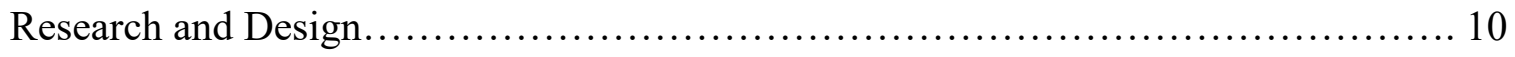

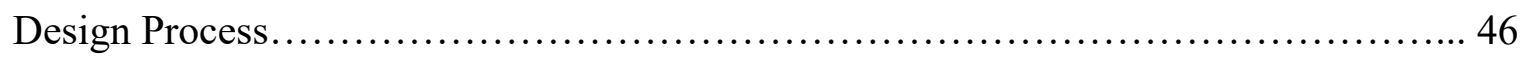

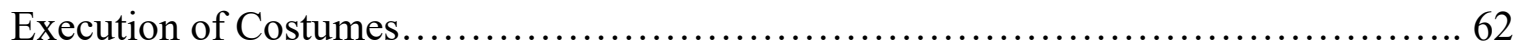

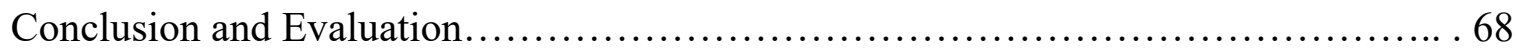

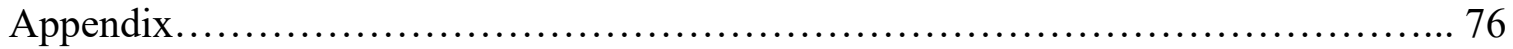

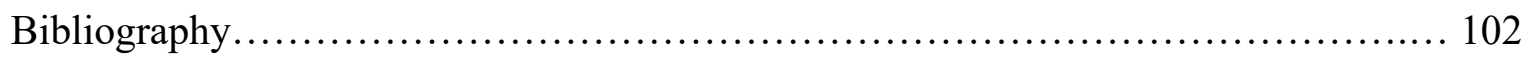




\section{INTRODUCTION}

The following document provides a detailed account of the costume design for The Phantom Tollbooth by Norton Juster adapted for stage by Susan Nanus. Which was the second show in the School of Theatre \& Dance at West Virginia University's 2019-2020 season. This thesis begins with Summary and Analysis of the script and source material. This section describes characters as well as the plot to aid the reader in understanding design decisions made on the production. In Research and Design the script is interpreted for theme and character research. Themes, such as dreams and toys, were directorial choices made for this production. The Research and Design section delves into psychological studies of children's dreams and imagination, as well as, childhood associations to toys. This chapter also justifies the interpretation of the research into individual character designs for this production. Design Process and Execution of Costumes details sourcing and creating the costumes from fitting to opening. It provides documentation of finalized designs, building requirements, and decisions made to achieve the final production. This section also addresses any adjustments made to the costume design to better aid performers and complete the production. Conclusion and Evaluation is a self-evaluation of design decisions and final execution. This addresses flaws in individual character design choices and evaluating the impact of The Phantom Tollbooth for the modern children's theatre audience. 


\section{SUMMARY AND ANALYSIS}

The story of The Phantom Tollbooth is a tale of a child alleviating boredom by imagining a dream quest. This quest was a challenge to his mind by constantly using puns and riddles to cleverly engage the protagonist in a quiz-like thought process. This story is relevant today because its ultimate goal is sharing with children the message that learning is interesting. For children, it uses a large collection of vocabulary like ignorance, dyne, and balderdash. Through larger than life characters, the children's theatre audience finds connotations with words that they would not likely be exposed to until later in their life. The author for the original novel, Norton Juster, has said in interviews that he came up with the story when he interacted with a child who started asking him about the largest number he could think of. Juster and the child played a game of adding one to it, because the largest number is infinite (Stone 2). The book sets up the character of Milo with this quote

"There was once a boy named Milo who didn't know what to do with himself — not just sometimes but always. When he was in school, he longed to be out, and when he was out, he longed to be in ... Nothing really interested him - least of all the things that should have" (Juster 5).

In the play, this notion of Milo being listless is stated by a clock face and it adds an excellent visual that a child, or an adult, can recognize for wasting time. The clock alludes to how time will be manipulated in the story "Funny thing is, time can pass very slowly or very fast, and sometimes even both at once" (Nanus 10).

The purpose of this story is to present different subjects of education with characters that bring them to life and engage the student being educated. The characters even seem to follow an 
average school timetable: The Whetherman is the morning announcements, Azaz is English, Kakafonous is Music, Dodecahedron is Physical Education, and Mathemagician is Arithmetic. Milo is sharing this story from his dream subconscious working out what a day of average school feels like. The characters, contrived in his imagination, help Milo to find a way out of his listless boredom.

This story is all about Milo, a young boy who comes home and is vexed by boredom. The affliction of boredom is common for a modern ten-year-old who has infinite options for entertainment. Milo has video games, toys, and could even spend time with his family, but none of these things seem to interest him. Instead Milo lays down on his bed and looks up to suddenly discover a mysterious package. The package contains one tollbooth, three precautionary signs, a map, and a handbook. These items would surely provide Milo with entertainment if he simply knew what to do with them. He picks up the handbook, begins to read, and then falls into a dream.

The first place discovered in Milo's dream is Expectations, where he encounters the Whetherman who gives Milo multiple options for proceeding. Whetherman relates directly to the imagery of possibilities offered by maps with an infinite list of options but no set destination. This character spirals around Milo as he tries to decipher the maps and signs he comes across. Milo has options to entertain himself but often the sheer mass of options is oppressive. Whetherman is the embodiment of those choices; the character is reminiscent of advertising, loud and persuasive. Eventually Milo moves forward through Expectations, but without a set path. This is how he ends up in the Doldrums.

The Doldrums are populated by the Lethargarians who display the laziest tendencies of human nature. In this scene they share their rules and regulations for life "it is illegal to think or 
think of thinking" (Nanus 15). That of course is the only true pathway to the Doldrums, one must stop themselves from thinking. This scene also includes an iteration of the Lethargarians daily schedule which includes; "putting off for tomorrow what could have been done today, loafing and lounging and of course a healthy portion of dilly dally" (Nanus 15). These characters mock the initial introduction we have to Milo being excessively bored. They constantly nap and the only way to aggravate them is bringing logic and thought into their lifestyle. These characters show how being lost in a lethargic cycle can lead to vast amounts of wasted time. This concept of wasting time is the motivation for the next character Tock, who has the difficult job of preventing time loss in the Doldrums. Tock literally represents the concept of time; he is described as having a clock face on his stomach.

Tock's entrance occurs after the Lethargarians have had a subduing effect on Milo and he begins to fade into sleep with them. This supports the concept of the play being a dream imagined by Milo's subconscious. Tock's abrupt entrance forces Milo to continue with his imagination and not fall into an average dreamless sleep. To get past the Doldrums, all Milo has to do is think. Milo then asks Tock to accompany him to Dictionopolis, and Tock provides Milo with the story of the banishment of Rhyme and Reason.

The story is told through puns in two kingdoms of this realm called Dictionopolis and Digitopolis, each kingdom is divided by its belief in the fact that letters or numbers are the ultimate form of communication. Dictionopolis, the kingdom of words, was ruled by King Azaz the Unabridged with his sister Princess Sweet Rhyme. Digitopolis is the kingdom of numbers and its leader was The Mathemagician with his sister Princess Pure Reason. The leaders of these kingdoms consistently feud over the value of numbers and letters, each feud only being resolved by the compromising efforts of Princess Rhyme and Princess Reason. One day the leaders had a 
particularly rough row, and instead of listening to Rhyme and Reason, they banished them to the Castle in the Air. This caused strife in both kingdoms who could no longer trade and communicate through their once peaceful borders.

As the story ends, Milo and Tock move into Dictionopolis and immediately discover the Word Market. This is a thrilling market where the wares for sale are words and letters. Each letter is sold on how it tastes when pronounced, words are sold for singular usage and budget bundles for common phrases. While in the Word Market, two more characters are introduced, Spelling Bee and The Humbug. These two characters are foils for one another who compete in their use of language. Spelling bee is regimented and consistent, always being able to provide the spelling of words he uses. Humbug on the other hand exemplifies the ostentatious nature of language; he frequently uses words like "Balderdash" and exaggerates syllables and speech patterns. These two characters are the only ones described as bugs. In the scene, they buzz around Milo rapidly debating their value to the kingdom. Both characters band together to guide Milo and Tock into Dictionopolis proper, where they have a meal with King Azaz the Unabridged and his court.

The five ministers of Azaz's court are personified examples of synonyms in language. The ensemble of five use redundant language in a rhythmic pattern to disorient Milo and Tock, who end up following the ministers and await King Azaz at a grand dining table. Once the King arrives the whole party begins to feast, not upon food but instead on their words. Since Milo is the guest of honor, he is expected to choose the menu. Instead of describing a lavish grand meal, Milo requests a "light snack" and immediately trays are brought out that emit glowing light but not food. Milo is also offered food from the "half bakery", where you can eat "half-baked ideas" like "The earth is flat". Unfortunately, Milo and the guests soon learn that half-baked ideas do 
not digest well. The idea of having to eat the words and concepts that you speak shows the audience how interpretive and literal language can be. The rules of Dictionopolis seem to be that thoughts can become reality; if a thought is buzzing around your head it ought to exist. Words themselves are never wasted, and interpretation of those around you is what gives credence to concepts.

Once the dinner party dies down, Milo begins to discuss the fate of the princesses with King Azaz. Milo suggests the princesses should be released and the king agrees, but claims that the Mathemagician is the problem. Not only is the Mathemagician an obstacle, but the Castle in the Air is very far away and guarded by terrible demons. Humbug tells an animated tale of how challenging this journey will be and, since he knows the path well, he is reluctantly guilted into guiding Milo and Tock. This finalizes the trio of heroes needed to complete the journey, and finishes Act One. The heroic trio of this story are beautifully paired, inquisitive Milo, dutiful Tock, and ostentatious Humbug. Using these character traits as strengths, the trio is ready with many defense tactics for the terrors ahead as described by Humbug.

Act Two opens after the trio have travelled in the electric car for some time. They encounter Kakafonous A. Dischord, Doctor of Dissonance who appears in an overwhelming crash of jarring sounds. Kakafonous, as it happens, is a collector of the worst sounds known to man. He also has a wagon full of jars with a variety of sounds. One such being "a blindfolded octopus unwrapping a cellophane covered bathtub" (Nanus 41). Kakafonous also has an assistant who he sends to collect the horrible sounds, called the Awful Dynne. Dynne is a huge amorphic creature that is kept in a bottle and is made of smoke. Both of these characters provide a chaotic scene full of aggressive sounds which included a large amount of yelling. They bring to mind a 
child hearing sounds for the first time and how much a crash or bang can assault the senses, but there is also a musical quality to it --though very poorly composed music.

The next character the trio discovers on the road to Digitopolis is the Dodecahedron, which is a twelve-sided dodecahedron. This character represents the struggle of coping with human emotion. Each of these twelve sides or faces are used to express a different emotion, and therefore this character also only has twelve emotions. It shows these emotions by constantly turning like a twelve-sided dice and landing on individual expressions. Dodecahedron is mathematical in its movements and, due to its geometric qualities, the way it expresses emotion is clinical. The character represents things Milo interacts with that express emotion but lack depth, like cartoons or toys. The scenes when Milo interacts with Dodecahedron show how confused he gets by skin deep or surface emotions. This character is from Digitopolis and fills a similar role as the gatekeeper in Dictionopolis. Dodecahedron eventually guides the trio to the Number Mine of Digitopolis.

Once the trio enter the Number Mine, they quickly encounter Mathemagician, the leader of the kingdom of Digitopolis. Mathemagician is a theatrical character; he even carries a number two pencil as a magical staff. His powers as presented to Milo seem limitless, and he has an answer for every question. In fact, Milo seems to be more in awe of Mathemagician than any of the other previous characters as he represents positive educators throughout Milo's life. In this scene, the trio of protagonists even sit down to watch an arithmetic lecture by Mathemagician, something that never even for a second bores Milo. We see this because he asks questions and is engaged in the topic. Mathemagician ends his lecture by agreeing with Milo's message from Azaz that Rhyme and Reason should be returned to the realm, but leaves Milo worried about the obstacles to come. 
Milo, Humbug, and Tock now move towards The Land of Ignorance-- the final battle ground before they reach the Castle in the Air. In this land they encounter 4 entities/demons; The Everpresent Wordsnatcher, The Terrible Trivium, The Demon of Insincerity, and The Senses Taker. The demons all have childish threats, like stealing the words from your head, doing trivial tasks, and asking an overabundance of questions. None of these characters threaten violence -their voice may drop an octave for dramatic effect, but unlike a classic villain the stakes are never life or certain death. The demons try to deter Milo from using logic and reason to finish his quest.

The trio finally reaches the Castle in the Air, narrowly out running the demons of ignorance. Milo uses the letters given to him by King Azaz to spell "O-P-E-N" on the doors of the castle. Rhyme and Reason are finally free, but as the heroes turn to leave they are overrun by the demons that have been chasing them. However before the demons could get to them, all of the characters from the quest come forward to help. With the help of the large crowd of support the demons are quickly defeated. Now with the quest finally complete they all part ways, and Milo finds himself back in his room coming to the realization that it had all been a dream, and his dream quest had only elapsed one hour of real time.

The story of The Phantom Tollbooth at its core is about finding value in things often taken for granted. Milo heroically illustrates a world of demons, princesses, and realms but each experience is grounded in his life. The thing that challenges the imagination and engages excitement is learning new things. Separations between letters and numbers is much like education dividing a school day into subjects. The fantasy of the Mathemagician differs very little from an engaging elementary school math teacher showing how exciting finding a solution to a complex problem can truly be. As he accumulates souvenirs throughout the show, these 
trophies end up giving him the ability to open the "castle in the air" and defeat the demons. Much like knowledge at the end of a school day, all of the knowledge from each subject can help provide solutions to life's biggest dilemmas. The Phantom Tollbooth is a letter of appreciation to a well-rounded education. Something that Milo a bored ten-year-old coming home at the beginning of the show fails to recognize but Norton Juster reflects on beautifully. 


\section{RESEARCH AND DESIGN}

The story of The Phantom Tollbooth is a childhood favorite for many people. For elementary age children it is often the first long chapter book reading assignment. Norton Juster speaks about reading as a child himself, often picking up family books in Yiddish; "I would read them and have no idea what I was reading, I just loved the way they sounded... if there is a sense of rhythm, a musicality to the way you read the words they can go past almost any difficulty of understanding” (Stone 2).

The Phantom Tollbooth was published in 1961 and both the author and illustrator were veterans from World War II. Norton Juster, particularly, speaks about a child he met and debated with about the largest number. It became a game of adding one to each number, never reaching infinity. In more recent interviews, Juster discusses how children's reaction to his story helped him understand a post war world. Young fans shared with Juster their interpretation, and how they saw the world through their imagination. The wonder of the children being inspired by the story informed Juster of the resounding impact of The Phantom Tollbooth (Stone 2). The illustrator Jules Fieffer saw things differently, he viewed himself as a satirical cartoonist, using comedy and cynicism to reconnect with the world after war. The original illustrations in the book had no backgrounds just gestural sketches of the characters without any environment. This allowed readers to create the world using more of their imagination rather than relying on a clearly defined visual. 


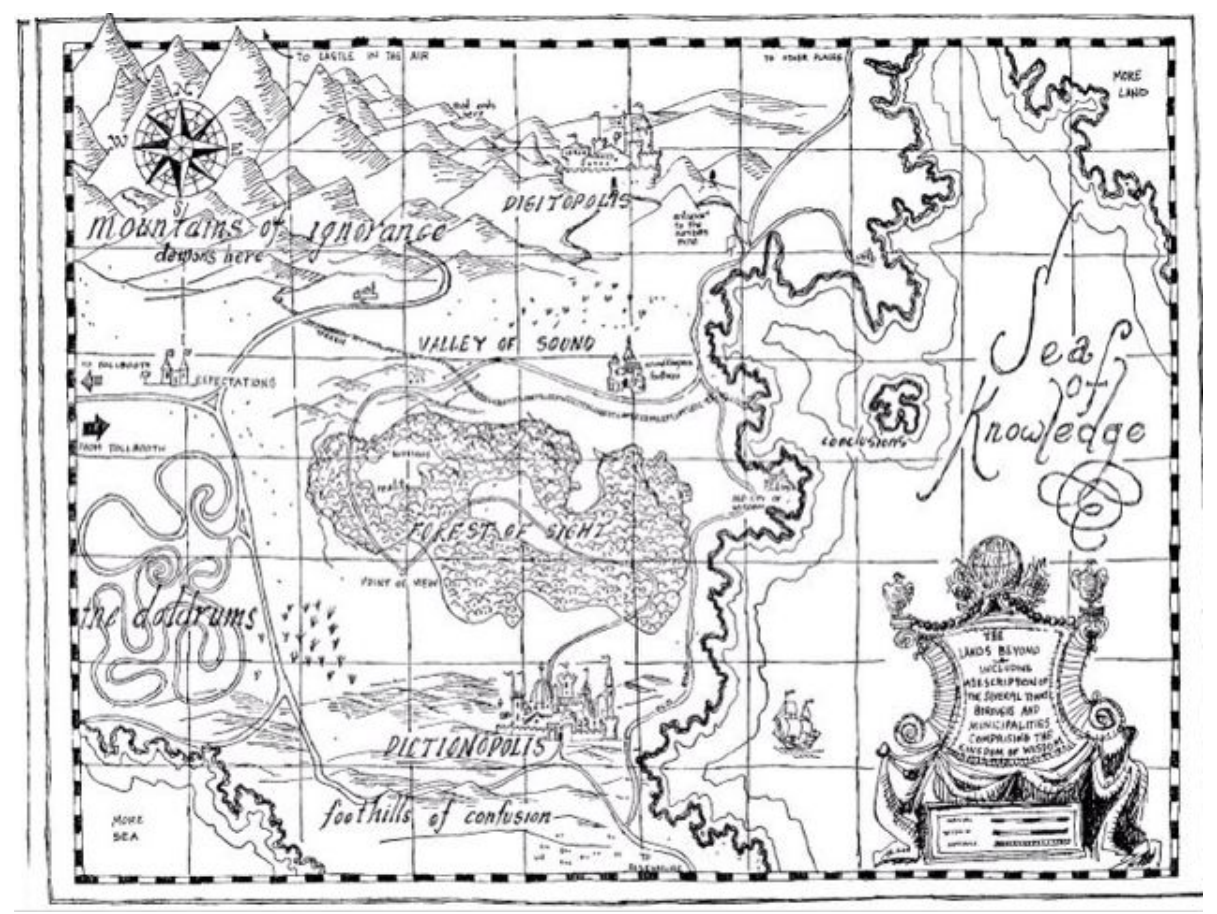

Figure 1.1: Illustrated map from The Phantom Tollbooth Novel (Fieffer i).

Tackling this show began with reading the script and exploring all the source material. This initial preparation helped me as an artist understand not only how relevant this production could be to a young audience today, but also why this story should be a theatrical production. In addition to the research, the first discussion I had beyond my own reading was with the Director, Professor Leland Blair. He gave three essential guidelines for this production: this world was Milo's dream, the time period is modern day, and toys should be the primary inspiration for the characters.

I began the research process looking into the symbolism of adult and childhood dreams. There is consistent evidence showing that highly creative people discover ideas and concepts while asleep. For example Paul McCartney dreamed the melody for "Yesterday" and upon waking was shocked that it was an original idea and not something from his memory (Bateson 
and Martin 3). Studies of dreams conducted on children find that they have often invented several characters and that the scenarios involving those characters often relate to moments of high emotional impact. For Example, in Sharon Saline's study The Most Recent Dreams of Children age 8-11 a subject provides this dream recollection followed by analysis:

"Katie said 'Me and my best friend were on my guest bed jumping around. Then suddenly we jumped to some rings. We held onto them like monkey bars. We kept going diagonally upwards on the monkey bars. With every swing we went through a picture of a generation of our family until we got to the pilgrimage. Then, we fell on to the bed that had been following us when we were traveling up. Try as we might, we couldn't get to those monkey bars again but they were still above us.' In her dream, this girl seems to be aware of fostering new relationships in her life as seen in the presence of her best friend and in her place within her familial history. She also appears to understand the links that connect her to her ancestry, and she is aware of her role in carrying the family forward as she jumps from bar to bar. She sits in the middle of a complicated network of past, present, and future relationships" (Saline 87).

This trial provides a snapshot of how life experience is translated into a child's dream. This study was produced in 1999 as time progressed, technology expanded drastically. Generation Z children are raised with video games, cell phones, and social media. There is also evidence of television having a great effect on children's dreams. Often the subjects and characters of entertainment consumed can invade the environment created in the dream. Interestingly, with television and advertising as a factor, children who recalled their dreams often recalled more nightmares or characters with evil intentions (Stephan et al. 2). This progression of imagination 
in dreams changed how I looked at The Phantom Tollbooth. Milo experiencing this story in 2019 would have a relationship to current pop culture and it would be present in his dreams. This helped me divide characters in the story into nightmare and positive dreams. Characters, like Tock, I treated as a physical toy that Milo knew and loved. As opposed to the demons that feel like levels of a video game, increasing in intensity, as Milo gets closer to the Castle in the Air.

In addition to dreams, the concept of toys became really important to the scenic and costume design. In the beginning of the process, the design team looked at Milo's bedroom and the general consensus was that it should be covered with toys, showing that he was overlypampered with choices. The abundance of toys and opportunities for enrichment that Milo has in his life mocks the concept of boredom, and the director really wanted to highlight that in the story. The moral being that toys for play are really nothing, unless you can inject life in the storebought characters using imagination. To help support this concept, I began wandering toy aisles at big box stores and quickly became overwhelmed by the flashing advertisements and bright colors. This process yielded new varieties of toy themes to consider such as Minecraft, LOL Surprise, and what is currently being developed with the Star Wars franchise. What I discovered was that, in spite of all the innovative and shiny new toys that are popular now, I found myself nostalgically drawn to older products.

As Millennials become parents, toy companies often reproduce nostalgic toys for them to purchase for their children. I found Litebright, Rubiks cube, Boggle, and Spirograph all rebranded for a new decade, but still very much the same product. Since this play was also being produced by a university and most of the audience and performers would experience a similar 
nostalgia for 1990s and early 2000s, it felt like the correct choice to blend those toys with modern ones.
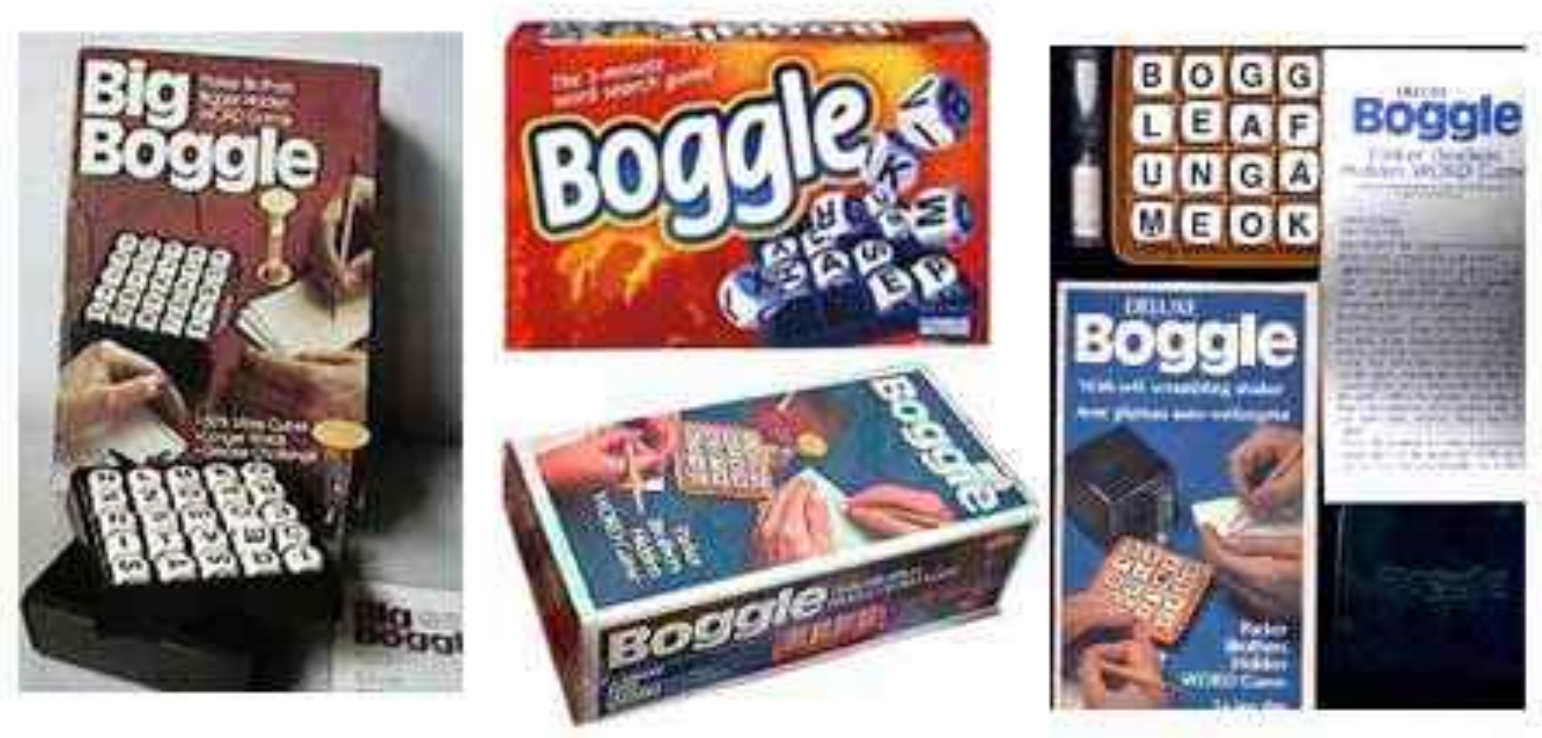

Figure 1.2: Boggle boardgame (Toys in the 90s - The Greatest Popular Toys from the 1990s).

Some of the toys that we wanted for the show came from a broader concept of toys, like Tock as a beloved stuffed animal. The director and I both felt that Tock would be the soft children's toy that Milo slept with, and therefore unlike some of the other characters, he is more at ease in Tock's presence. In child psychology, there is a concept known as the "transitional object" which is often an object that follows from crib through childhood and displays the inherent connection and dependency between mother and child (Singer and Singer 31-32). This concept fit Tock perfectly, since not only did he bring Milo comfort but as a Watchdog he provided protection in a very maternal way. Tock is also the first character to accompany Milo on his journey. These transitional objects are often carried around by the child during early childhood to alleviate stress in new environments. The soft toy or blanket provides a safety from 
the outside world, particularly for children before school age with low exposer beyond the home. This comfort and companionship is usually replaced by acclimation to environments like school with the gaining of friendships (Singer and Singer 36-38).

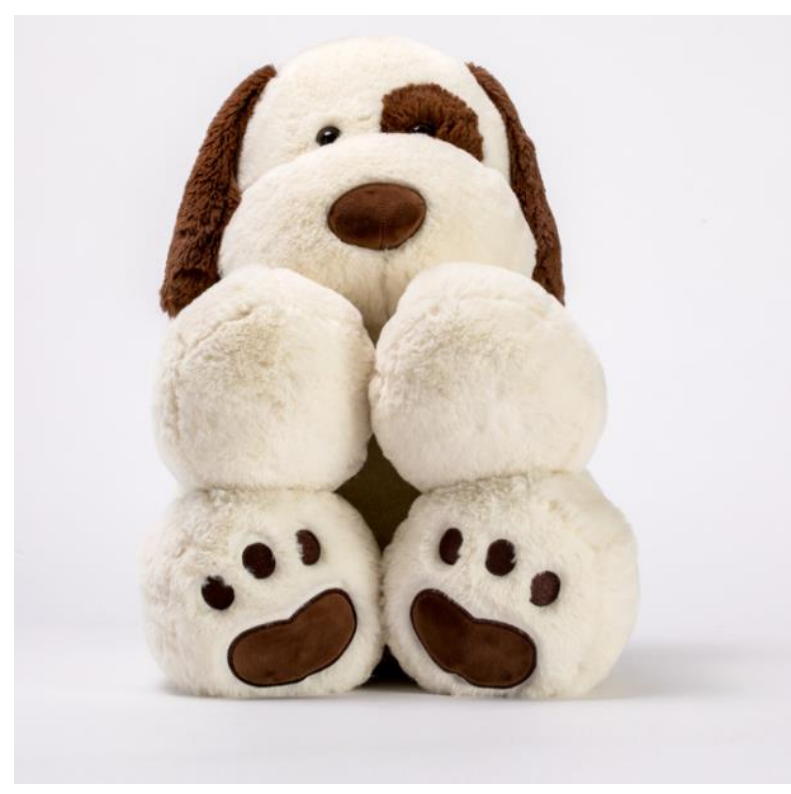

Figure 1.3: (“Cute Sitting Dog Plush Toy”)
The director and I discussed how the concept of toys should not restrict the design process. Every toy used for the realized, live characters did not need to be seen in Milo's room. A lot of the characters came from things that were more synonymous with childhood such as King Azaz the Unabridged who was based on a child's bookshelf, wherein the spines of illustrated books are full of color and meant to entice a child to read more. The world of

Dictionopolis is really built around the concept of a fairytale land.

In general fairytales and/or the fantasy story is one way, that children can become exposed to the concept of romanticized monarchy. These stories center around a Princess longing to be saved by a heroic prince. The act of saving a princess assumes betrothal to the Prince (Engin 103). This is why Dictionopolis uses the term "King" as opposed to Digitopolis that uses a broader term like the "Mathemagician" for their leader. "Fairytale monarchy" was the inspiration for Princess Sweet Rhyme in that her character consistently reminded me of Rapunzel; waifish, flaxen haired, and trapped in a castle. The idea for her costume came first from Boggle, since she speaks exclusively in rhyme, I wanted her to be based on a word game. I felt that Boggle frequently gave her chains of 3-letter words that rhymed in a way similar to that 
of her speech pattern. I found images of cloth princess dolls that reminded me of what a quintessential western European princess, with a dress and full skirt, form fitting bodice, unforgivingly yellow hair and the silhouette roughly resembling the Medieval era. This caricature of a princess was really important in the development of Rhyme, it made her feel both silly and warm. The "highlighter" yellow hair was reminiscent of a child trying to depict blonde hair in a drawing with limited color choices. However, the silhouette and shape of the clothing created a strong connection to the "fairytale" time period.

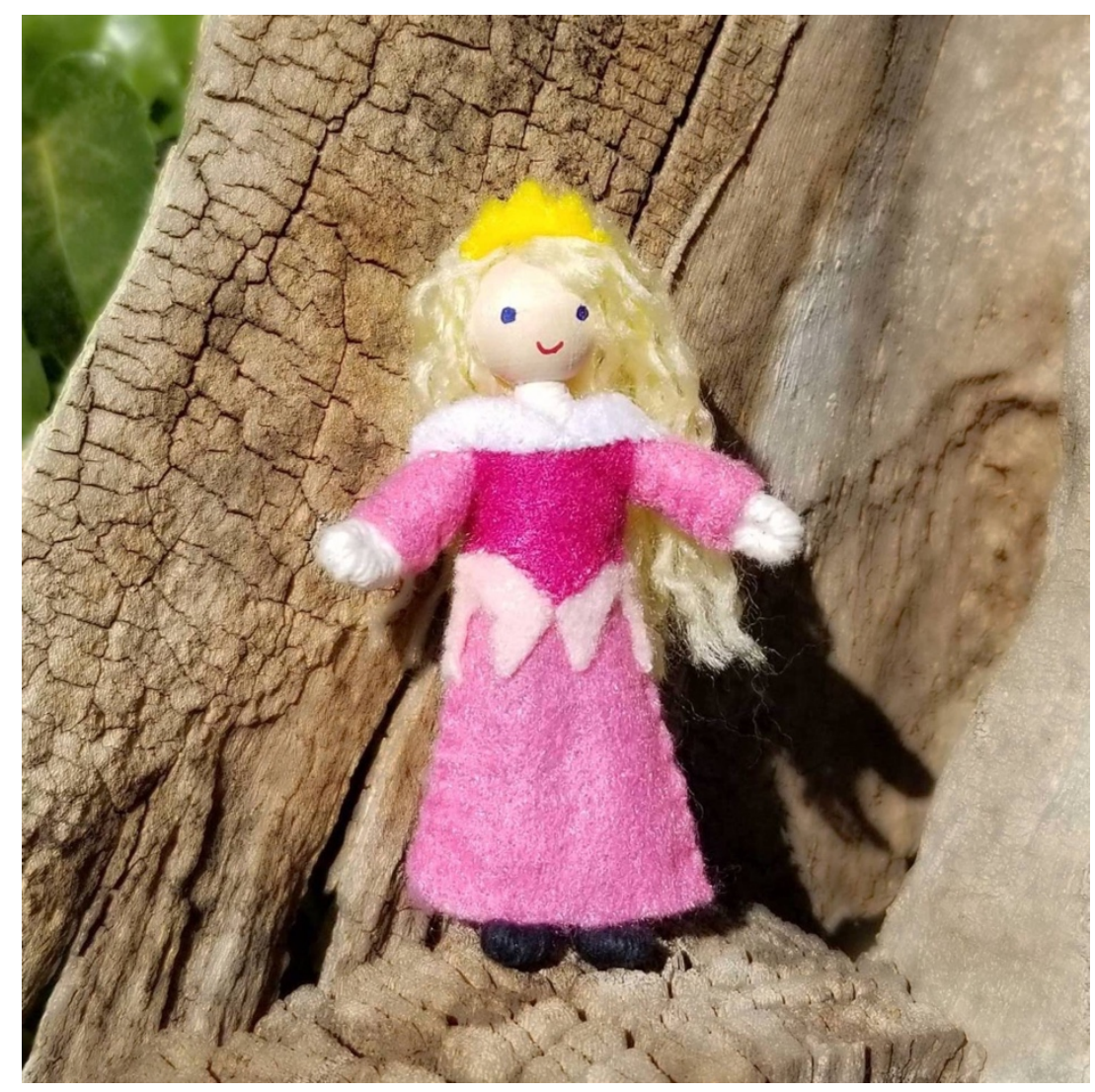

Figure 1.4: Wooden princess doll (“Barker Toys”).

Also in Dictionopolis, King Azaz has an ensemble of five court Ministers who each speak in lists of synonyms using each other's words. Their base costume was a doublet and breeches, with mostly silhouettes from the 1600's to match them with King Azaz. To make the 
Ministers relate more to Milo's imagination I wanted each to have a pop culture head. I was inspired by video game character selection menus; every time Milo asks the ministers a question, they respond by each saying a synonym for the answer. It felt like scrolling through a video game with characters stuck in a ten second animation on repeat. I used this inspiration to assign pop culture heads mostly from video games that a modern ten-year-old boy or girl would use like Minecraft, Mario Party, Lego, etc. The director really enjoyed the idea and so we added a toy soldier to act as the leader and moved the figures around in a militaristic manner. They felt more like toys had come to life rather than people.

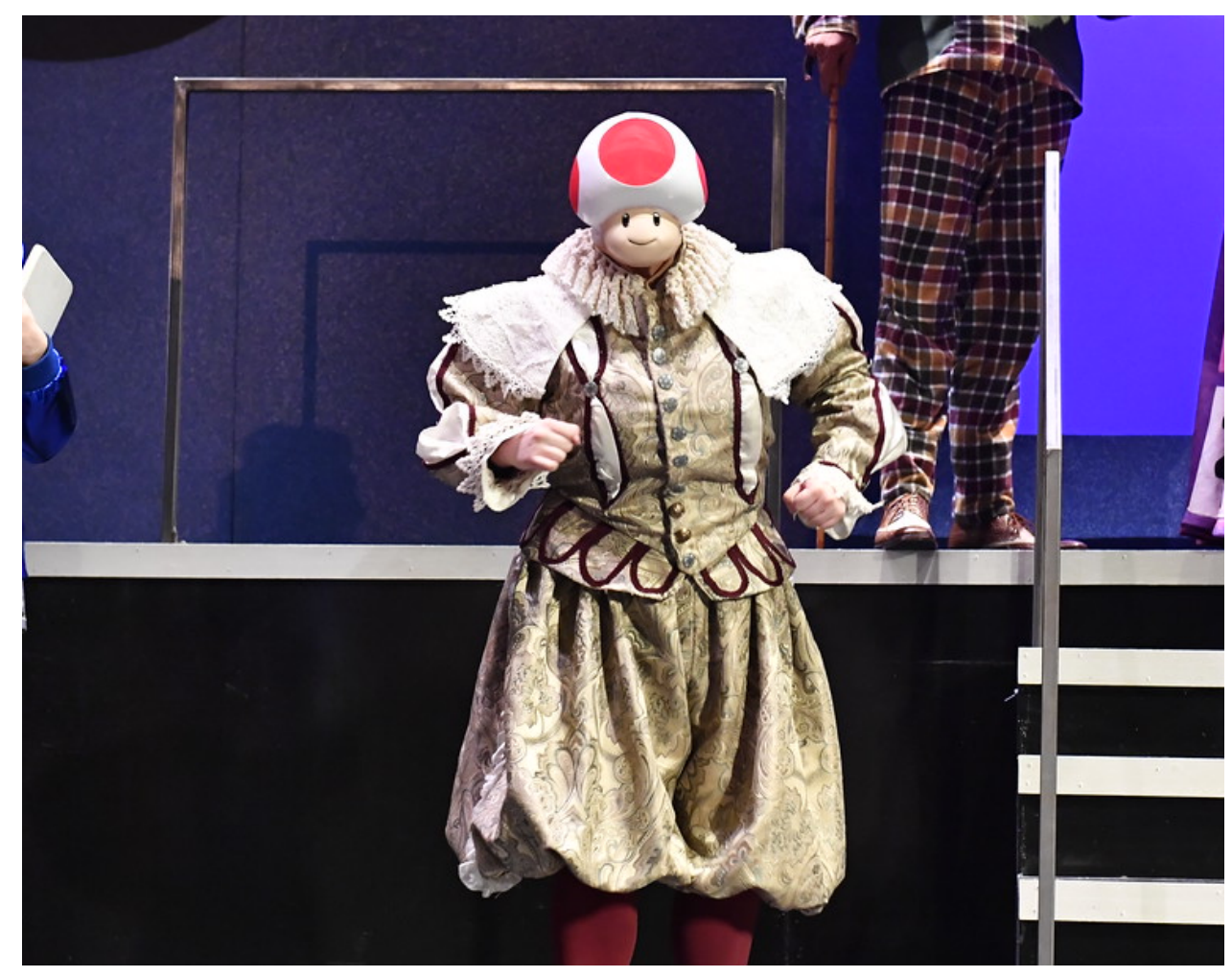

Figure 1.5: The Count of Connotation in Dictionopolis

While driving toward Digitopolis in their electric car, the character they come across is Kakafonous A. Dischord, Doctor of Dissonance, the Purveyor of Horrible Sounds. This character is based on a phonetic toy for infants that engages auditory understanding by associating it with touch and light. Equal inspiration for Kakafonous were children's musical instruments, brightly 
colored tactile objects that are made for children to bang on until they discover rhythm. The toys associated with this character were not just about making sound, but sound that can also be very annoying, like toys that parents remove the batteries from just for their own sanity. Kakafonous A. Dischord was given a baldric with light up buttons that he could hit while performing to activate sound cues. Playing with this toy is using the action of touch for facilitating innovation and while also using play as an effective mechanism for encouraging creativity (Bateson and Martin 78). The light and sound function of these infant-development toys trigger an immediate reaction to a child's touch thus giving the child a sense of control. Hence, these types of toys have remained in fashion for the last thirty years or so.

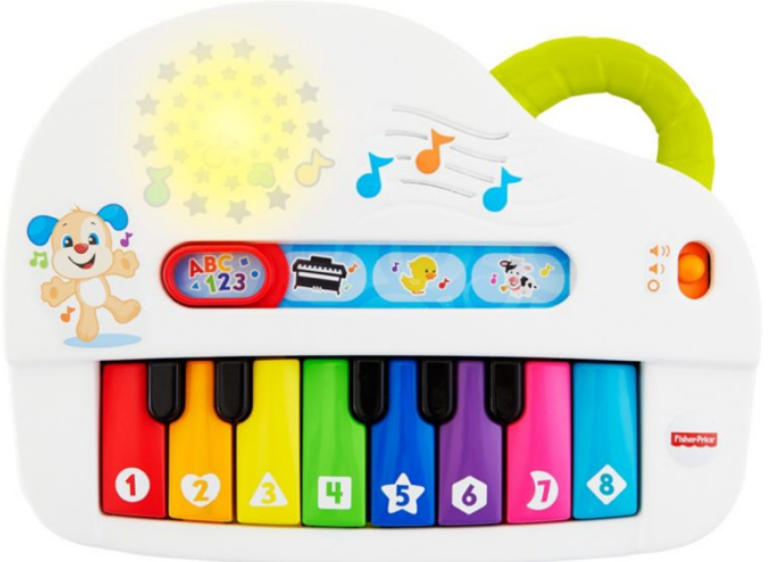

The next encounter for the trio in the story is Digitopolis. The research and design process quickly revealed this to be much more futuristic than a fairytale-like Dictionopolis. All of the toys I focused on for this portion of the play were rooted in math and science and had much less of an

Figure 1.5 (Fisher-Price US | Baby Gear and Toys | Home)

illustrated quality to them. Toys for this world were based on angles and geometry, focusing on imagination as inspiration for building something entirely new. Immediately, the research guided 
me to Tinker Toys, Magnetix, and Legos, this idea of building and expanding for Digitopolis comes from the industrious nature inherent to their culture.

Another character who encapsulated the toys of Digitopolis was Princess Pure Reason. In discussion with the director we wanted Princess Reason to be in juxtaposition to Princess Sweet Rhyme. She was a more modern princess and matched the futuristic appearance of Digitopolis. However, it was still important to the Director for Princess Reason to have a classical princess silhouette like a ballgown. During the research process I explored historical silhouettes to find a large female skirt that was structural in nature, which led me to an Elizabethan farthingale. This silhouette has a flat structure coming out from the waist, the understructure is built in a similar manner to spokes on a wheel. The rigid nature still created a ballgown shape but was reminiscent of shapes made by structural magnet toys. The boning channels created spokes to connect between the inner and outer hoop much like with Magnetix. The pattern of the tracks for the boning in the farthingale became the inspiration for the outer layer of the fabric in this skirt, with the magnetic toys acting as trim, highlighting the pattern of structure. 


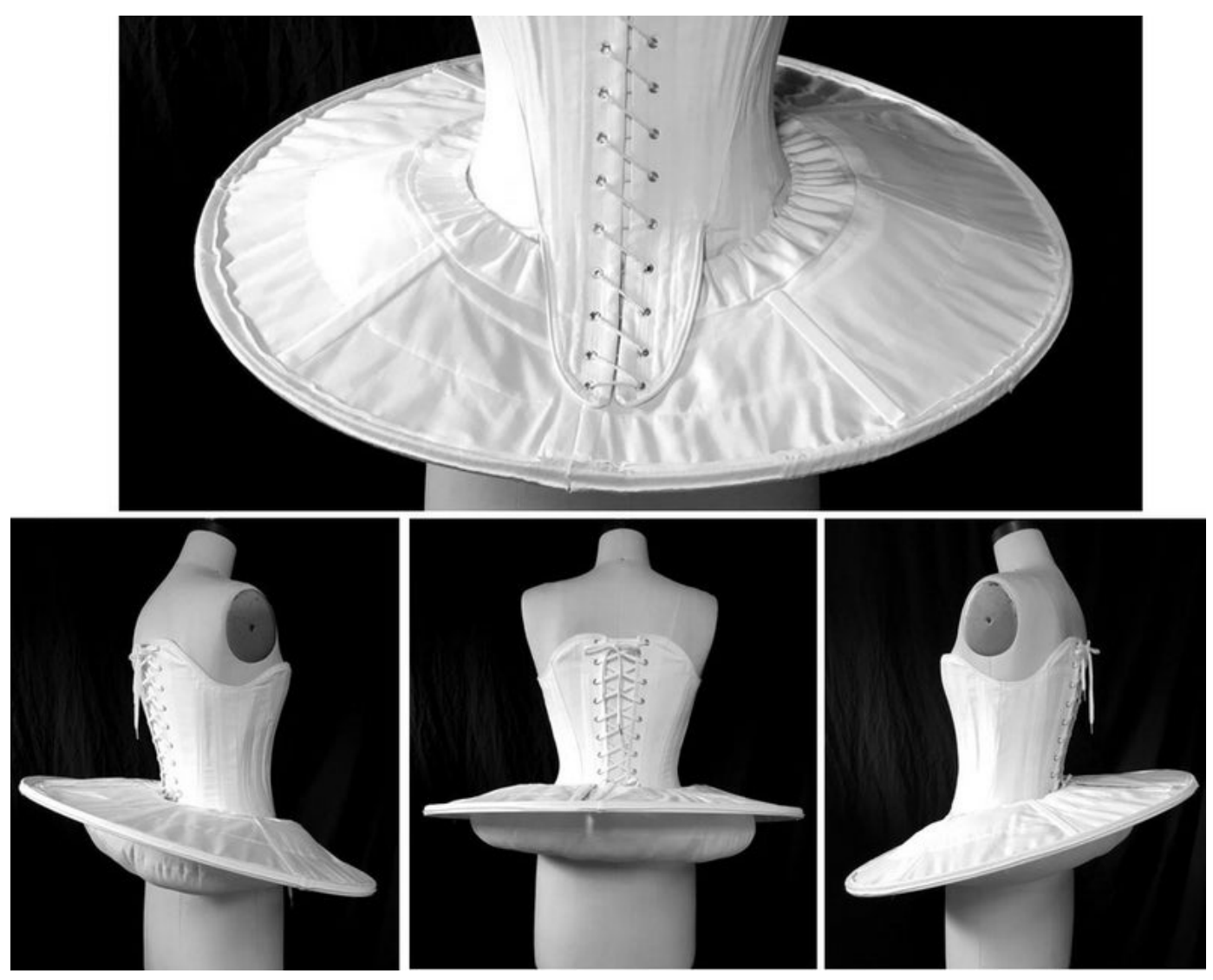

Figure 1.6: ("Farthingale” Period Corsets).
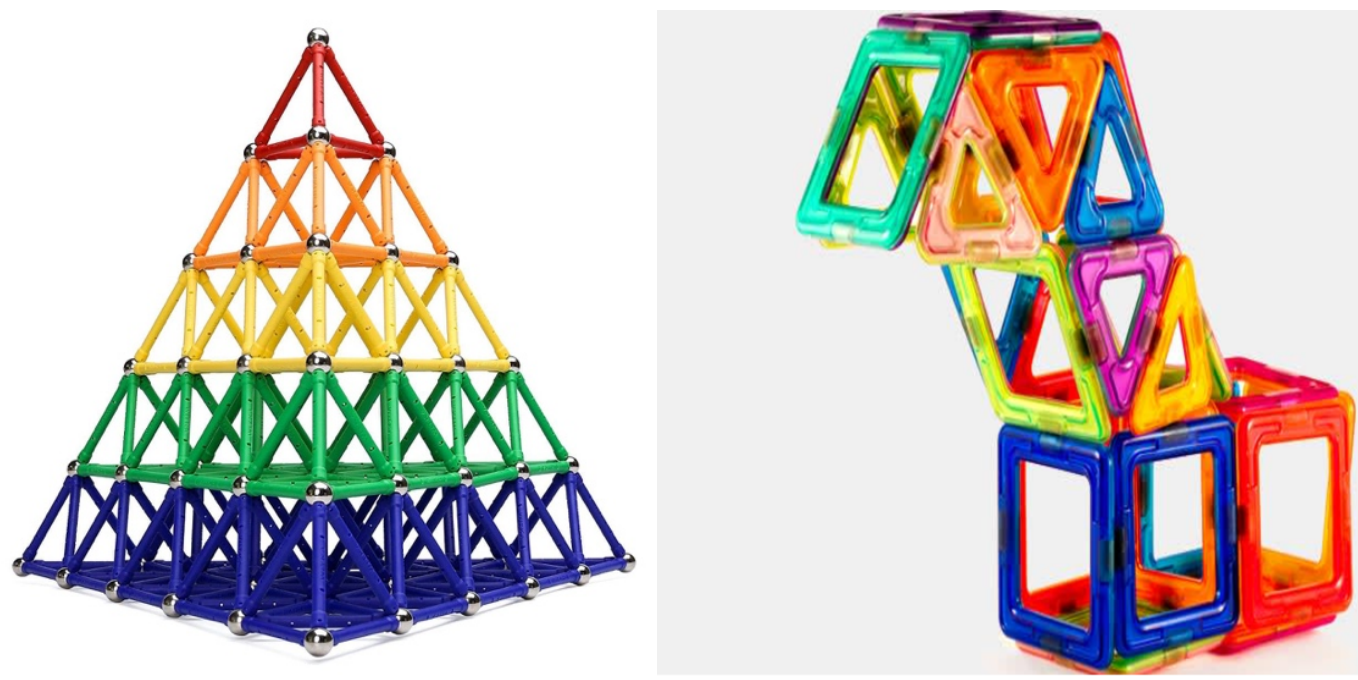

Figure 1.7: (“Best Magnetic Toys for Kids to Buy 2020”). 
As the story moved away from Digitopolis, I wanted the characters to lose the sense of reality and relationship to the human form. Since Milo is dreaming this loss of reality follows a deepening R.E.M cycle into the unconscious of his dream. This led me to researching in greater detail at early developmental imagination, particularly imaginary friends. The call for imaginary or invisible forces is not exclusive to children, adults use religion, astrology, and superstitions to cope with common difficulties of humanity. This is why the idea of an imaginary friend for a child that encapsulates some form of spirit or energy could be looked at as a learned behavior. The term "paracosms" refers to a person mentally inhabiting an imaginary world or society, which often can be very elaborate and detailed. Examples of this are most works of fiction and fantasy, specifically J. R. R. Tolkien who developed an entirely new realm and established a world beyond himself for his characters to thrive (Singer and Singer 49). This idea of a paracosm is obviously relatable to Milo creating the journey and world for The Phantom Tollbooth.

The Demons at the end of the play show a darker side of the imagination, often how innocent interactions can be taken with more negative connotations by young minds. I have already addressed how a character like Tock represents a strong connection to love and maternal protection, but a developing mind might not immediately recognize positive interactions as positive.

“As the baby glances at its mother's face and begins to explore her features, it is attempting to assimilate this strange but interesting object into its consciousness. Is this face "like a ghostly mask" looming so large overhead something to be feared or something to enjoy? How can we assume that mother-child interaction eventually leads to pretend play and its whimsical characteristics?" (Singer and Singer 82) 
The formative childhood years provide a variety of experiences that develop emotional understanding and relationship health. However, Singer looks at the specifics of infancy to show how often healthy interaction can also leave a negative effect on the brain. The demons of The Phantom Tollbooth are inspired by the idea that these creations are filed deep into one's unconscious and as Milo progresses further through his paracosm, he discovers them looming in the recesses of his brain.

Visually, the inspiration for the demons came from children's drawings. I approached this as the epitome of their imagination. Often these drawings are very rough and purely about expression of color and shape, not necessarily seeking defined forms. Yet there are several companies and private artists who work to create keepsakes for parents and children alike that are soft stuffed creatures or sculpted ceramic versions of children's drawings. These became the perfect inspiration for the demons of Milo's unconscious because once the brain is further developed the lack of development in these imaginary creatures can be jarring. Using the drawing to create soft toys took the already twisted body shapes and contorted them further to make them three-dimensional. This added element often took simple beautiful drawings and gave them a sinister edge that only the mother of the child who drew them could truly love. 


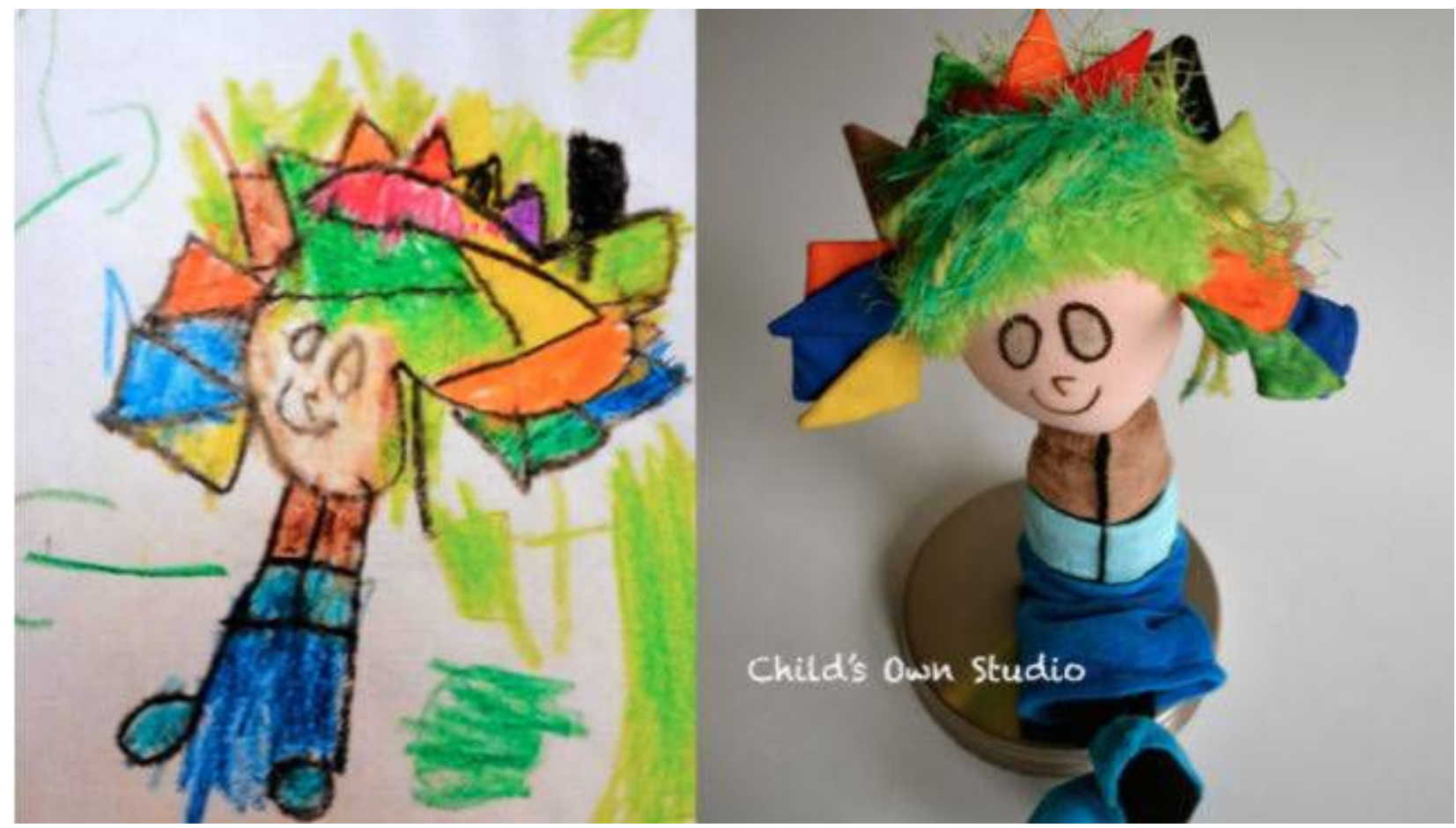

Figure 1.8: Child's illustration and plush toy created from it ("Toys Manufacturer").

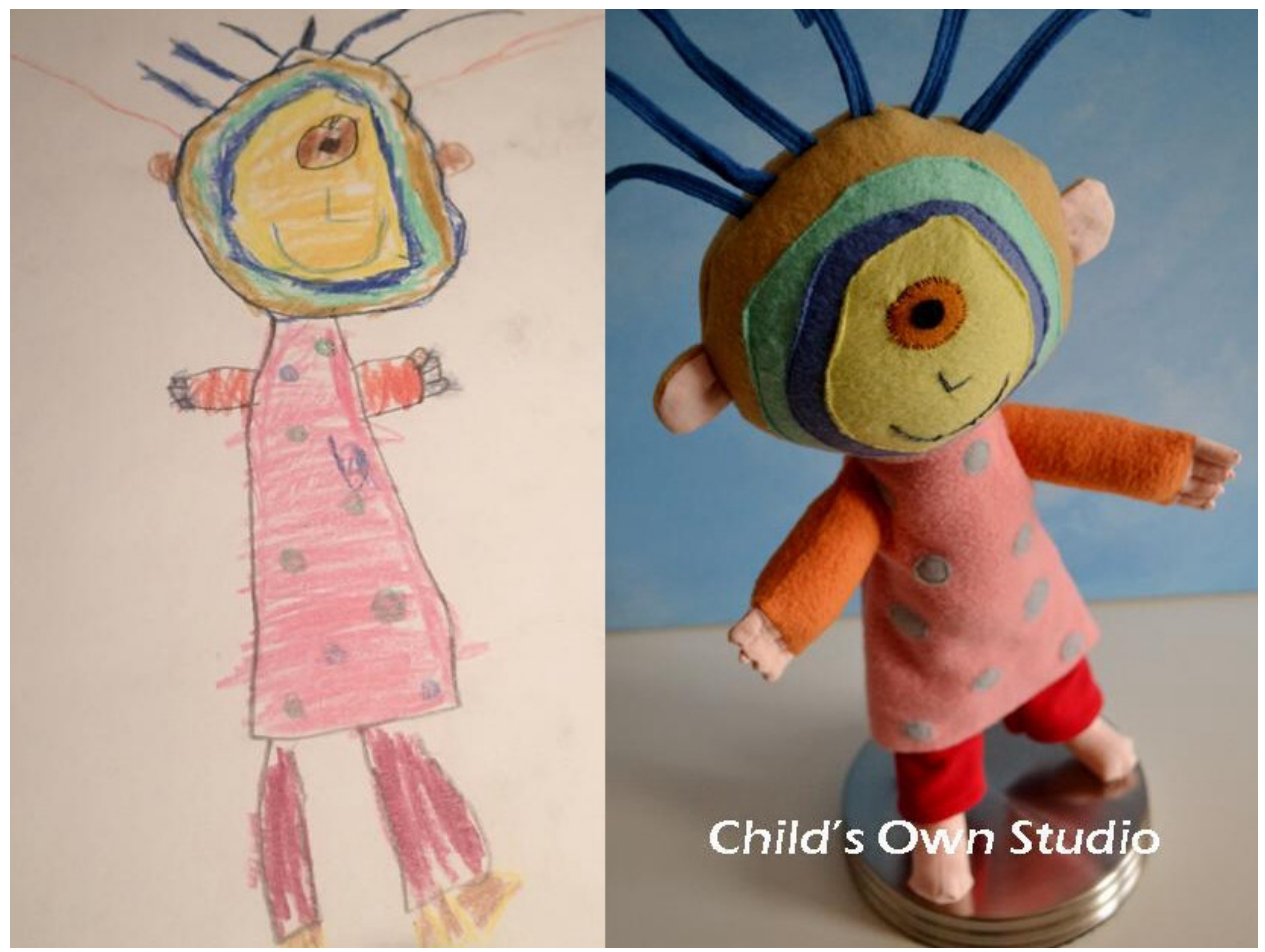

Figure 1.9: Another example of child's illustration made into toy ("Toys Manufacturer"). 
My first one-on-one meeting with the Director happened on Tuesday April $16^{\text {th }}, 2019$. In this meeting I provided options for most of the characters. Many of these initial sketches and ideas did eventually become part of the final design but not all. The first character concept that I struggled with was the Whetherman. The initial toy that I associated with this character was the game Twister; where there is a mat with four rows of colored dots and a dial that the player spins to see which body part lands on which color. I associated the unpredictability of the game of Twister to that of the character of the Whetherman. This character presents Milo with many different directional, seemingly random options for the road trip. To complement the idea of weather puns, I interpreted the spinning twister dial as a weathervane hat. The director expressed that he wanted the idea of the pun "weather" as opposed to "whether" to be more at the forefront of this costume, perhaps with the inclusion of rain garments.

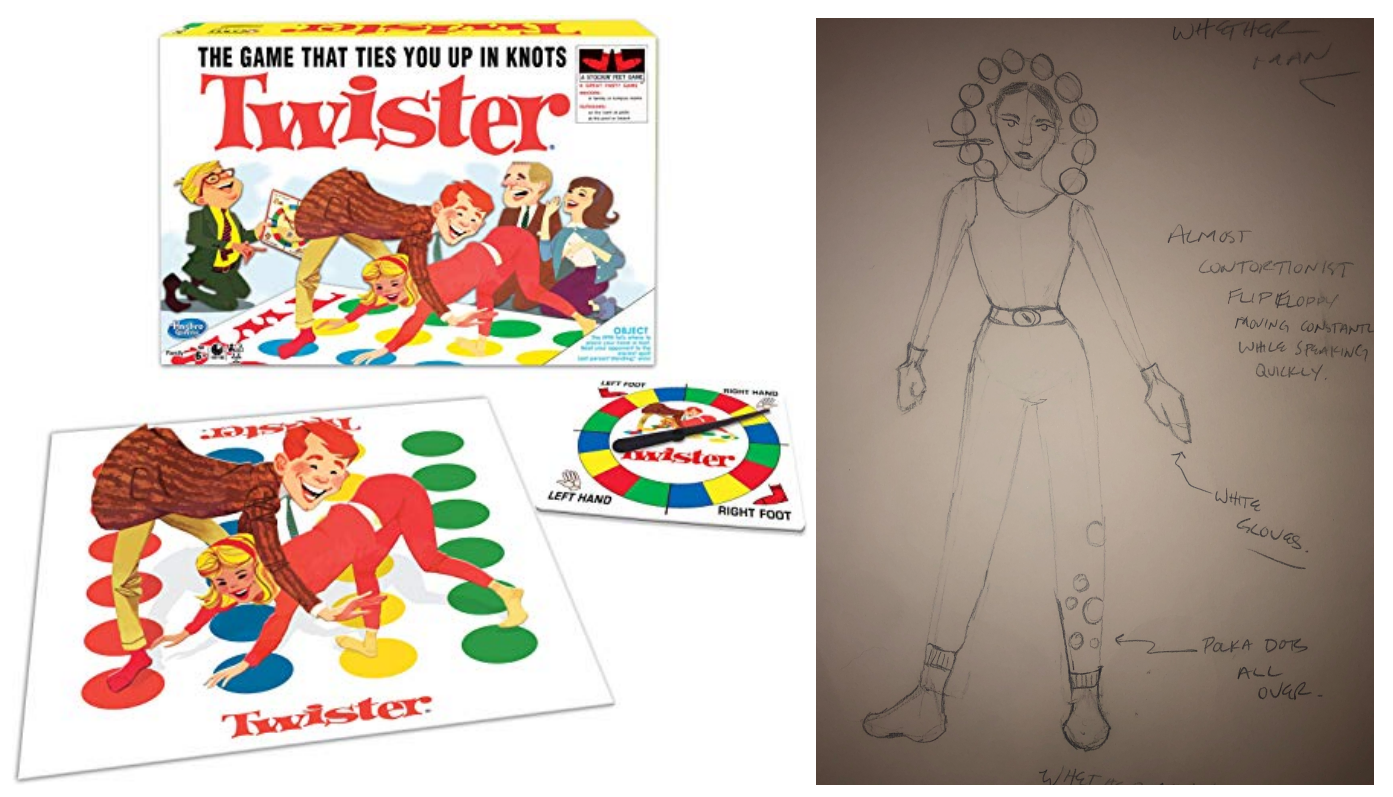

Figure (1.10) Whetherman initial sketch and research (Toys in the 90s - The Greatest Popular Toys from the 1990s). 
The second character that created some debate for us was the Watchdog, also known as Tock. It was established at the beginning of the meeting that the director and I wanted Tock to be a stuffed animal, so I came up with two designs. The first was to make a full mascot suit that covered the performer from head to toe, reshaping their entire body. The second idea was to apply a mascot head, hands, and feet, but let the torso and legs have a police uniform that encapsulated more of the "Watchdog" element of the character. Prior to this meeting, Professor Mary McClung had discussed that the full mascot suit for Tock would be a great project for a student and something that Professor McClung had experience constructing. Professor Blair wanted to work with a students to teach them about performing in a full mascot suit and his preference between the designs definitely leaned toward the mascot suit. The decision seemed to be made but should the multitude of exterior factors not go as per plan, I was comforted by the fact that both designs could work.
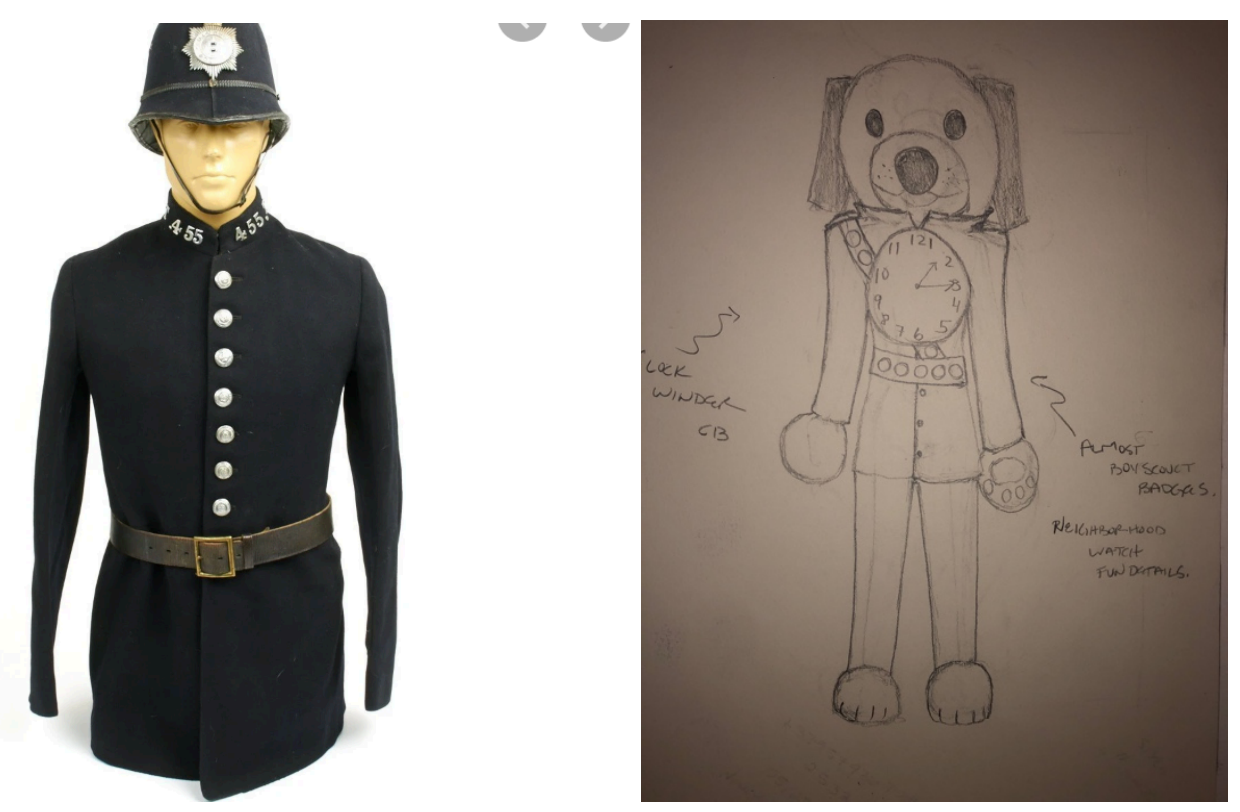

Figure 1.11: Tock the Watchdog initial sketch with police uniform research. 
The Spelling Bee evolved after several discussions with the director. Initially the concept that I sketched was distinctly bee-like by applying the bulbous shape of a bumblebee as a rigid pannier like structure on the hips. From the initial design meeting in March it was determined that Spelling Bee was female, so I never sketched a male version. Spelling Bee as a character reminded me of an arcade prize booth shown in Figure 1.12. I wanted her to have the "ten ticket prizes" from arcades; woven finger traps, sticky hands, popping suction cups, squishy rubber balls, etc. My inspiration for this was that Spelling Bee was a bit of a goody-two-shoes always knowing the correct answer and claiming the prize. I wanted her to be a visualization of Milo's envy. The Director liked the arcade prizes but wanted something that highlighted more of Spelling Bee's age, he saw her as a teenager that Milo could be jealous of because she is so cool. The one article of clothing that Professor Blair was interested in seeing on this character was a leather jacket, to add a more traditional James Dean style cool appearance. This combination of accumulating prizes and being the cool teenager is what eventually became the main factors in the Spelling Bee's design.

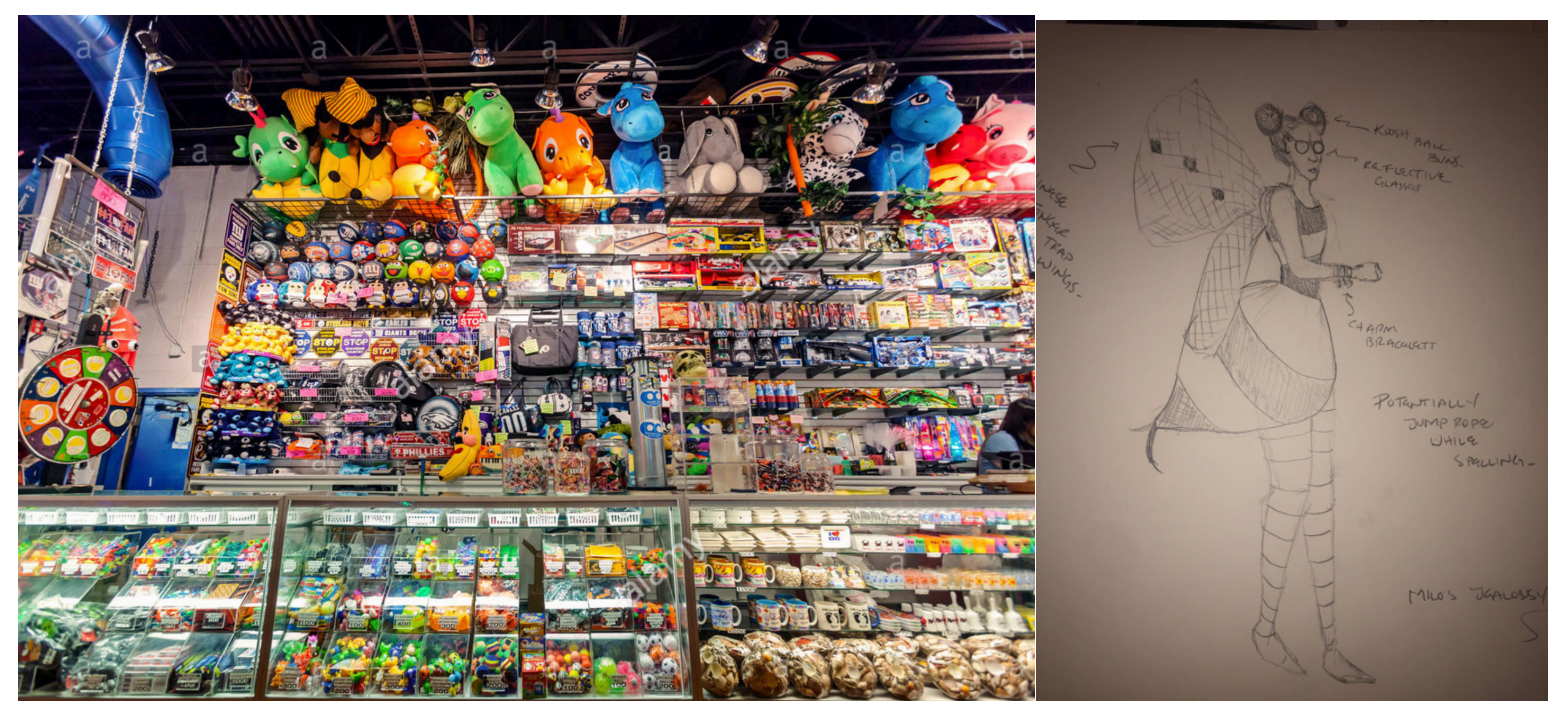

Figure(1.12) Spelling bee initial sketch and research. 
The final character the Director and I saw differently was Milo. My original sketch had Milo in a striped polo, shorts, brightly colored socks and sneakers. I wanted to push the lead character forward from all of these elaborate characters with his own set of colors and palette. The Director however, wanted Milo to have simpler color block clothing, with no patterns. He specifically asked for a solid bright red piece of the costume that would pull focus among the more elaborate characters. After this discussion, I looked into what most current children wear to school and found that a lot of school districts require casual collared shirts and khaki pants or skirts. These dress code policies were public school alternatives to private school uniforms. I therefore thought that this could provide a connection to contemporary students in the audience. Once adjustments were made to the initial sketches, I could move into final rendering. 


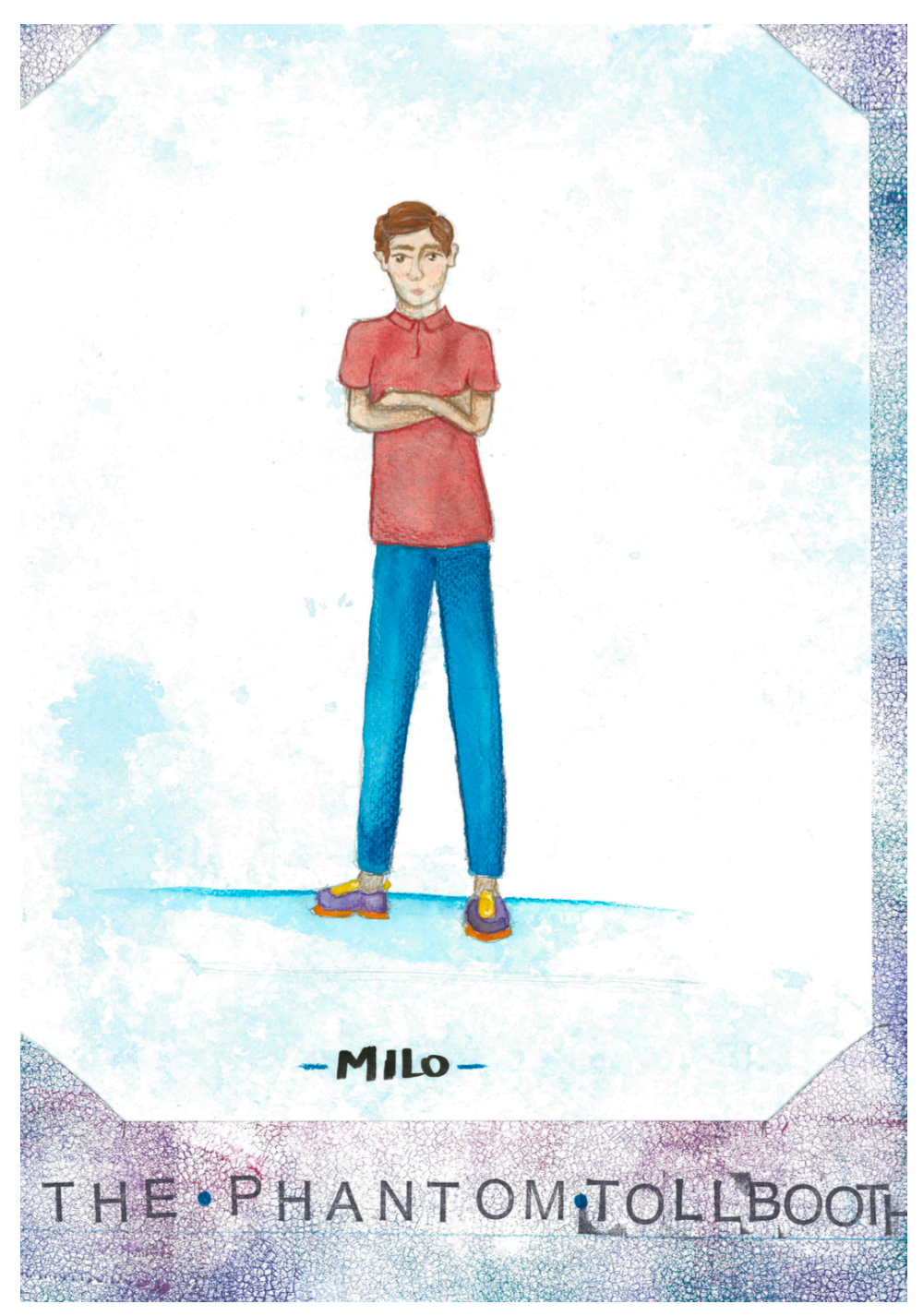

Figure 1.13 Final Rendering of Milo.

Milo needed to look like a ten-year-old returning from school particularly for the first scene where he discovers the tollbooth. For the children in the audience, it was most important to make Milo feel relatable to them. Color choices for Milo came from wanting him to hold attention on stage amongst all the larger fantastical characters. The bright red color isn't present anywhere else in the show, it draws the eye to Milo even when he is being dwarfed by the rest of the trio. 


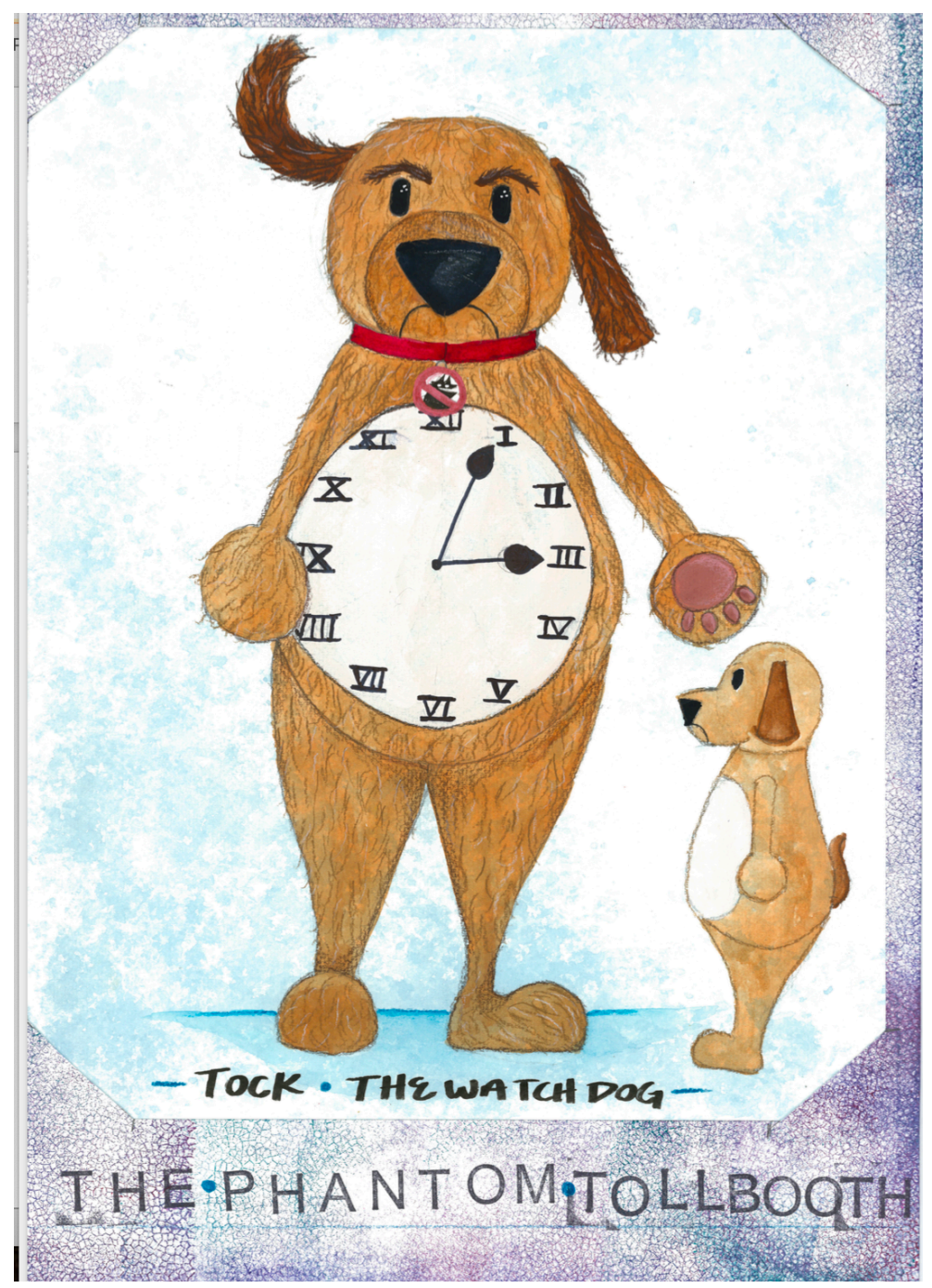

Figure 1.13: Final Rendering of Tock, The Watchdog.

Tock is part of the trio of adventures in The Phantom Tollbooth, his outfit is a mascot suit with ears that move from a trigger mechanism in the paw. His body and head contain a variety of materials, but the understructure is comprised of closed-cell foam, upholstery foam, and muslin. The symbol on his collar is from a neighborhood watch sign, and clock on his stomach is called for in the script. This costume increases the mass of the performer to make Milo appear smaller. He is based on a stuffed dog toy that is of great importance to Milo. 


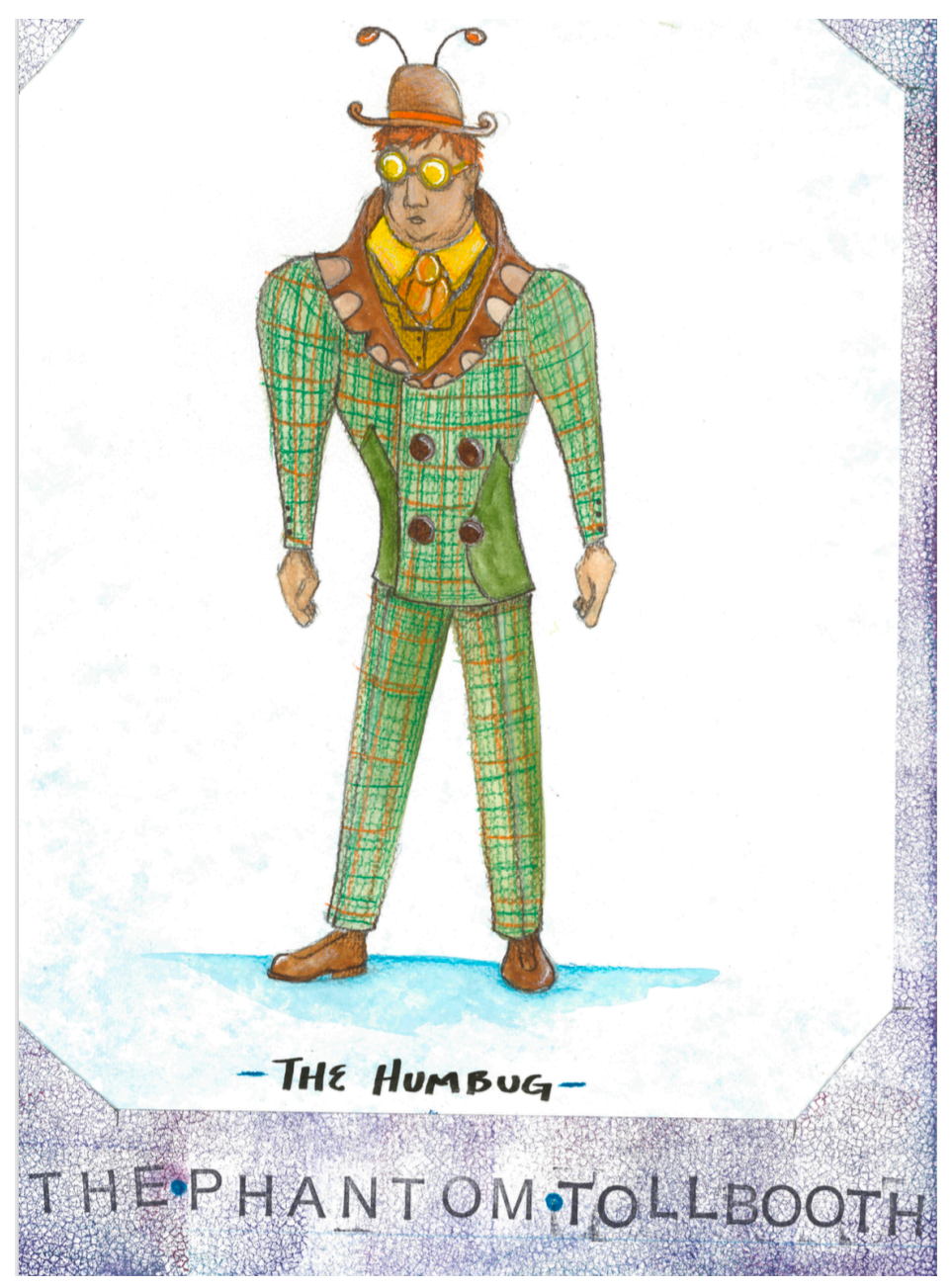

Figure 1.14: Final Rendering of The Humbug.

The Humbug was a two-piece suit with a foam understructure that creates wider shoulders and an oversized bowler hat. The entire jacket is made to zip up in the back, with the vest and shirt pieces on the front as a dickie. The cut of this suit was also tapering the width of the sleeve and leg to give the illusion of smaller bug-like limbs. The collar lifts up to condense the performer's head and make him appear more bug-like by removing their neck. The color palette for this character was pulled from research for plaids, in stage directions the plaid and the bowler are mentioned, and I wanted to give him elements of an upper crust British man in the 1960's. This would highlight the very particular vernacular of the character being so different from the rest of the ensemble. 


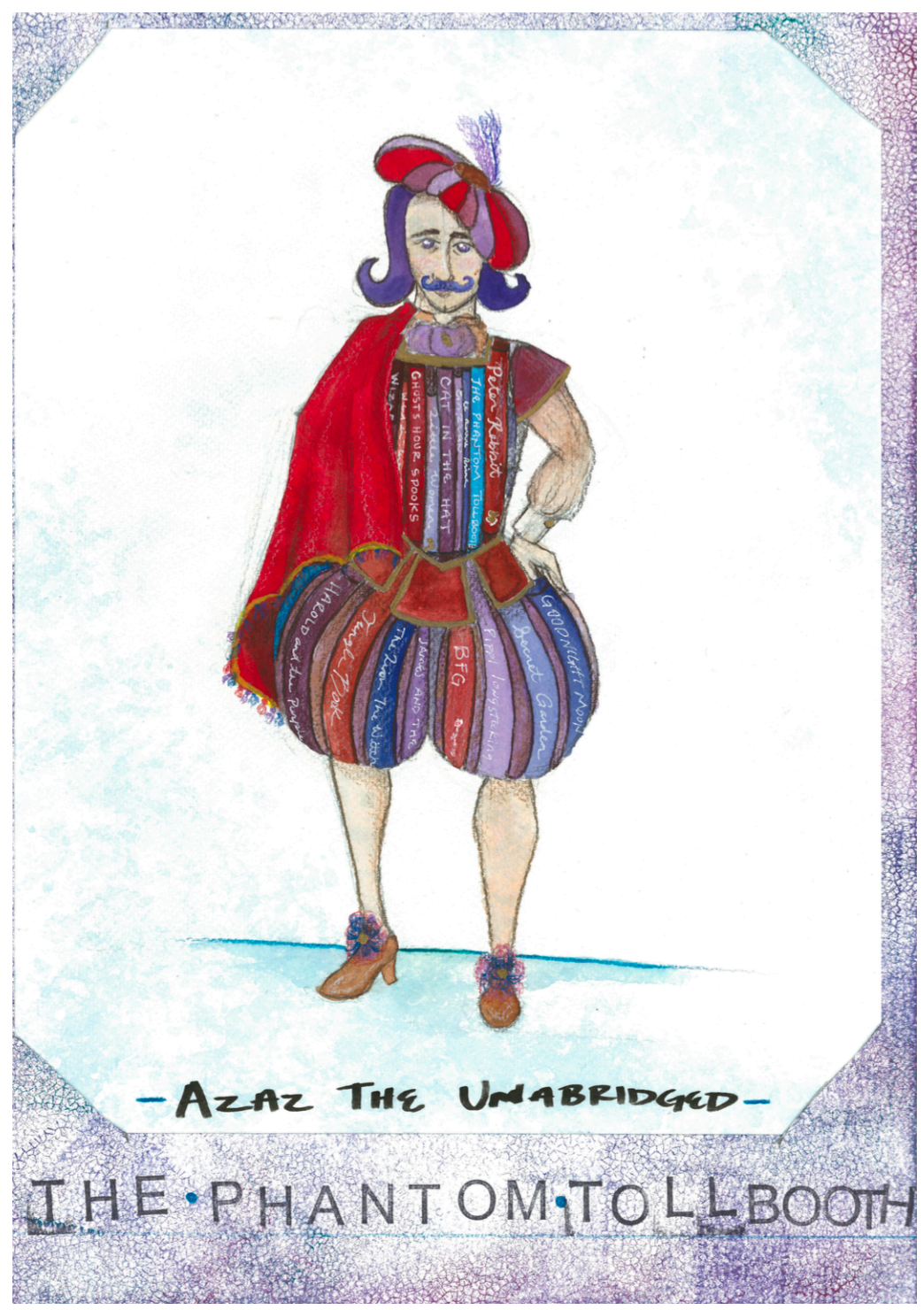

Figure 1.15: Final Rendering for King Azaz the Unabridged.

King Azaz costume contained a doublet pumpkin breeches and a red circle cape. The entire costume was decorated with book spines of children's books. This character is inspired by the general idea of a child's bookshelf. The refined color palette from the original sketch came from common regal colors like rich reds and purples, with blue added as an accent color. While the hat and cartoon style purple hair were later changed, originally the structured purple hair was intended to make this character feel more foreign to Milo. However, the clothing being from a time period so distant to Milo, proved sufficient. 


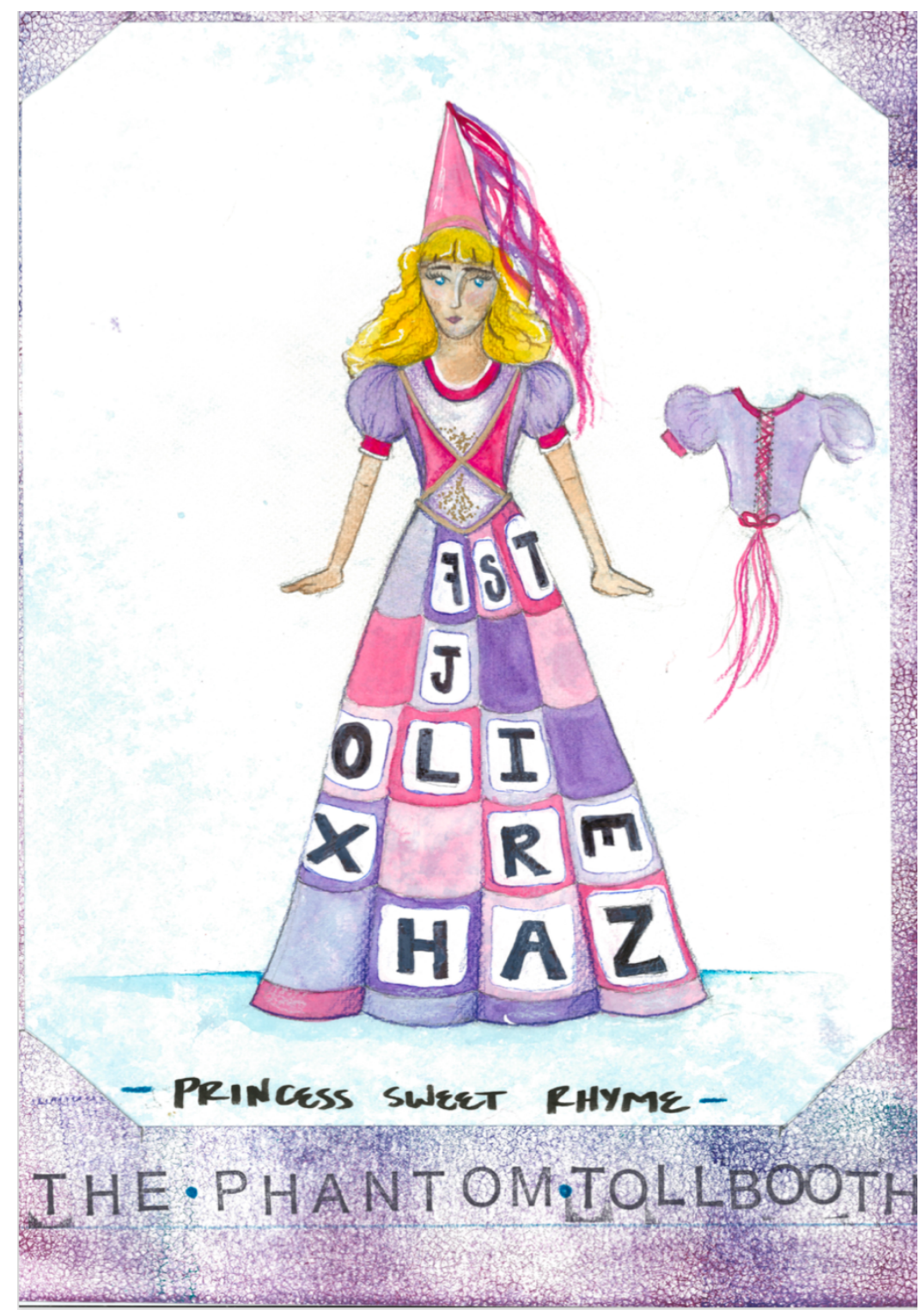

Figure 1.16 Final Rendering for Princess Sweet Rhyme.

Princess Sweet Rhyme was in a full ballgown and conical hennin with a veil made of ribbons. Princess Rhyme was based on Boggle the Board game as well as traditional princess tropes. The shaping of the style lines on her bodice are an illusion to the sand timer used in the board game, to emphasize these lines gold piping is applied in the seams. The entire dress is painted with the checkerboard colors with the white letter die painted on top. Her hair color was bright yellow to remind the audience that it was inspired by child drawings. 


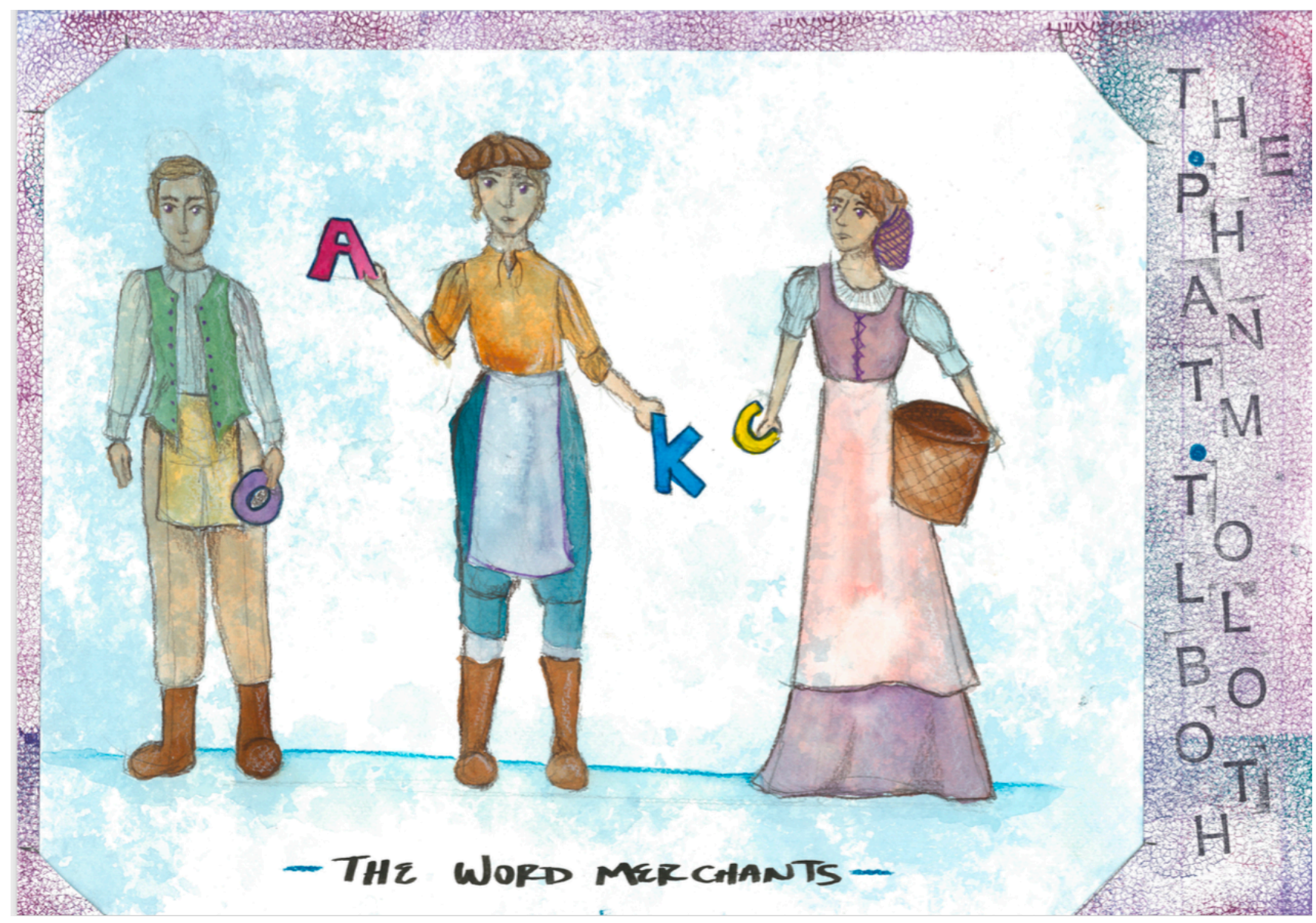

Figure 1.17: Final Rendering of The Word Merchants.

This ensemble served two purposes in the script; as the word merchants and populating Dictionopolis in various scenes. Their clothing needed to evoke peasant clothing from the early seventeenth century to set the time of Dictionopolis in classic fairytale. The biggest difference though is that the colors needed to be bold and bright. The Word Market is Milo's first introduction to Dictionopolis and having a large variety of color in the costumes would make it seem more fantastical to him. 


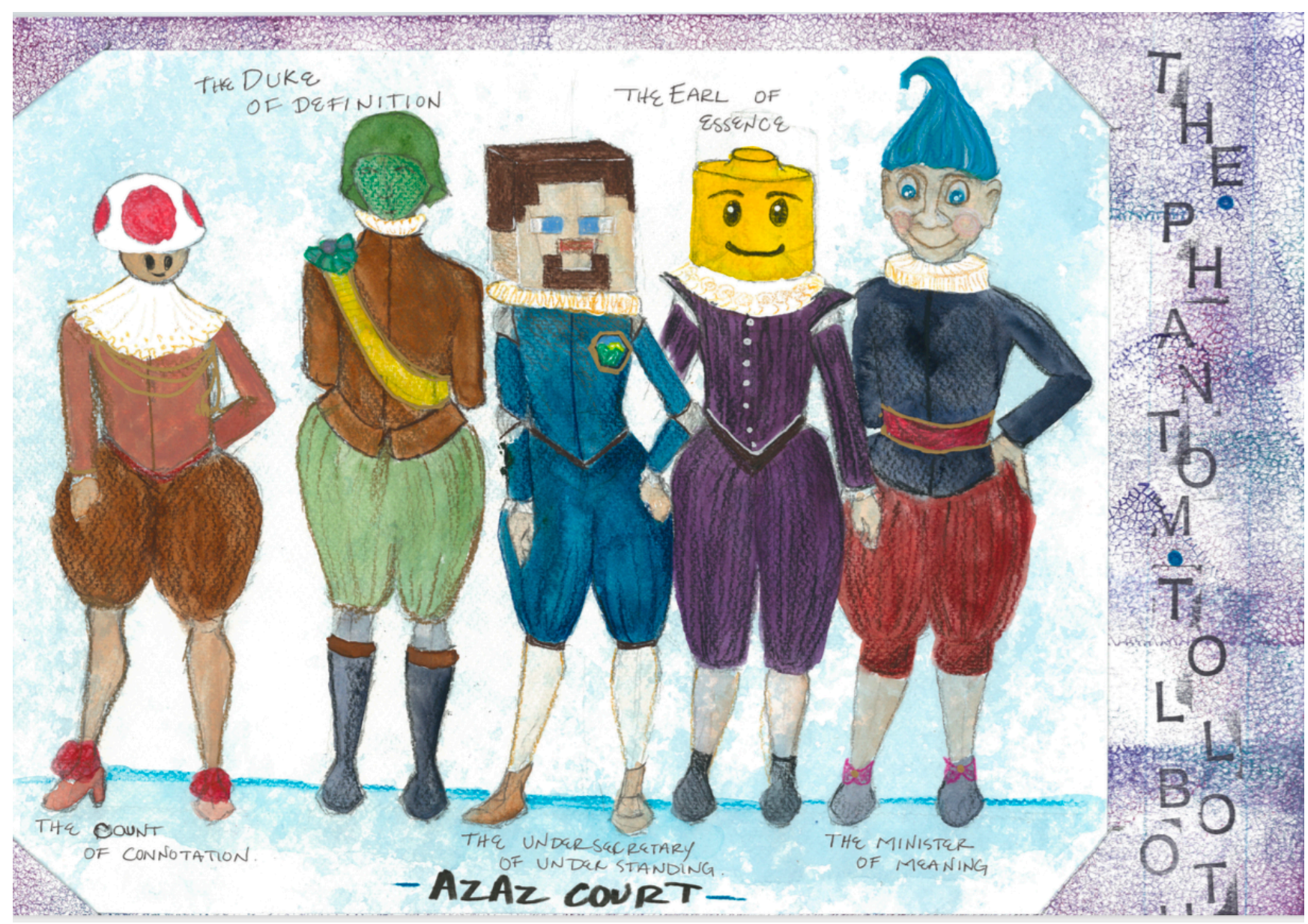

Figure 1.18: Final Rendering for King Azaz's Court including: The Duke of Definition, The Earl of Essence, The Count of Connotation, The Undersecretary of Understanding, and The Minister of Meaning.

This ensemble was created to match the time period of King Azaz, however the biggest difference is the pop culture mask heads. These masks were applied because of the concept of going deeper into Milo's dream and how the subconscious often warps reality. Each of the masks is based on common modern toys like Lego, Nintendo, and Minecraft. All of the doublets and breeches were sourced from costume stocks, but this rendering showed a general idea of shape and color. In the end, the costumes were much darker colors with several patterns. 


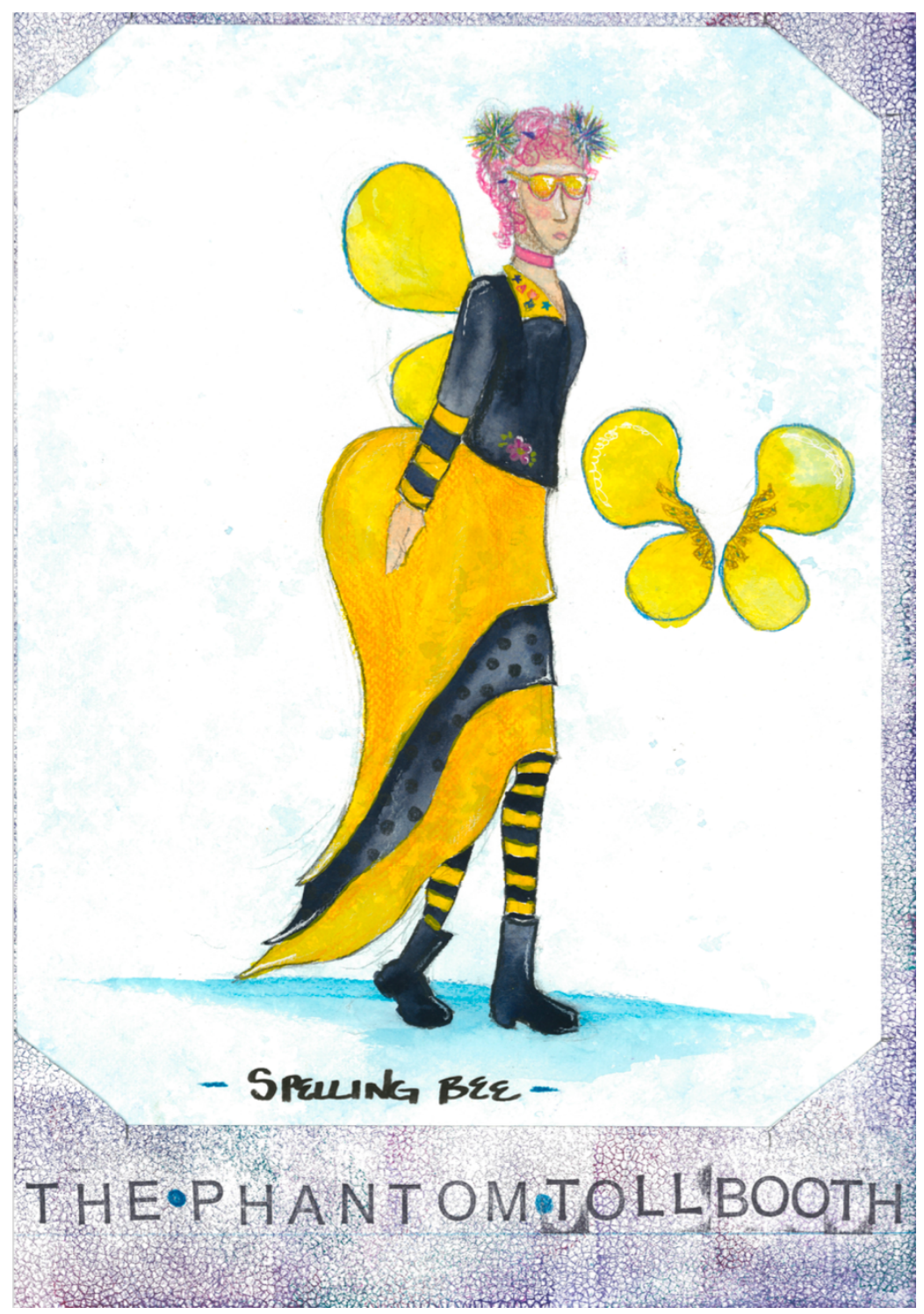

Figure 1.19: Final Rendering Spelling Bee.

Spelling Bee's costumes was comprised of a three-tiered skirt, leather jacket, and wings.

The skirt had a large bustle understructure to create the more bulbous body of a bee; and this roundedness was also the inspiration for the shape of the wings. Black and Yellow were the clear choices for the coloration of the bee but I controlled the stripe placement. I used the tiered skirt, tights, and jacket to show the stripes of a bumble bee, while shifted the scale to integrate the performer's body. I designed the wig to also pull focus, with bubblegum pink hair, koosh ball buns, and multiple hair clips. 


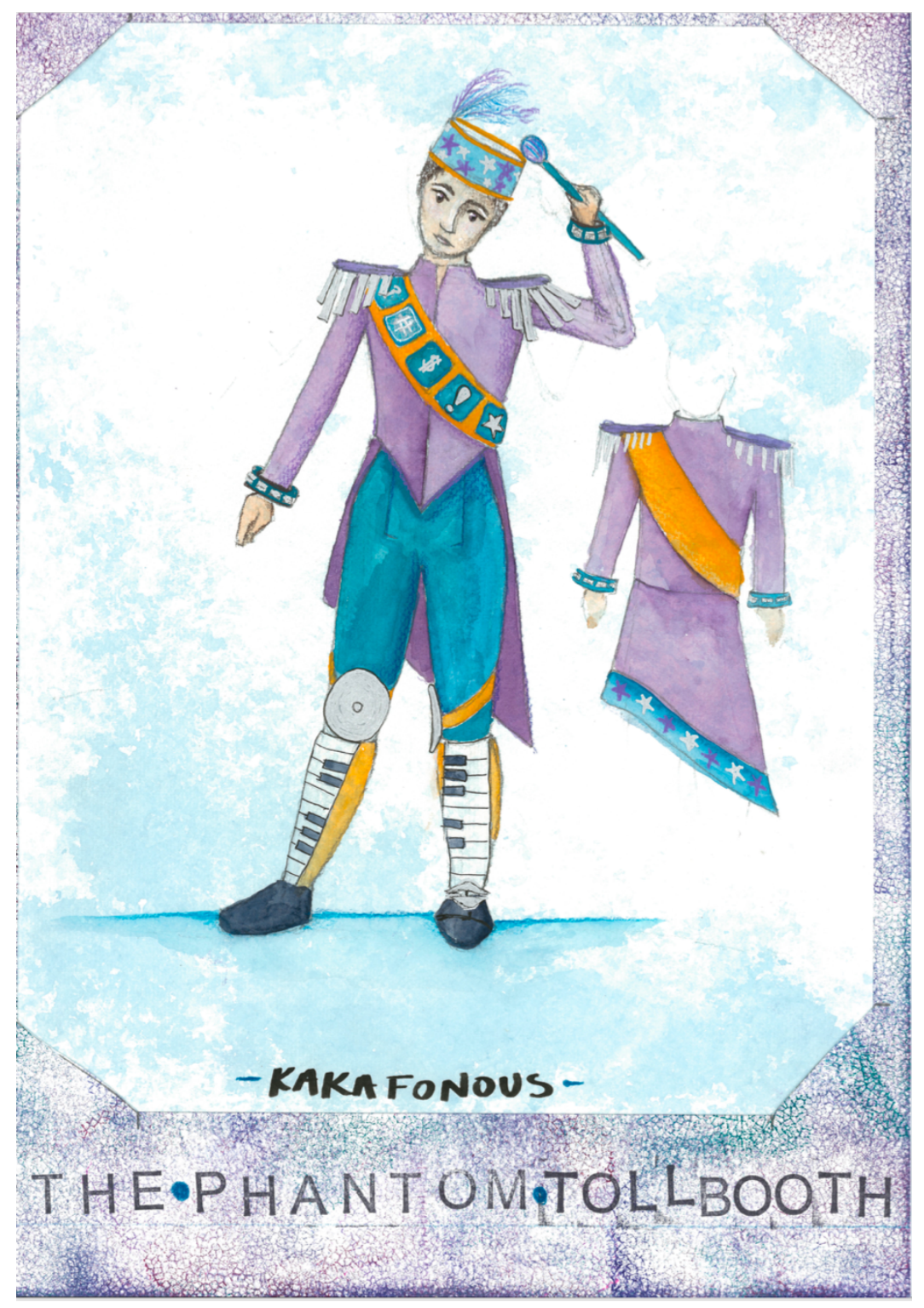

Figure 1.20 Final rendering of Kakafonous A. Dischord.

Kakafonous was based on a one-man band specifically was the one-man band made up of children's instruments. I wanted this character to be able to interact with the instruments during his movement around the stage, we wanted sound associated with it. So, the epilates with wind chime fringe were going to be real as well as the foot symbols and larger symbols at his knees. The baldric across his chest is based on an infant toy with light-up buttons as the performer uses the buttons to indicate sounds all around the stage. 


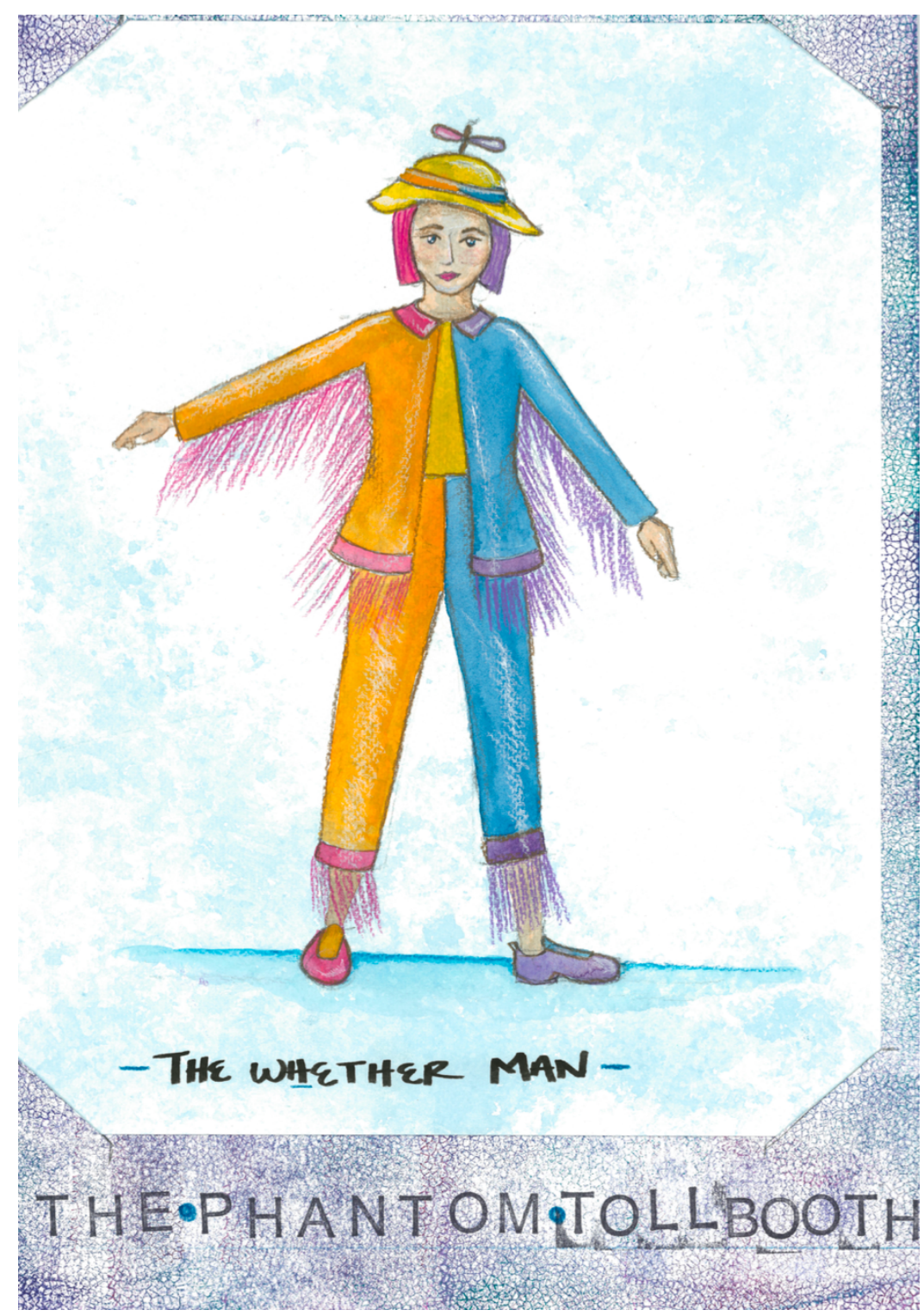

Figure 1.21: Final rendering of The Whetherman.

This costume was comprised of a rain cap, two-toned jacket, and pants. Whether man was a representation of a fork in the road. I knew this character was going to be very active on stage which made the fringe important because it activated the costume with the performer. Another element of duality for this character was between whether and weather. To highlight the weather portion all of this clothing was vinyl rain gear. 


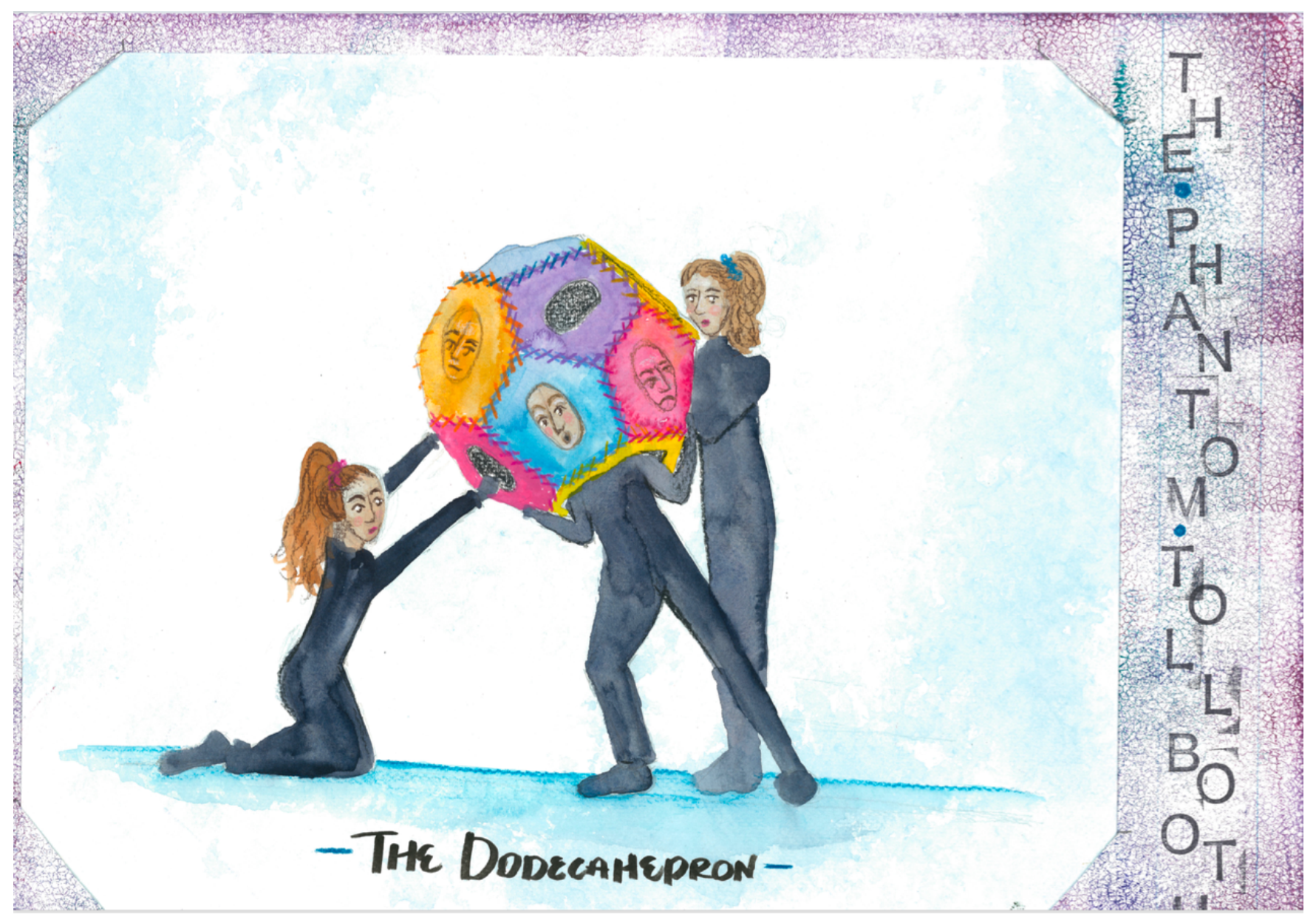

Figure 1.22: Final Rendering of The Dodecahedron.

The Dodecahedron was performed by an ensemble. Each performer was in puppet blacks and could stick their upper bodies and faces into the foam dodecahedron to deliver lines. I wanted this ensemble character to perform like children playing ball on field. The foam puppet could be thrown around the stage and turned rapidly. When Milo crosses paths with the Dodecahedron he should feel ensnared as they throw the ball around him and speak in riddles and rhymes. 


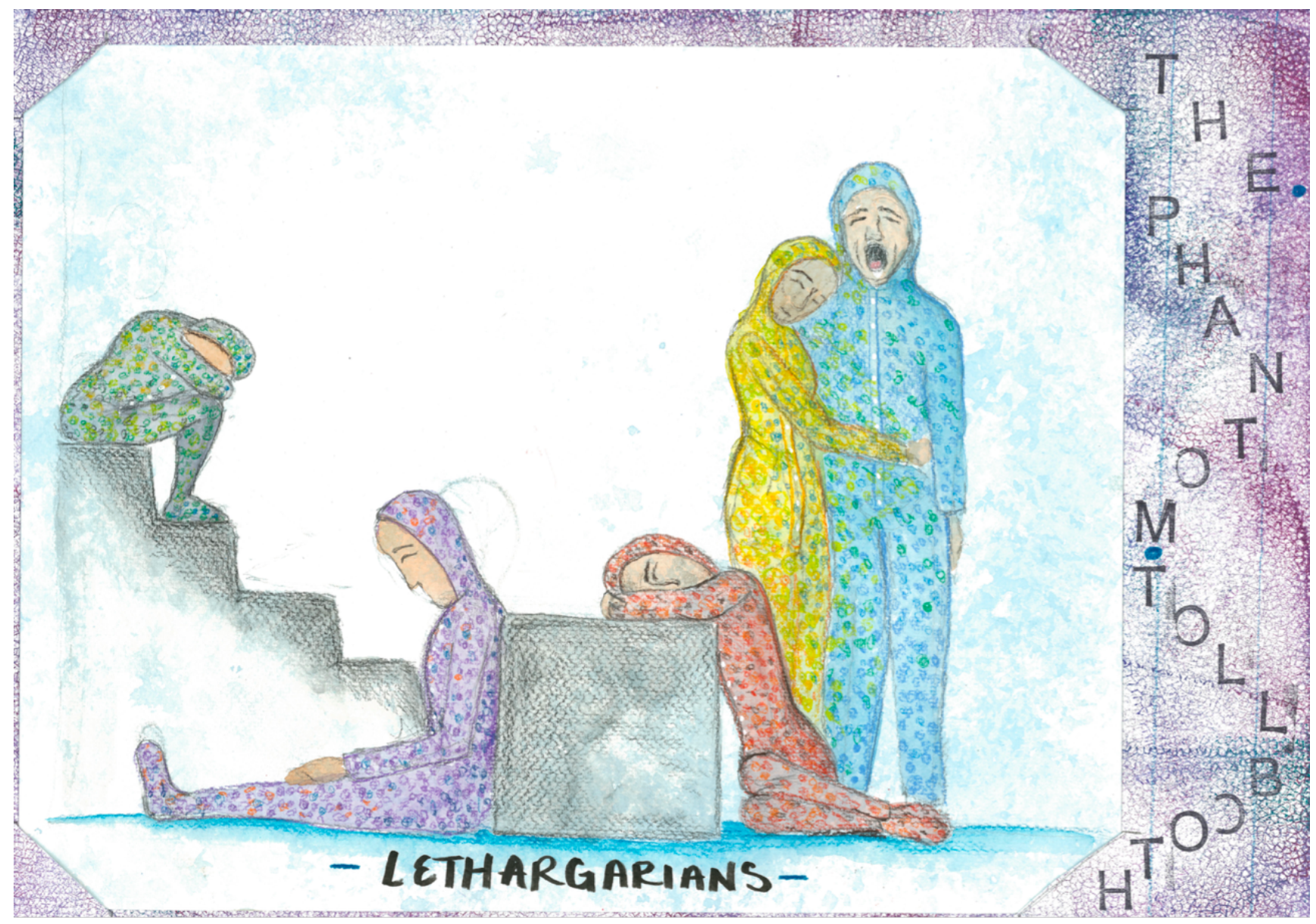

Figure 1.23 Final Rendering of the Lethargarians.

The Lethargarians spend the entire scene in the Doldrums trying to sleep. It was important to have them in very comfortable sleepwear so that children in the audience could immediately relate their behavior to slumber. The other challenge was that at the top of this scene the ensemble is draped all over the set and camouflaged from Milo and the audience. This is where I came up with the concept of optometrist colorblind tests which blend bright colors in dots to determine if a person can identify color without defined shape. Using these tests as the inspiration for the colors meant that I could camouflage the characters into the set while still keeping brighter colors from the rest of the show. 


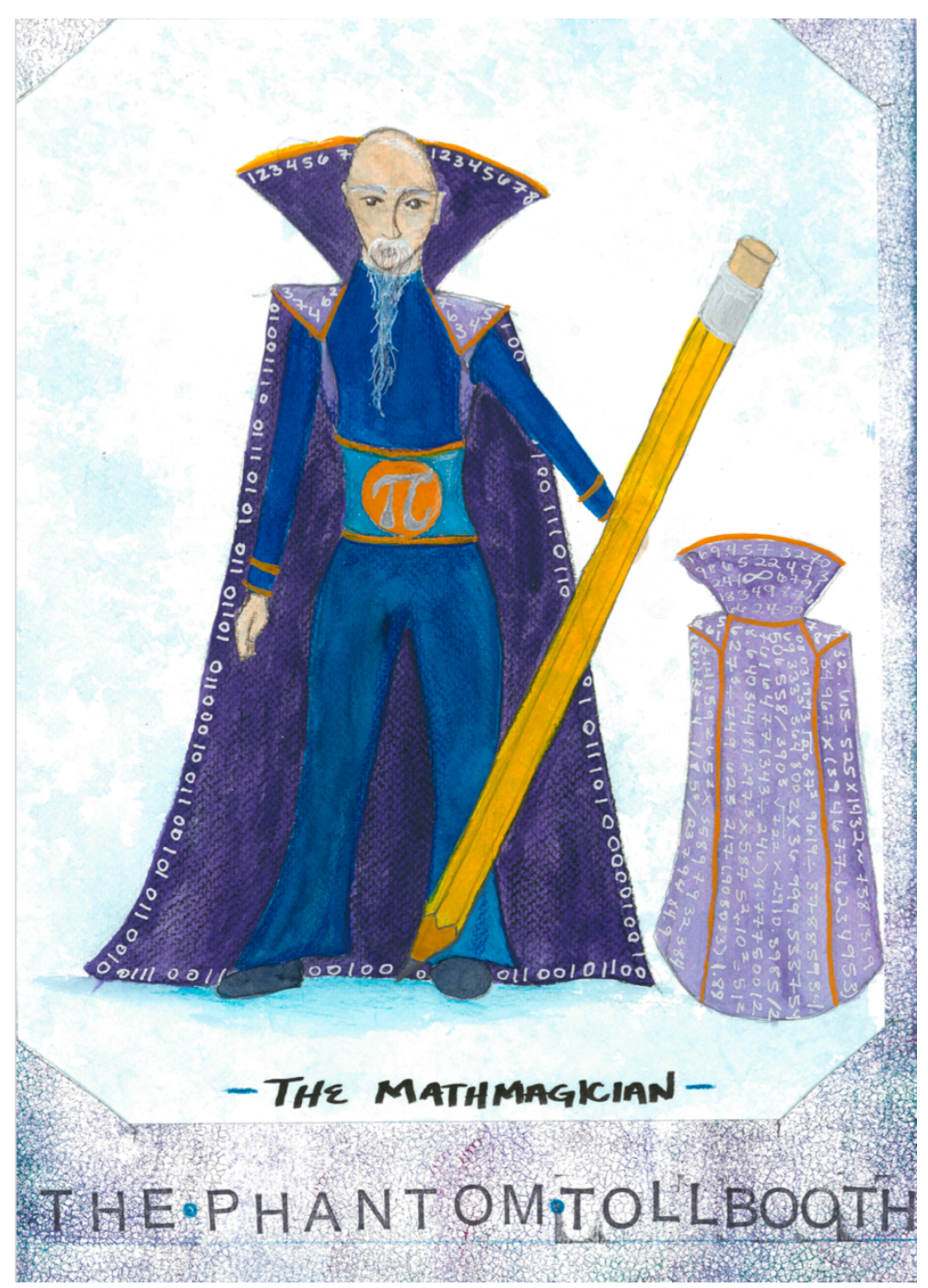

Figure 1.24: Final Rendering of The Mathemagician.

The Mathemagician appears like an oracle obviously because he carries a magic staff. On first meeting the Mathemagician, Milo is a little doubtful because his appearance is a little overwhelming, even a bit sinister. The magic of Mathemagician comes from a ten-year-old perspective of math being mysterious and difficult. The silhouette and details of the magician's costume; the standing, angular collar on a massive, purple cape along with details such as the belt-buckle with a pie symbol, were designed to help personify the land of Digitopolis. The central belt of the costume has a large pie symbol to use as a focal point for his mathematical prowess. 


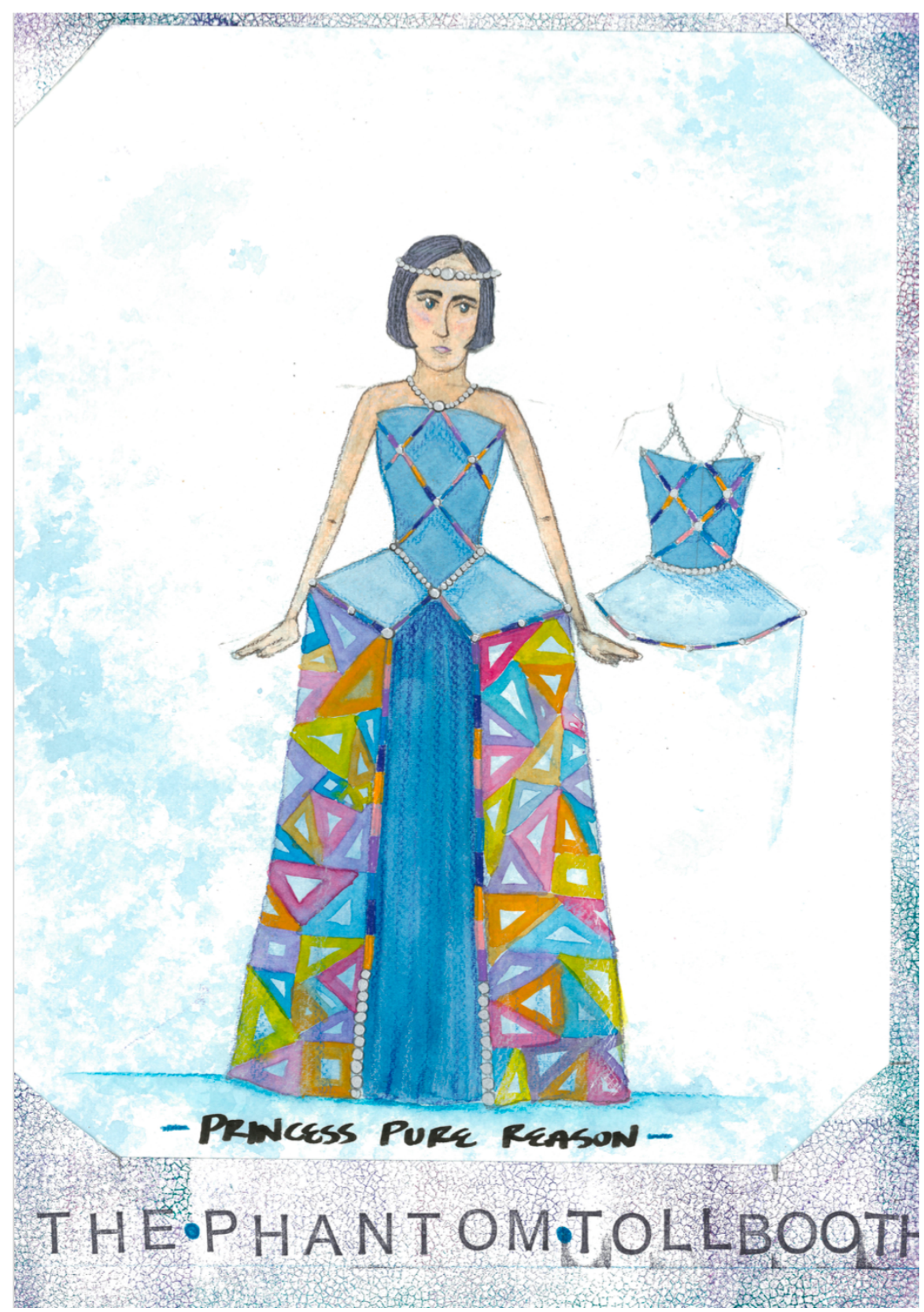

Figure 1.25: Final Rendering of Princess Pure Reason.

Princess Pure Reason had a ballgown and overskirt all based on kinetic toys. I wanted Princess Reason to feel very orderly; the colors and shapes made by kinetic toys created the appearance of stained glass. Her beauty comes from the concept of amazing architecture. Her bodice has repeating lines and the farthingale understructure supporting to her dress gives her a more rigid shape. 


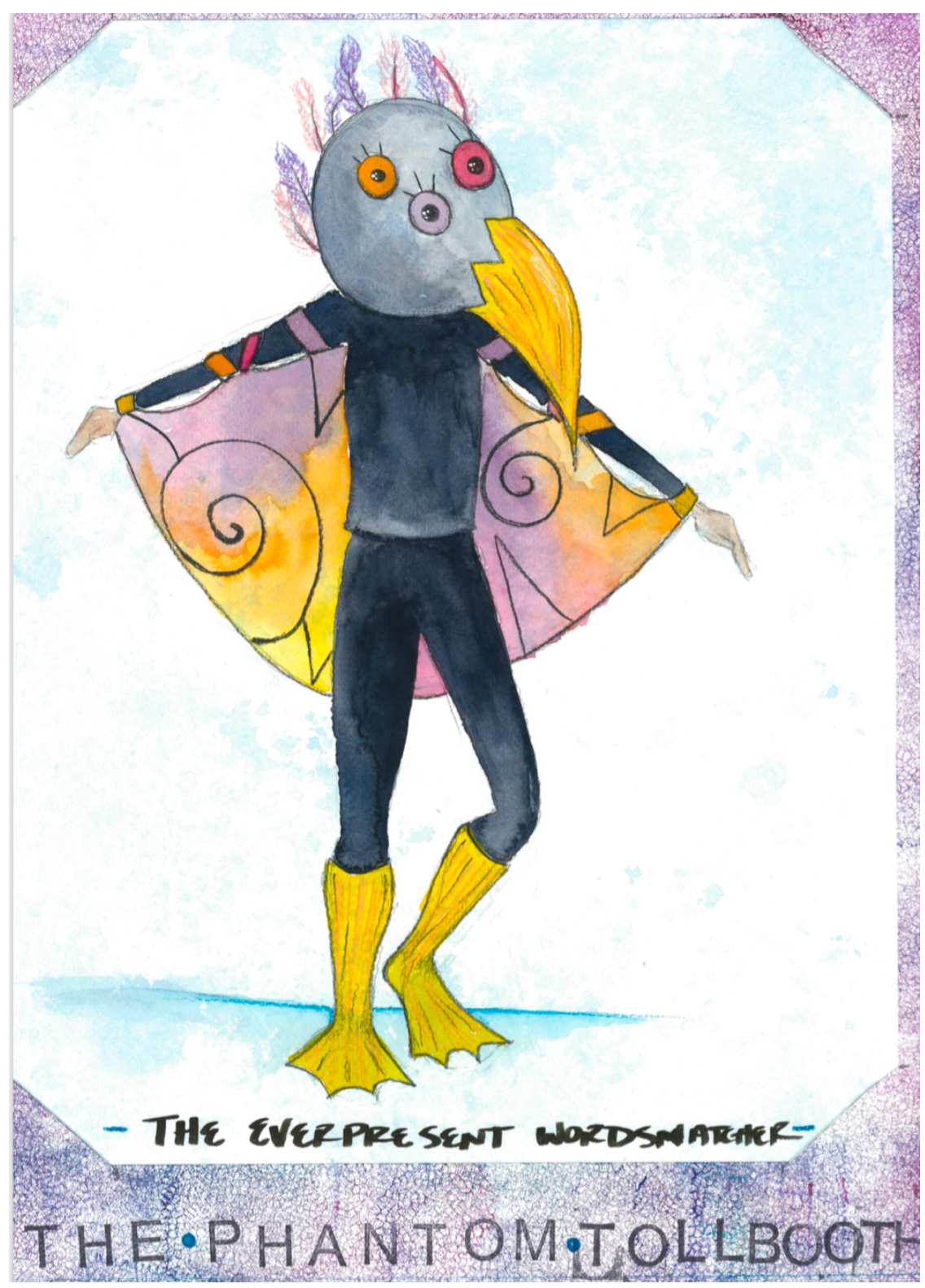

Figure 1.26: Final rendering of The Everpresent Wordsnatcher.

Everpresent Word Snatcher has a large foam head, wings, and bird feet spats. The base of the costume is puppeteer blacks. This character is written to behave like a bird and like the other demons, it is based on children's drawings. I used the haphazard style of children's drawings to create a bird with odd qualities. The head has five eyes and an enormous beak that feels very threatening as Milo moves closer to the nightmare portion of his dream. This character is the only demon that is specifically described as bird-like and fliting about the stage. 


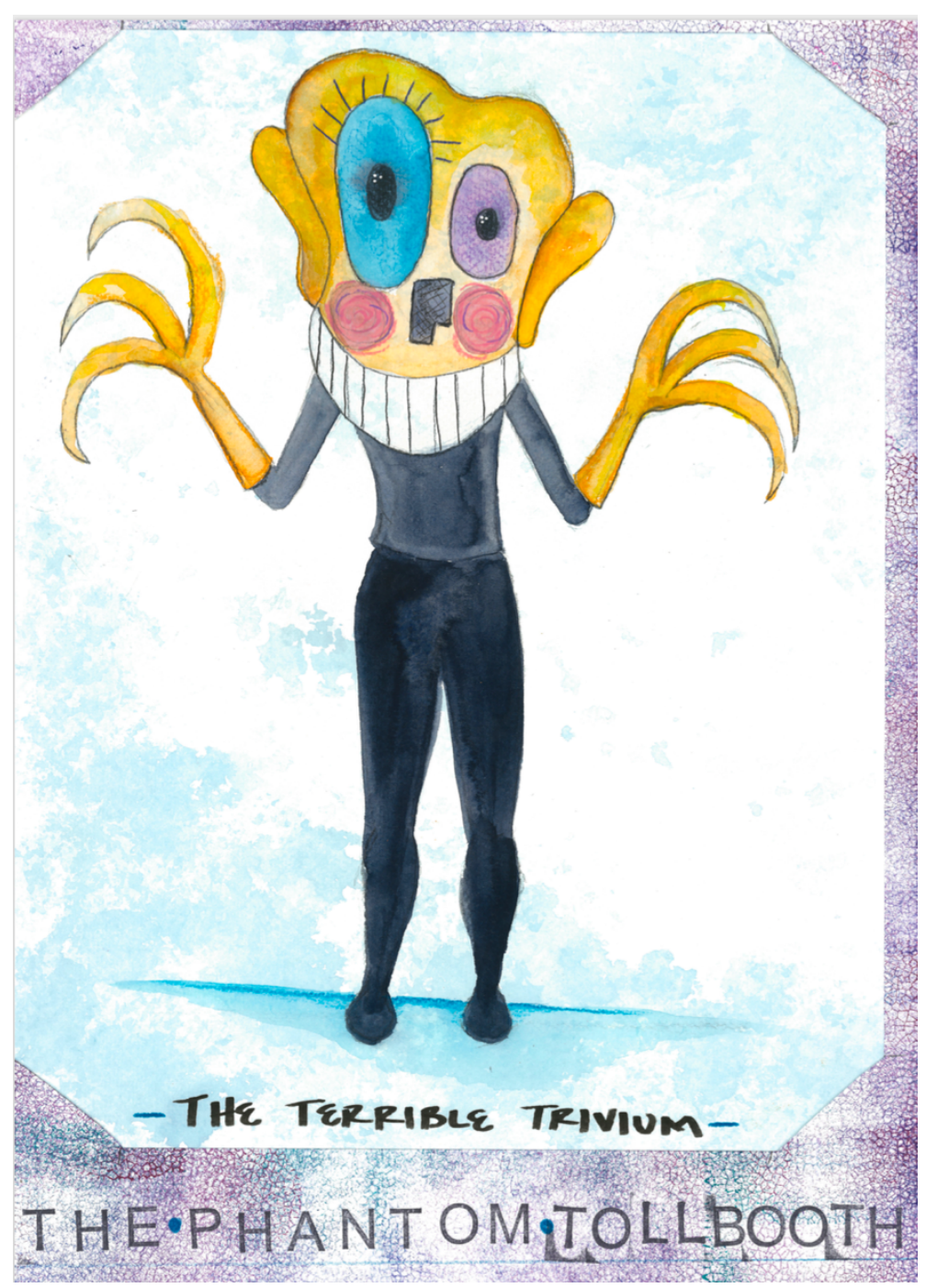

Figure 1.27: Final rendering of The Terrible Trivium.

The Terrible Trivium had a large, oversized foam mask and three-finger claw gloves over a base of puppeteer blacks. This character was also inspired by children's drawings. Trivium makes Milo, Tock and Humbug do very trivial tasks which is why I wanted his hands and finger to be articulate. Trivial tasks like moving a pile of sand with tweezers and empty a well with an eye dropper was the waste of helping hands and I wanted this demon to represent. The oversized face with disproportioned features was meant to evoke the response of creepy but cute. The sheer size of the mask meant that when Trivium is menacing towards Milo it's face would tower over him with sharp claws. 


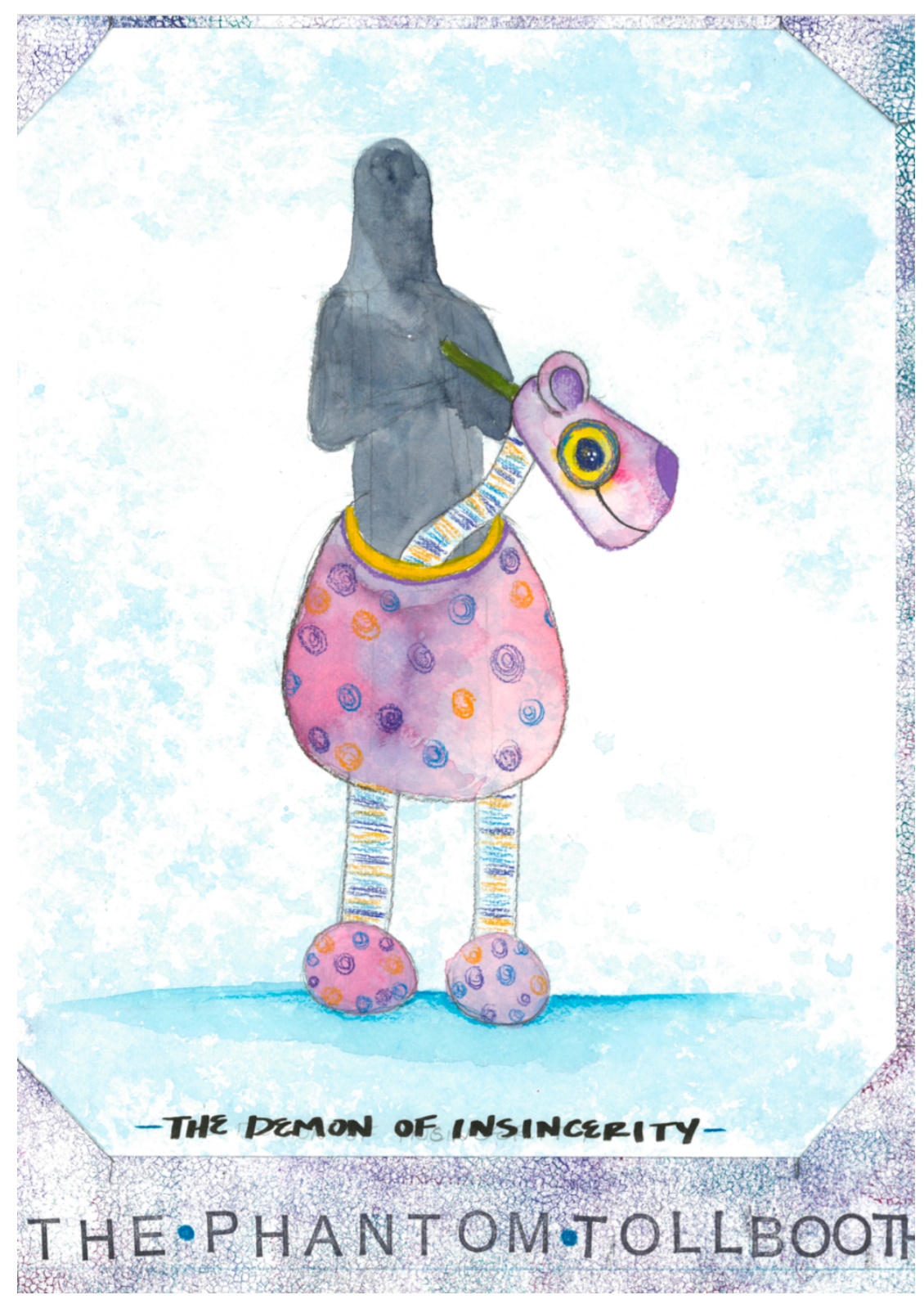

Figure 1.28: Final Rendering for The Demon of Insincerity.

The Demon of Insincerity is a half-body puppet, the puppeteer is inside the body of the puppet with their legs and feet disguised as the character. More than the other demons, Insincerity is extremely sweet to Milo at the beginning of the scene, hence I wanted the character to be extremely soft and round. Then when the demonic tendencies appeared , an expandable snake-like neck could come out of the body, to stretch and slither toward Milo. That change could make something cute suddenly also appear as terrifying. 
Each character in this production was meant to feel individualistic. As Milo, Tock, and Humbug discover every character on their quest, every new appearance should excite the audience. The research presents the concept of unconscious imagination in dreams, characters become less human-like as the story progresses. The Lethargarians feel rather pedestrian compared to the Terrible Trivium, but the color palette places them in the same world. The colors used in this show came from the toys that inspired the design. The bright and flashy advertising I found for children's toys, inspired the varied color palette. With the final designs set for The Phantom Tollbooth the costume shop began to move toward planning the execution. 


\section{DESIGN PROCESS}

Once the designs were finalized, the first priority was to set a shop meeting with Professor McClung and Professor Delligatti to discuss what a realistic build list looked like for this show. The meeting determined that King Azaz, Tock, Humbug, and Princess Rhyme were fully built costumes. King Azaz and Sweet Princess Rhyme had to be entirely painted and building the costumes meant we could simultaneously paint pieces of the costume while it was being built. Tock and Humbug were built because of the distinct body shapes; sourcing an already built design to alter would have taken more time. Partially built costumes were Spelling Bee's skirt, Mathemagician's Cape, and Princess Reason's overskirt. The larger discussion from this meeting was the sheer number of craft projects that could overwhelm the shop. Almost every item as designed needed to be finished with paint, foiling, dying, etc. The puppets and masks also needed to be completed early in the timeline in order for them to go to rehearsal. Because the costume shop accommodates a six season show build, a further discussion involving the shows that came before and after The Phantom Tollbooth needed to be addressed. The first was MUD by Maria Irene Fornes and the costume designer was Professor McClung. MUD involved three characters and a small ensemble with limited to no builds. In the meeting we concluded that The Phantom Tollbooth could be brought into the shop earlier than usual and could work through fittings and alterations in tandem with $M U D$. As the designer this meant that I should and could start as soon as possible in August with purchasing supplies, ideally ahead of time or within the first few weeks of the semester. That became my mission leaving the meeting; myself and the professors understanding that the build list was ambitious and needed as much preparation as possible. 


\begin{tabular}{|c|c|c|c|c|c|}
\hline Builds & Actor & Who & Crafts & Actor & Who \\
\hline Rhyme: Period dress & Grace Alvarez & Tiffany & Drum hat* & Adam P & Buy \\
\hline $\begin{array}{l}\text { Reason: Elizabethan } \\
\text { Understructure }\end{array}$ & Jordan Phillips & Tiffany & Princess hat* & Grace Alvarez & Buy \\
\hline Reason: Elizabethan Skirt & Jordan Phillips & Tiffany & Epaulettes* & & Jake \\
\hline Humbug Jacket & Jacob Masters & Joanna & Duck Feet & & Tiffany \\
\hline Humbug pants & Jacob Masters & Joanna & Masks (x2) & & Chloe \\
\hline Azaz breeches & Joe Z & Desiree & Lots of painting* & & Chloe \\
\hline Azaz Doublet & Joe Z & Desiree & $\begin{array}{l}\text { Reason: Dress } \\
\text { decoration }\end{array}$ & Jordan P & Chloe \\
\hline Azaz Cape & Joe Z & Desiree & Humbug Structure & Jacob Masters & Chloe \\
\hline Azaz Ascot & Joe Z & Desiree & Bee Wings & \begin{tabular}{|l|} 
Megan \\
Wright
\end{tabular} & Jake \\
\hline Bee skirt & Megan Wright & Tiffany & & & \\
\hline Bee understructure & Megan Wright & Tiffany & & & \\
\hline Mathemagician cape & Riley B & Tiffany & & & \\
\hline Spats & Adam P & Jake & & & \\
\hline Mathemagician belt & Riley B & Jake & & & \\
\hline Everpresent Arm Wings & Caleb McClung & Joanna & & & \\
\hline Baldric & Adam P & Joanna & & & \\
\hline Hoods & & Desiree & & & \\
\hline
\end{tabular}

Figure 2.1: Costume Shop build and craft list for The Phantom Tollbooth.

Moving into the summer, I gave myself a long "to do" list of tasks to achieve before the Fall semester began. First was an initial budget, this contained estimated figures to establish caps for each segment of the budget. With the number of projects on the build list, raw supplies like fabric and foam claimed more than half of the four-thousand-dollar costume budget. Supplies also included dyes and paints, and even though the shop had a healthy supply of these items the crafts and the puppets for this production would require its own stock. The major item I chose to not include in the budget was shoes, unless specifically required, I intended to pull all of the shoes for this production from the existing costume stock and this cut around 200 dollars from the budget. I had a limited number of items I wanted to purchase, mostly for ensembles that 
needed matching outfits like the Lethargarians and Number Miners. The rest of the purchasing budget was held for contingencies after fitting pulled and purchased options. This first budget was very useful for the summer and did assist me in regulating large first purchases especially fabric, but as emergencies arose this budget did prove to be realistic Figure 2.2.

\section{Preliminary The Phantom Tollbooth Costume Budget Total $\$ 4000$}

\begin{tabular}{|l|l|r|}
\hline Item & Characters & Amount \\
\hline Fabric & Multiple & 1900 \\
\hline Foam & Multiple /Puppets & 600 \\
\hline Craft Supplies & Multiple & 300 \\
\hline Dye/ Paint & Multiple & 150 \\
\hline Puppet blacks & Puppeters & 100 \\
\hline Clothing to purchase & Multiple & 400 \\
\hline Dry Cleaning & Multiple & 100 \\
\hline Extraneous & Multiple & 450 \\
\hline & & TOTAL 4000 \\
\hline
\end{tabular}

Figure 2.2: Preliminary costume budget for The Phantom Tollbooth.

Purchasing the fabric for this show was a very long process. My summer plans included a lot of travel and I used that time to shop for fabric in person instead of online. The three cities where I sourced fabric were New York City, Nashville, and Atlanta. Of the three, the only fabric market I knew well was Nashville, and I was able to find the leather for King Azaz and the lining of The Mathemagician's cape there. New York has the largest fashion district and options, but to remain on budget I only purchased from smaller retailers who were open to haggling prices. The best deal I got was the fur for Tock. I found a fabric store that was closing and was able to get 
twelve yards for fifteen dollars a yard. Any other store I saw fur, with such a long nap, it's pricing started at twenty-five dollars a yard. Atlanta had Fine Fabrics, which is a beautifully organized warehouse. Almost every time I picked up a fabric, I was quoted seven to ten dollars per yard. I finished the rest of my shopping list there, getting fabric for the Spelling Bee, King Azaz, The Mathemagician, and Humbug. The only fabric I was forced to hunt for online was the plaid for Humbug's suit. The director and I had discussed the plaid in detail, both of us wanting a 1970 's vibe in color and texture. However, any time I found a good plaid there was not enough of it or the weight of the fabric was wrong. The search online, emailing distributers, and waiting for swatches meant that this was the last fabric I ordered. I didn't end up placing the order until the first week of September, two weeks after the semester started. I used this time to consult with Professor McClung and Professor Delligatti about the options. A flannel fabric from the website Etsy ended up being the best choice.

Once the fall semester started, (regular production meetings are always established on Fridays of each week) I presented the final renderings at the first production meeting. The Director wanted a couple of changes to the King Azaz costume. He liked the newly refined color palette, but didn't enjoy the shaped hair, he also wanted to make Azaz feel more regal. He suggested adding a crown instead of the hat or a full-length cape. I decided upon the crown since the fabric for the cape had already been purchased. The rest of the notes included color modifications, i.e. Milo's polo being the most vivid red possible with no notes of burgundy, and King Azaz's court having a tighter, darker color palette. All of those adjustments were taken into account moving forward but none of them were rendered again.

After the first production meeting of the semester, the director changed his mind about one of the characters previously planned to be projected. The scenic design by Professor 
Klingelhoefer featured a projection screen and projection designs as the central focus of the set. In early conversations, we talked about a character named the Awful Dynne being projected center stage, however after rereading the script in the Fall, the director decided he wanted something more practical. This led us to the idea of a large spectacle puppet. This came from the director wanting the performers to be engulfed by the smoke as the Awful Dynne emerges from his bottle. In my career I have made several spectacle parade puppets and felt confident moving forward with this design pictured in Figure 2.2. This, however, was a budgetary issue. I decided to use an inexpensive silk habotai that I could dye and planned on making his head out of craft paper mache because that was the most cost effective.

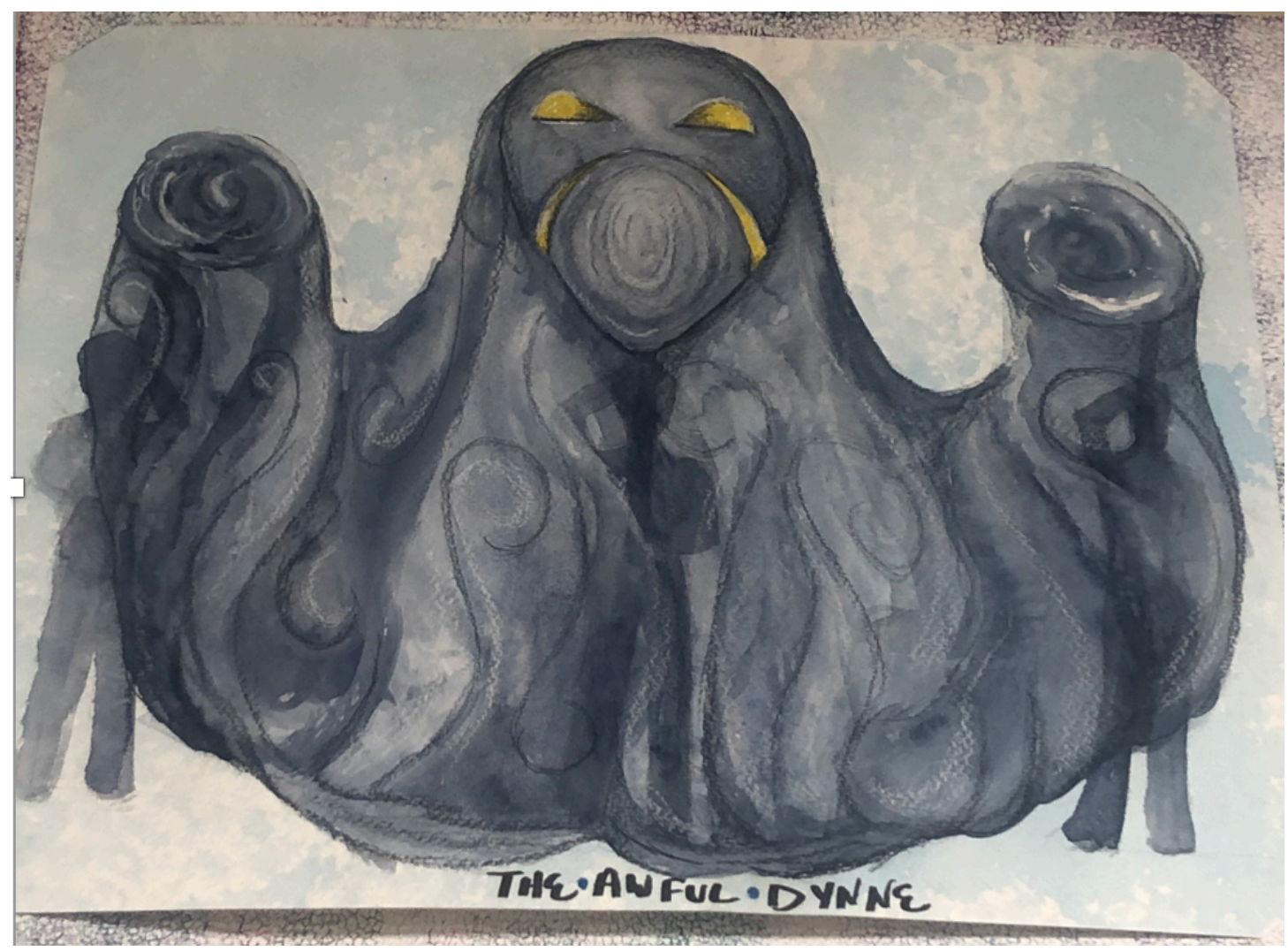

Figure 2.3: Final rendering of The Awful Dynne. 
Auditions occurred the first week of the semester and call backs the second. Since the director had maintained that the gender and race of all the characters was considered pliable during the casting process, I didn't know what to expect. Once the cast list finally came out there were not a lot of drastic changes. The only big change contrary to the script was that Milo was now being played by a woman, Sydney Miller. Initially when I saw the cast list, I started researching female, options for Milo, and I set a date with the director to look over alternate research options with me. I had assumed that Miller would be playing the character as a young girl but when the Director saw the research, he informed me that Sydney would be playing the role as young boy, and my adjustment in design should be to make her look less feminine. My initial concern was that the performer had a very shapely figure that would be hard to cover while still making her look young. I eventually planned on changing her visually by putting her in a backwards baseball cap, placing her hair in cornrows, and adding oversized clothing with undergarments that minimized her figure. The director agreed to these choices and we moved forward. I had ordered all the items for her fitting, when I got an email from the director stating he wanted to meet. The director told me that during rehearsals, he couldn't help but associate Sydney with a female character, so much so that he wanted the role to revert back to being played female. The name of the character would also be changed to "Mila" instead of "Milo". Since this was such a fundamental change to the script the director needed to seek permission from the publisher. It took the publisher one week to respond and they said that no changes could be made to the gender of the lead character without approval from the rights holder. In the email, a representative for Samuel French also explained that having a female play the young boy was against the contract of licensing the rights to West Virginia University. 
This began a long waiting game for the costume shop. While the lead character's casting was in limbo, but rehearsal was progressed as if the changes would be approved. The director, Professor Blair, had admitted to me that if the publisher denied his casting request, then he was going to move the parts around within the cast, Alexander Evans who was cast as the Whetherman and The Terrible Trivium would play Milo instead, and vice versa for Sydney Miller. This was a huge issue, I could no long order or fit anything for the main character and items I had previously fit for Alexander Evans would not fit Sydney Miller. The publisher had not provided an answer by the fifth week of the semester, Professor McClung stepped in and told the Director that a decision had to be made. The director decided to go ahead with Sydney Miller playing Milo as a male. As soon as that decision was made the publisher finally responded and said that the casting request had been accepted, and that Milo could be played as Mila.

During the casting process, the Director added three characters to Digitopolis. When Mathemagician teleports the trio and himself to his office, he says, "when I have to be multiple places at once I simply multiply" (Nanus 50). He then writes "1x3" on the chalkboard behind him and three copies of himself appear. Before casting this moment, it was never discussed, and I assumed the copies of himself would be projected. The Director had a different idea. During casting he saw acting potential in three musical theatre majors who had been cast in the ensemble and wanted them to be like a Greek chorus. This would support the scene wherein the Mathemagician repeated and shared his lines singing them in harmony with his multiple selves. Initially my worry was that he wanted, as the script implies, three identical versions of the Mathemagician. It was a question of time and money; the main feature of the Mathemagician's costume was a structured cape, hand-foiled (a time consuming process involving cutting small hand-stenciled numbers, laying each out onto the cape in a pre-grided layout and then using a 
heat press to apply the numbers, one $14 \times 14$ area at a time) with equations--suddenly making four of them was not an option. These characters ended up in silver and black bowling shirts with silver numbers down the front, holographic grid pants, and shiny blue bomber jackets. Since they merged so well with the scenic elements of Digitopolis, this made these characters relate to the Mathemagician but didn't divide the attention of the audience.

The final clarification during the casting process was a concept the director brought about for the final sequence called "circus demons". The director wanted additional characters for the scene when Milo, Tock and Humbug are in the Land of Ignorance. These would be three members of the ensemble that worked as part of the set to move the scenic stairwells around creating new spaces for the trio of protagonists. These characters would facilitate havoc and try to slow the trio from reaching their goal of rescuing the princesses. The circus theme for their appearance was assisted by the sound design that played a warbled, off-kilter circus theme while they moved the scenic pieces around. The costume design for them had to be something simple as all three ensemble members played the Dodecahedron in the previous scene. They used their puppeteer blacks from the Dodecahedron with some additional whimsical costume items found in stock and masks to disguise their faces.

After the show was cast, the costume shop collected measurements from the performers. Once completed, I finalized orders and began pulling garments from stock. Because of a reciprocal costume borrowing arrangement with Carnegie Mellon University, I scheduled a day to pull a portion of the costumes from their stock. The most useful items I got from Carnegie Mellon were ruff collars for King Azaz's court. Then, I pulled a selection of doublets and breeches, as well as colorful peasant wear for the Word Merchants of Dictionopolis. About a quarter of these items were used but is was helpful to have a large selection to choose from while 
conducting fittings (Figure 2.4). Certain items I purchased immediately included the jumpsuits for the Lethargarians, the coveralls for the Number Miners, and the silver modern wear for the three copies of the Mathemagician. Fittings started around September $11^{\text {th }}, 2019$ for most of the ensemble. These fittings produced a variety of alterations from hems to quick-rigging. Having most of the ensemble fit early in the process left more time for the large list of built costumes that were already in mockup phase.

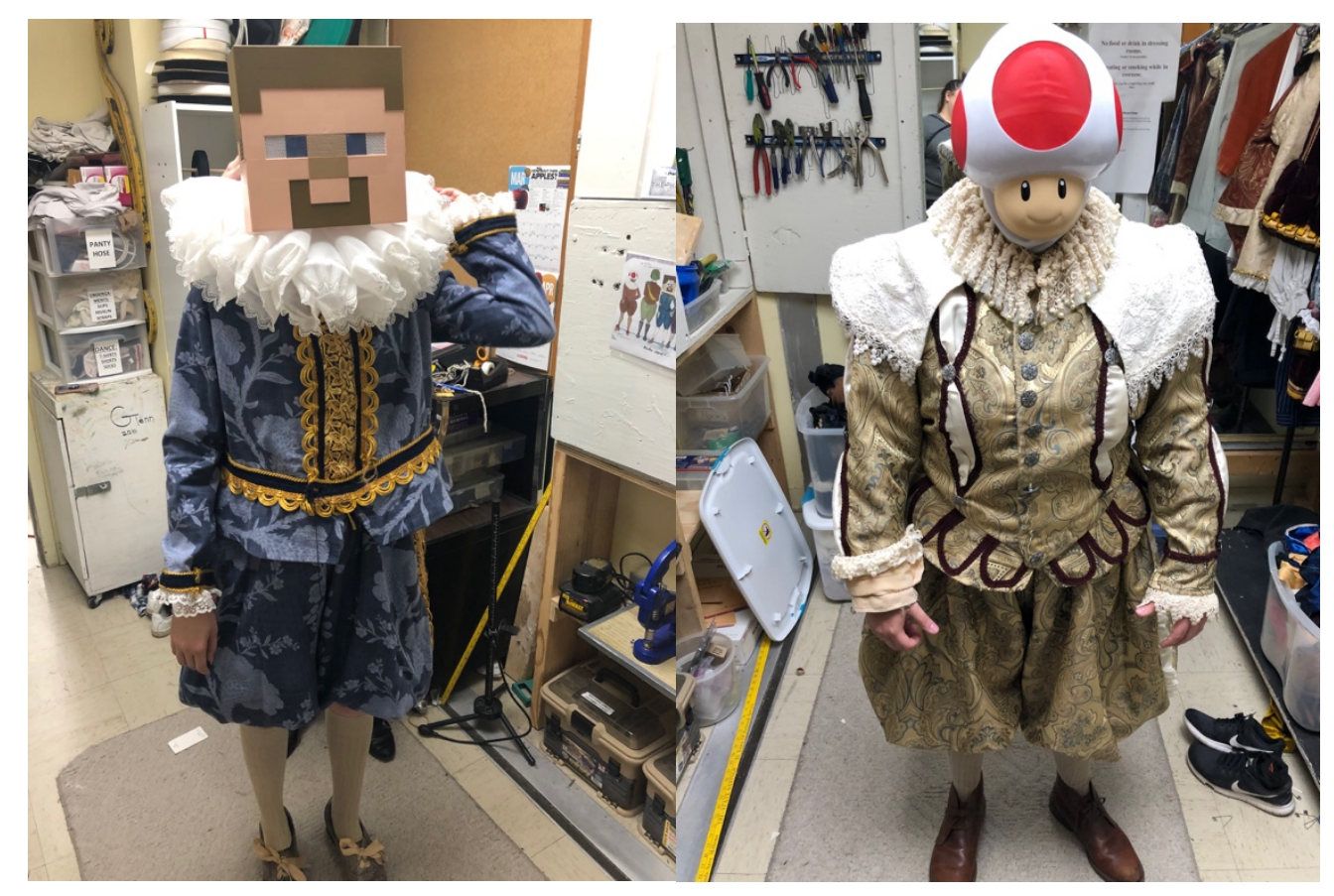

Figure 2.4: Performers Rhowyn Saffel and Alexandra Ashworth first fittings for Ministers of King Azaz's court.

Costumes built by the shop have a more complicated process for completion; the finalized build list first is compiled by the cutter/draper. The Costume Designer then assembles a notebook containing working drawings, flats, swatches and color copies of each rendering. The cutter/draper for this production was Professor Tiffany Delligatti. She completed the initial 
drapes for the costume builds and then made paper patterns that needed to be tested as a muslin mockup. These fittings started September $17^{\text {th }}$ and continued for approximately two weeks. The time from pattern to mockup, was used to ensure that costume style lines, as well as fit, were as accurate to the design as possible before using final fabric. All these fittings went smoothly. The only mockup fitting we called in a second time for clarification was Princess Sweet Rhyme. I designed her bodice with very distinct style lines to mimic the shape of a sand timer or hourglass in a board game. In order for that concept to show up best on that performer's body shape, we needed some additional time to rework the seam lines on the front of the bodice.

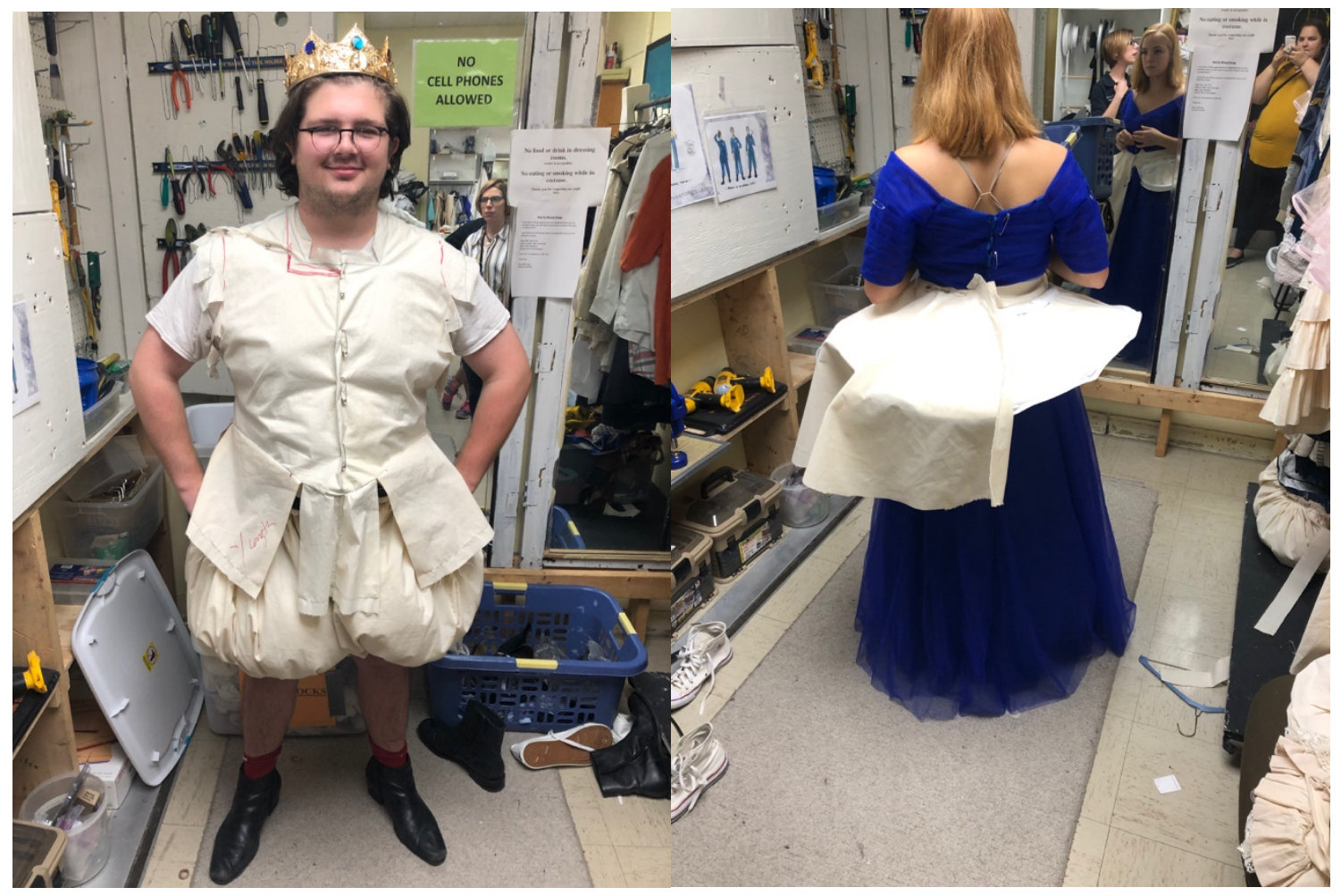

Figure 2.5: Left performer Joseph Zecevic first mockup fitting for King Azaz. Right performer Jordan Phillips first mockup fitting for Princess Pure Reason. 
As the mockup fittings were completed, the next stage was taking all the builds into final fabric. These fittings began the week of September $7^{\text {th }}$ and progressed for around two weeks after that. In general, these fittings went well. The garments that had individual struggles still came out looking nicely, but the process was different. For example, with the Mathemagician's cape, Professor Delligatti determined the best way to complete this task was to foil all the pieces of the garment before the cape was constructed. There was a student in charge of the foiling process, but she could only come in to work every other day for limited hours. It became obvious that cutting down the amount of foiling on the cape was necessary and after a discussion it was determined for spacing and size to do three rows of single numbers on each of the panels of cape.

Originally the design had equations down the front edges of the cape with factors, and symbols. Not only was waiting for the foil press to heat an issue but the time required to cut out the numbers in the foil before applying was delaying completion. In the end, with the depth of the stage and the distance to the audience, the spacing worked out very well-- when the performer moved it glittered and called lots of attention to the numbers. In hindsight, I wish we had more time to put in a few actual equation symbols and factors instead of just singular numbers.

The other costume that created problems was the Humbug. The understructure for the shoulders of which it was my job to create. I was delayed, due to working on the Terrible Trivium and Professor Delligatti was subsequently delayed in draping the costume. I did finally finish the structure the last week in September. This delay on my part meant that there was no time to do a mockup of the costume in muslin, instead the drape was taken immediately to final fabric. The fitting for Humbug occurred beginning of the second week of October just before going into tech. This fitting was a serendipitous moment, and a compliment to Professor 
Delligatti being able to do great work with limited time, the costume looked fantastic. There were minor alterations to the seams in the back but the coat and pants were perfect (Figure 2.5). This costume was so transformative to the performer's physique that it immediately became my favorite costume created for the show.

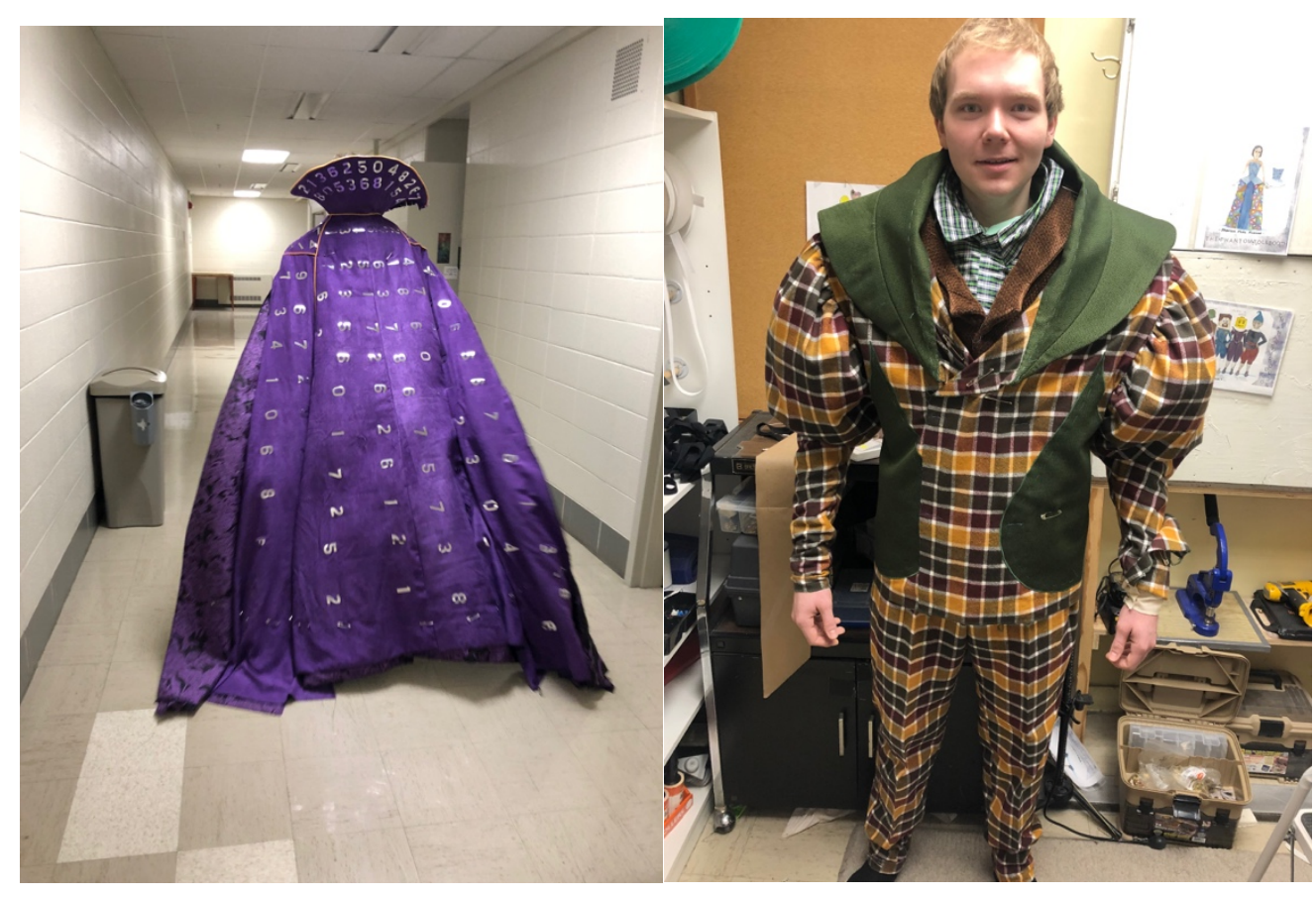

Figure 2.6: Left performer Riley Barringer--last fitting for Mathemagician cape. Right performer Jacob Masters-- last fitting for Humbug suit.

Moving toward tech week, I created a more detailed costume plot that provided information specifically for the costume crew. This included the Graduate Wardrobe Supervisor Jacob Currence, the Undergraduate Wardrobe Supervisor Emily Bishop. For this production I listed the actor and which character they began the show and which character they needed to change into (Figure 2.7 and 2.8). I used the phrase "approximately ten minutes" for any changes with two or more pages of dialogue between them, but I informed the costume crew that it was their responsibility to get an accurate time and set location for the change from the performers. 
The Phantom Tollbooth Costume Plot

Costume Designer: Chloe Cappuccilli

\begin{tabular}{|c|c|c|c|c|}
\hline Act:Scene & Actor & Character A/ Character B & $\begin{array}{l}\text { Change Location (predictions } \\
\text { always check with performer) }\end{array}$ & Speed \\
\hline 1:1 & Sydnee & Mlla- Stasis no changes & $\mathrm{N} / \mathrm{A}$ & $N / A$ \\
\hline 1:2 & Alex $\mathrm{E}$ & Whetherman / Number Miner & Dressing Rooms & Approx 15 minutes \\
\hline $1: 2$ & Eryk & Lethargarian/ Shopper & Dressing Rooms & Approx 10 minutes \\
\hline 1:2 & Chidera & Lethargarian/ Merchant & Dressing Rooms & Approx 10 minutes \\
\hline $1: 2$ & Aliza & Lethargarian/ Gatekeeper & Dressing Rooms & Approx 10 minutes \\
\hline 1:2 & Carley & Lethargarian/ Merchant & Dressing Rooms & Approx 10 minutes \\
\hline $1: 2$ & Drew & Lethargarian/Shopper & Dressing Rooms & Approx 10 minutes \\
\hline $1: 3$ & Joe K & Tock -Stasis no changes & N/A & $\mathrm{N} / \mathrm{A}$ \\
\hline $1: 4$ & Grace & Princess Rhyme / Dynne & Dressing Rooms & Act 2 \\
\hline $1: 4$ & Jordan & Princess Reason / Dynne & Dressing Rooms & Act 2 \\
\hline $1: 4$ & Riley & Mathmagecian- Statsis No change & $N / A$ & $N / A$ \\
\hline $1: 4$ & Joe Z. & King Azaz the Unabridged- Stasis no change & $N / A$ & $N / A$ \\
\hline $1: 4$ & Rhowyn & The Three/ The Undersecretary of Understanding & Dressing Rooms & Approx 10 minutes \\
\hline $1: 4$ & Noah & Miner/ The Earl of Essence & Dressing Rooms & Approx 10 minutes \\
\hline $1: 4$ & Chidera & Merchant/ Dodecahedron & Dressing Rooms & Act 2 \\
\hline 1:5 & Mackenzie & Merchant/ Dodecahedron & Dressing Rooms & Act 2 \\
\hline
\end{tabular}

Figure 2.7: Page one of costume plot. 


\begin{tabular}{|c|c|c|c|c|}
\hline Act:Scene & Actor & Character A/ Character B & $\begin{array}{l}\text { Change Location (predictions } \\
\text { always check with performer) }\end{array}$ & Speed \\
\hline 1:5 & Carley W & Merchant/ The Three & Dressing Rooms & Act 2 \\
\hline 1:5 & Megan W & Spelling Bee / Dodecahedron & Dressing Rooms & Act 2 \\
\hline 1:5 & Jacob M & Humbug- Stasis no change & N/A & N/A \\
\hline 1:7 & Aliza & Gatekeeper / Miner 3 & Dressing Rooms & Act 2 \\
\hline 1:7 & Adam & Minister / Kakafonous & Dressing Rooms & Act 2 \\
\hline 1:7 & Caleb & Minister / Everpresent Wordsnatcher & Dressing Rooms & Act 2 \\
\hline 1:7 & Noah & Minister / Number Miner & Dressing Rooms & Act 2 \\
\hline 1:7 & Alex A & Minister / Dynne & Dressing Rooms & Act 2 \\
\hline 1:7 & Rhowyn & Minister / The Three & Dressing Rooms & Act 2 \\
\hline 1:7 & Eryk & Servant/ The Three & Dressing Rooms & Act 2 \\
\hline \multirow[t]{2}{*}{ 1:7 } & Drew & Servant/ Dodecahedron & Dressing Rooms & Act 2 \\
\hline & & INTERMISSION & & \\
\hline 2:1 & Adam & Kakafonous/Minister & Dressing Rooms & Approx 10 minutes \\
\hline 2:1 & Alex A & Dynne / Demon of Insincerity & Dressing Rooms & Approx 10 minutes \\
\hline 2:1 & Grace & Dynne / Rhyme & Dressing Rooms & Approx 10 minutes \\
\hline 2:1 & Jordan & Dynne / Reason & Dressing Rooms & Approx 10 minutes \\
\hline 2:2 & Chidera & Dodecahedron / Demon & Dressing Rooms & Approx 10 minutes \\
\hline 2:2 & Mackenzie & Dodecahedron / Demon & Dressing Rooms & Approx 10 minutes \\
\hline 2:2 & Megan W & Dodecahedron / Demon & Dressing Rooms & Approx 10 minutes \\
\hline
\end{tabular}

\begin{tabular}{|c|c|c|c|c|}
\hline Act:Scene & Actor & Character A/ Character B & $\begin{array}{l}\text { Change Location (predictions } \\
\text { always check with performer) }\end{array}$ & Speed \\
\hline 2:2 & Drew & Dodecahedron / Demon & Dressing Rooms & Approx 10 minutes \\
\hline 2:3 & Noah & Miner / Senses Taker & Dressing Rooms & Approx 10 minutes \\
\hline 2:3 & Alex $\mathrm{E}$ & Miner / Terrible Trivium & Dressing Rooms & Approx 10 minutes \\
\hline 2:3 & Aliza & Miner/ Page & Dressing Rooms & Approx 10 minutes \\
\hline 2:4 & Rhowyn & The Three/ Minister & Dressing Rooms & Approx 10 minutes \\
\hline 2:9 & Caleb & Everpresent Wordsnatcher / Minister & Back of house & QUICK \\
\hline 2:9 & Alex A & Demon of insincerity / Minister & Back of house & QUICK \\
\hline
\end{tabular}

Figure 2.8: Page two and three of costume plot. 
The sprint to "First Dress Rehearsal" centered around finishing the puppets and masks. Most notably the Awful Dynne, since this design was added after the initial design presentation it was last on the build list. Moving into "Technical week" (Tech week), the head was done and fabric body sewn, but it was not mounted to poles or have its mouth mechanism complete. Unfortunately, this meant that the main Dynne puppeteer Alexandra Ashworth didn't get the full puppet with fabric until “First Dress Rehearsal”. However, Alexandra is a very gifted puppet manipulator and she did bring a lot to the performance even with extremely limited rehearsal with the puppet. Even though the Dynne puppet was delayed, every other puppet and mask did get used in the rehearsal before first dress.

Craft projects for this show became the main allocation of the shop's time going into first dress. Costumes that needed to be painted entirely for this show were King Azaz, Princess Rhyme, the Lethargarians, and Princess Reason. The painting projects for those costumes averaged between twelve to twenty hours of work to complete. Fully painted puppets and masks also took time from crafts including: Terrible Trivium, Demon of Insincerity, Everpresent Wordsnatcher, Dynne and Dodecahedron. Almost every other character required at least partial paint like Tock, Humbug, Senses Taker, and Kakafonous. If the characters didn't need to be painted, they required additional detailing like Mathemagician with heat foiling numbers. The assignment of foiling for that cape was given to one student who spent around thirty hours on the cape alone. Crafts also worked on the masks for the Ministers of King Azaz's court each mask had whether it be paint or modification for sound projection. By far the largest time consumer of the craft department was painting details on the costumes. 


\section{EXECUTION OF COSTUMES}

This chapter covers any final augmentations to the costume design that occurred before opening night. These changes were made with consideration to time, performer comfort, directorial notes, and seeing the designs in the performance venue. During this phase of the process, a week before performance or "Technical Week", these decisions were made under a very limited amount of remaining time. I will explain how steps taken for the design adjustments at this stage often changed the original design to better coincide with the rest of the production.

The first thing that happened was "The Designer Talk". I went through the entire rack with the crew and explained the flow of the costumes, as well as any quick changes that might occur. Once performers arrived, each crew member checked the quick changes against information provided in the costume plot. The costume crew and performers worked well together and none of the quick changes were late during first dress.

Overall, "First Dress Rehearsal" was extremely successful. There were notes from the director that mainly pertained to two characters Kakafonous and King Azaz. Kakafonous lacked a color palette that made him stand out on stage. Immediately, I wanted to change his pants and add a cummerbund in a bright color, but Professor McClung had a suggestion of a bright green curly wig. I was hesitant to the suggestion because in my imagination it looked less scientist and more clown, but once he wore the wig in a florescent green color, it completed the mad scientist approach that was called for in this production. Meanwhile, the issues with King Azaz were more "a series of easy fixes" that unfortunately landed all on one specific costume. His shirt went missing in transport from the shop, his heavy cape needed to be sewn down, and the most 
distracting issue was that his breeches were riding very low and needed suspenders. I simply reassured the director that those changes were achievable, and no design alteration needed to be made.

The notes I focused on from "First Dress Rehearsal" were mostly in the area of paint. The Lethargarians needed several paint touches on each one-piece suit in the underarms and crotch. These areas were missed in the original painting process due to the fabric bunching on the mannequin. Princess Pure Reason still needed a lot of her kinetic toy trim to be sewn on. After seeing Princess Reason on stage along with Princess Rhyme, finishing her dress as planned became a high priority for equal stage presence. Professor McClung also suggested a larger crown and colored wig on Princess Reason. The wig department had a lilac purple wig in stock that would help add splendor and fantasy to Princess Reason. This color was especially helpful in juxtaposition to Princess Rhyme who had a bright yellow wig.

First priority for myself was addressing the changes to the Kakafonous costume. I scheduled a fitting with the performer and provided the new pants and cummerbund as well as saw him in the green wig. Once those were completed, I moved on to the list of items that still need to be pulled from stock. It contained a multitude of socks, a new shirt for King Azaz, and a variety of other small things. During this, Professor McClung was dealing with a set of issues for Tock from "First Dress Rehearsal", one of his eyes came off and the mechanism inside his head for the ears to move had broken. The poles originally used for the hands of the Dynne had been heavier metal and needed to be switched out for a lighter dowel rod option. The two performers operating the hands for Dynne found the metal poles too heavy to operate, as they were aluminum and 9 feet in length. Another note was the large fabric body of the Dynne which 
looked very one-dimensional on stage. I mixed spray bottles of dye and paint that could help make the fabric appear smokier in texture.

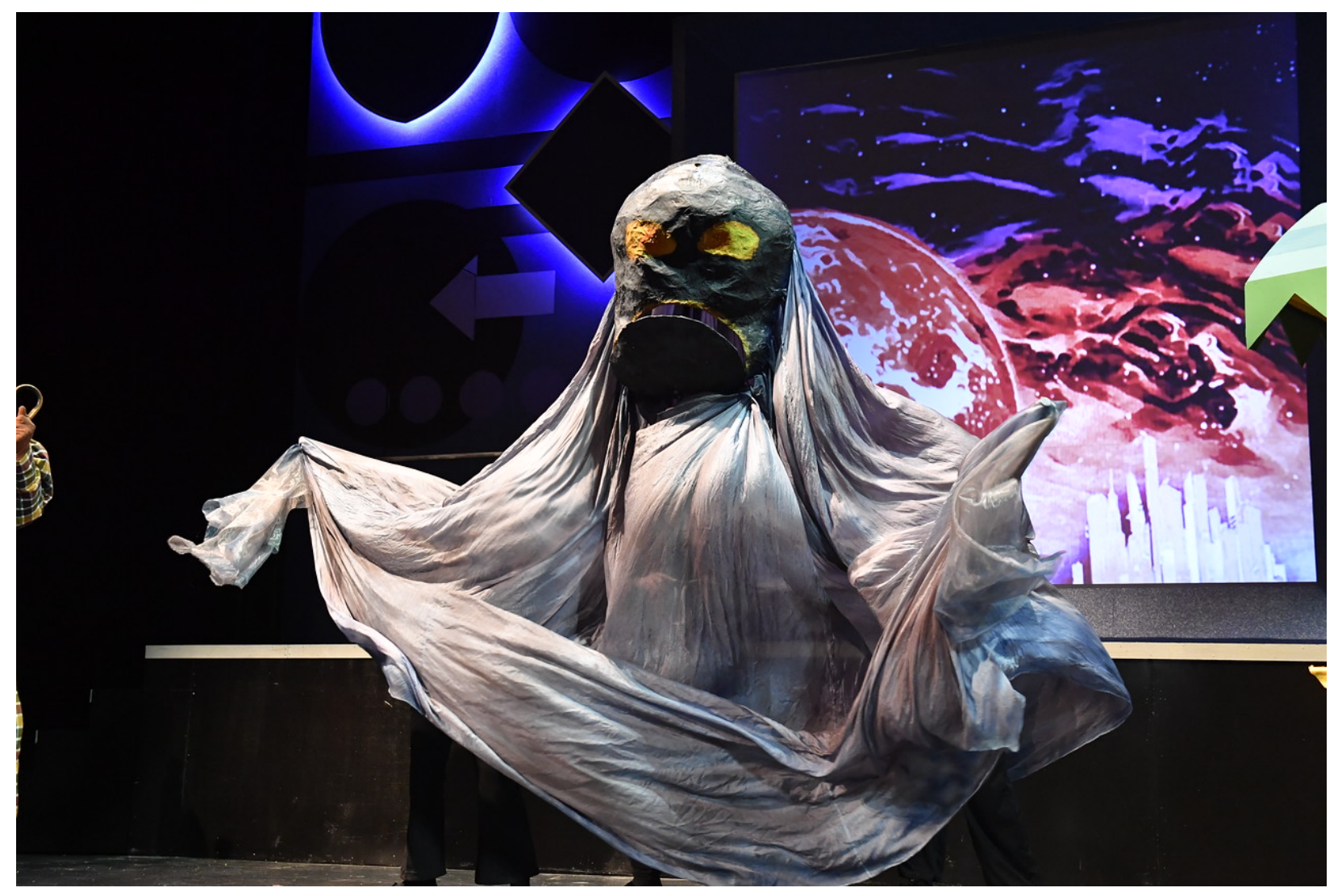

Figure 3.1: The Awful Dynne.

By Tuesday, and "Second Dress Rehearsal”, it was a much smoother day for costumes especially with all the hard work put in by the shop. With the exception of two puppeteers everyone now had socks. King Azaz had the alteration made to his garments and after seeing him on stage he looked much better. The biggest change was Kakafonous with his new pants and green wig. Everyone seemed satisfied with where that costume had landed after all the changes. Princess Reason looked great in the new wig and tiara, but the kinetic trim was still not completed.

Wednesday was "Third Dress Rehearsal" and notes had moved on from sewing alterations to fine detail work. A note the director and I shared was the Dodecahedron needed to 
be less flat under the stage lights. I fixed this by edging the sides in black and stippling dimension on the base colors. Dodecahedron has twelve sides with twelves plastic masks depicting individual emotions. Each head needed to be outlined in black to be seen under stage lights and the distance of the audience. I also mixed opposing colors of paint to sponge across the surfaces of Dodecahedron to give texture and contour the features of the faces. For the Terrible Trivium, I decided to add gold glitter to the tips of his claws to add the illusion of sharpness from stage. His claw-gloves required some additional foam work, a lot of paint touchups to the underside as well. The breeches of King Azaz were a high priority note that day. With the fittings and alteration notes being completed on King Azaz for "First and Second Dress Rehearsal", the costume had not come in for paint notes. The highest priority was the breeches of the costume that needed the colors of book spines painted on to match the doublet. That costume was made of a soft pleather and to build the colors up to the desired brightness took several thin layers of paint to keep it from cracking. However, the most satisfying note I remember finishing that day was putting Swarovski crystals on all of the puppets eyes to catch the light. 


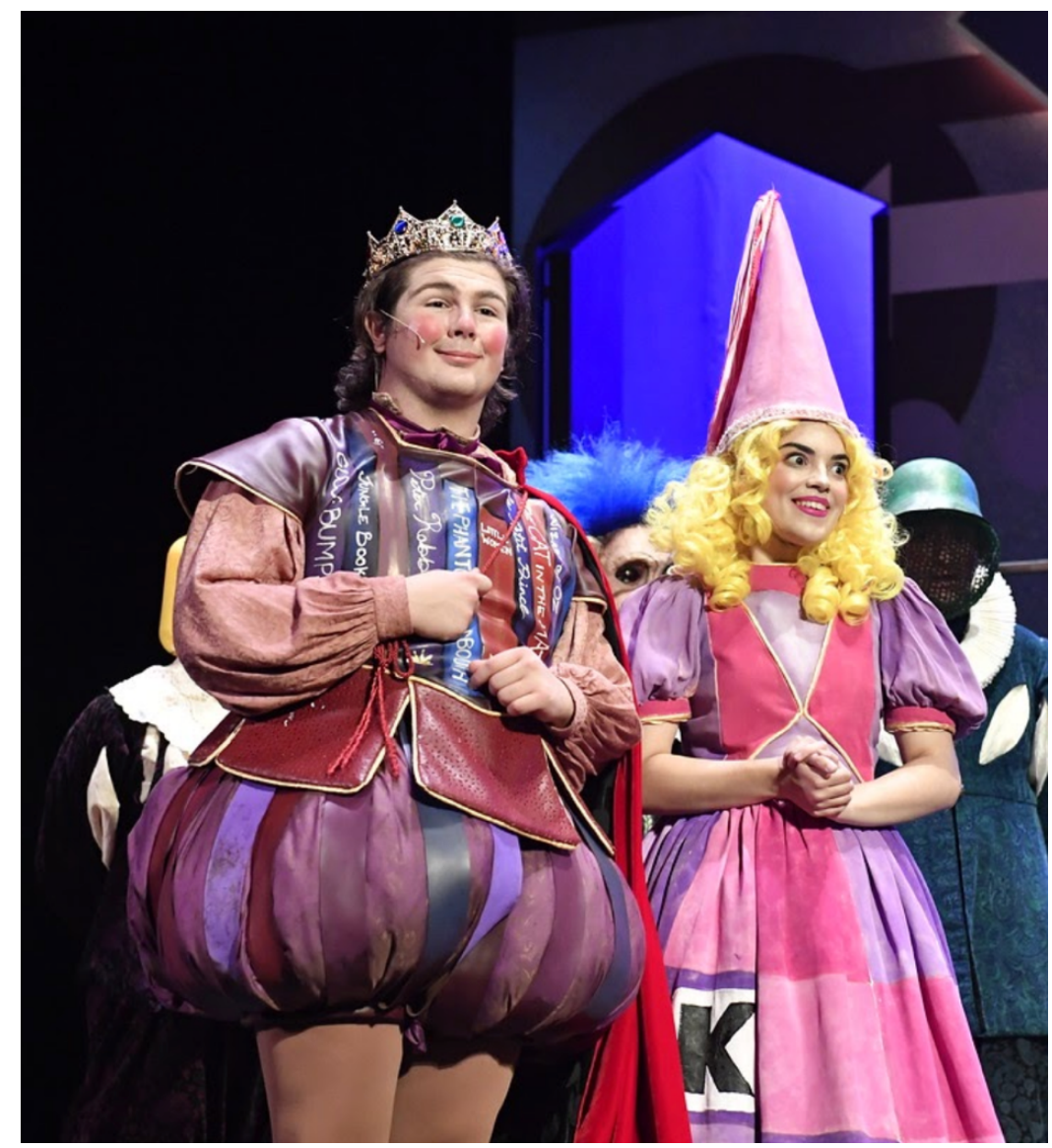

Figure 3.2: King Azaz and Princess Rhyme.

The last two notes of importance were painting related. For the Demon of Insincerity, I wanted to draw attention to the talking mouth mechanism and so I painted large pink lips on the puppet. This color stood out against the cool purple and blue background making the audience focus on the puppet's mouth. Demon of Insincerity was the smallest puppet in the show, having a central focus on its mouth helped that size of puppet on the large theatre. The other note was the fabric on Dynne's hands; it was very flat and unfortunately not shaped like the rendering. For the sake of consistency for the performers, I didn't want to add a ton of weight to the hands the day of "Opening Night". To give texture and correct the shape of the hands I added ripped chiffon 
fabric pieces with tattered distressed edges. When in motion the fabric pieces separated the hands from the rest of the body nicely.

Finally, the show was open and ran for the entire weekend. The costume crew worked tirelessly on this show. The maintenance of the costumes for the short run didn't require any emergency fixes. The show closed on Sunday October $27^{\text {th }}, 2019$ and was immediately struck by the costume crew. 


\section{CONCLUSION AND EVALUATION}

This production of The Phantom Tollbooth used elements of design to bring fantasy to life. The script takes a beloved children's novel and uses the eccentric characters to engage the audience's imagination. The costume design of this production strived to reach audiences of all ages in an effort to uphold the belief that imagination and dreams can bring things to life. The costumes also used classic tropes of fairytale characters interpreted through the lens of a modern child. Through this combination of principles, the characters moved beyond the original novel and invite a new audience to appreciate the story.

When I first read The Phantom Tollbooth, I was a petulant child who was constantly told to read more. Of course, that meant I never wanted to read anything. However, The Phantom Tollbooth was different, the characters were funny, and each chapter seemed more ridiculous than the previous one. The things that caused fear were demons, but the worst offense they had was deflecting the Hero from his goal. When Susan Nanus brought this story to the stage, the pace was completely changed. Instead of luxuriously dwelling in the Doldrums for twenty pages, the play gives you three. The script omits characters like Faintly Macabre, Alex Bing, and Chroma. The Forest of Sight is removed from the play entirely, so the theatrical production dictates the visual stimulation. The playwright adapts the story to an open foundation for theatrical artists to create the sight with their imagination instead of the text dictating it. This omission is what allows the story to flourish thoroughly while still recreating the characters from the book. This wide expanse of options to create the visuals for these characters engaged the imagination of my younger self while reading the novel. 


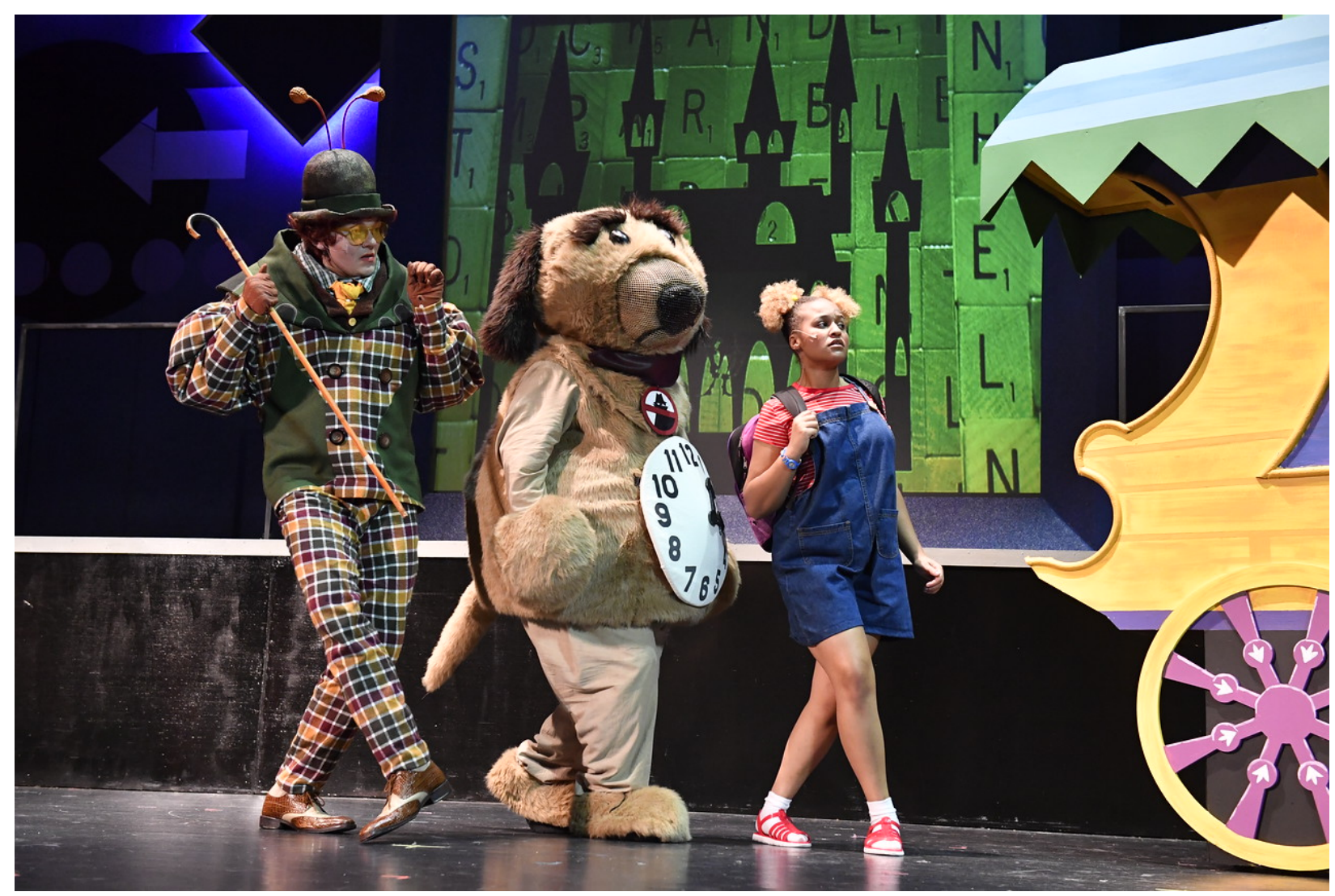

Figure 4.1: Humbug, Tock and Mila.

The costumes of this production were extremely successful. The three costumes in the design that needed to set the tone were Mila, Humbug, and Tock. Mila was perfect not only in color scheme but in using oversized clothing to make the performer appear childlike. This manipulation of scale was also being used for Humbug and Tock, who were both padded in their costumes to feel oversized compared to Mila. Humbug and Tock also opposed each other very nicely with their body shaping. Humbug appearing to have longer limbs that taper down to a point, like bug legs. The director and I agreed in a postmortem meeting that Humbug was the most successful costume. The formality of the classic structure of the garment with the dramatic body shaping worked extremely well with the performer's character choices. The trio as a whole were successful in setting the scale of Mila and her dreams for every scene. 
The design falters in different places throughout the show. First, the Ministers of King Azaz's Court-- the characters with pop culture heads. All of the garments used for the Ministers were pulled from stock, and the masks were repurposed, created, or bought. The pulled garments mostly came from a previous production of The Three Musketeers which set the Ministers in the $17^{\text {th }}$ century. However, King Azaz was more of a later Elizabethan silhouette. The design leaned too much on fantasy blurring history and fantasy. I would have felt better about the doublets and breeches in the end if all the ruff collars had been in a cartridge pleated style instead of falling ruffs. Creating a unity with that visually would have established a better base line for a precise era of historical fantasy in this production. Also, the masks were very difficult for the performers and Sound Designer to work with. Since all the masks were sourced from different locations and made of different materials, it caused difficultly for the microphones. Ideally this design choice either needed more time and money for custom masks made of variform, or other materials that worked better for sound.

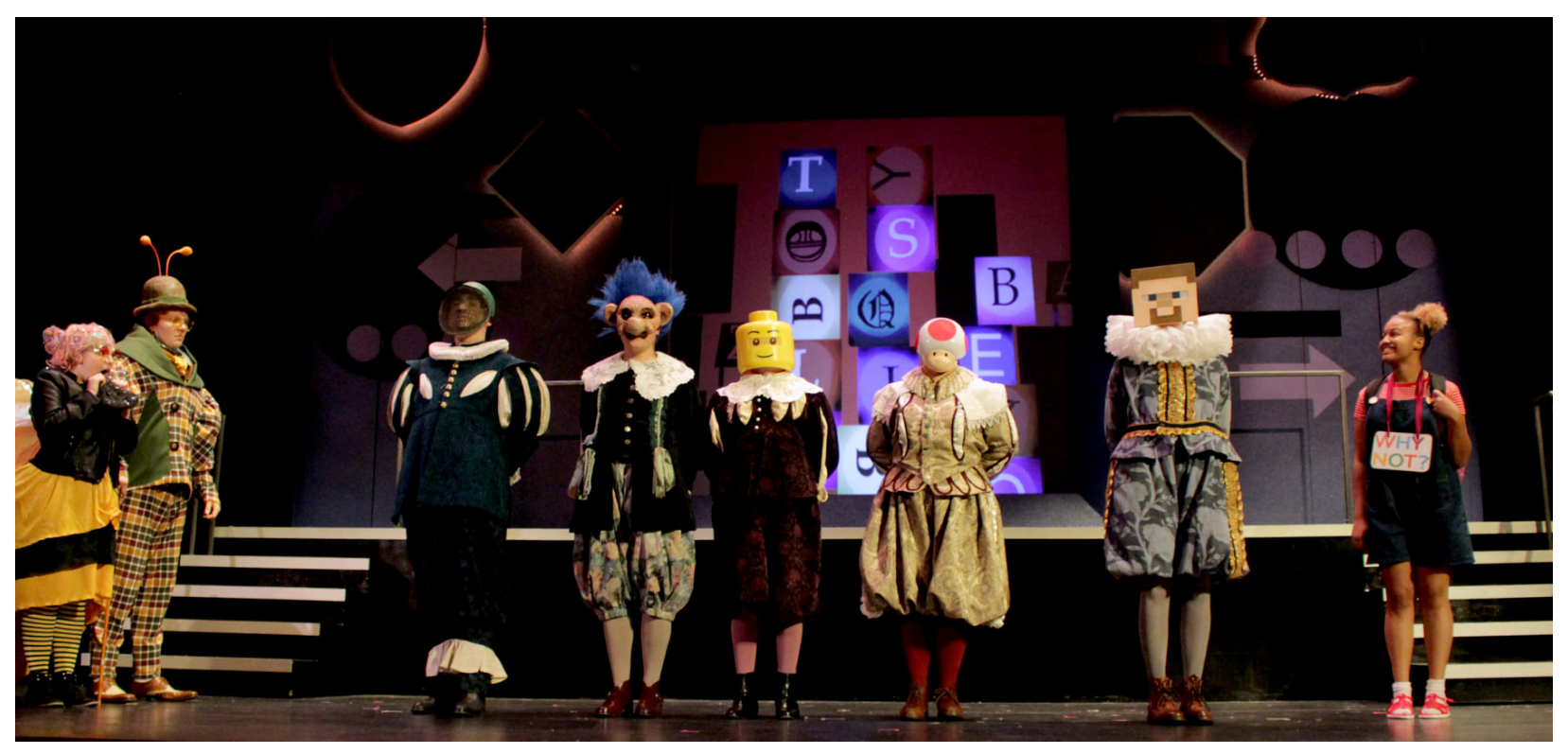

Figure 4.2: The Ministers of King Azaz's Court. 
Next are Kakafonous and the Dynne; these two designs took the largest amount of changes during tech week. I think that Kakafonous fell to a misunderstanding in communication between the Director and myself. We talked about a one-man band, a scientist, and a doctor. On paper I think the combination of those things went well. However, the Director and I had also connected over the baldric and having the performer make sound themselves. My excitement over these cool musical elements diverted my attention from the clothing. Then the Director gave the note to make Kakafonous more doctor like and less musician like in September. In the redesign, I kept every musical element and simply added a lab coat instead of a band coat. I should have taken more time to rework and resketch the design. I think the combination of musician and doctor could have been more apparent. Ideally I would have hidden more of the musical instruments, so the silhouette of the character was cleaner. This might have given the performer some room to choose when they wished to utilize sound best.

Dynne is a similar story since the character was going to be a projection until after design presentations, I simply didn't develop the design enough. Spectacle puppets made of papier mache are a large portion of my professional portfolio. I attended Columbia College Chicago and every year they hold a large street festival called Manifest. The theatre department would provide spectacle puppets for performance in the parade. When the idea for Dynne was established as a large-scale puppet, I immediately told the Director that I had a plan. Since this project was added onto the budget later, I chose to use papier mache for the head. Before learning puppetry at West Virginia University, papier mache was my medium of choice-- especially for large scale puppets. The main challenge with difference between Dynne and my previous experience was the talking mouth. When papier mache is cut off a sculpt it warps and curls. Dynne was a mask with no back so when it was removed from the sculpt it didn't hold its shape. When we cut into the head to 
form the mouth, it warped even more and made the mounting point for the mouth mechanism unstable. Peer Assistant Currence was able to add wood and supports for the papier mache head, but it was pretty misshapen in the end.

My experience with Kakafonous and Dynne reminded me that flexibility as a designer is a necessary trait. For Dynne, I could have used more input from Professor McClung about materials, but I chose to start the project alone one evening. As a designer, I often resent projects when changes happen to a design after presentation. Dynne could have been a great opportunity to make a spectacle puppet in my own style, not just the style I was familiar with. In the end the puppet worked in performance, but the result could have been more refined with different materials. In the case of Kakafonous, I experienced a similar situation. I was too attached to the original design. When my director asked for a change, I should have been more willing to let go elements of the original design to better suit the character.

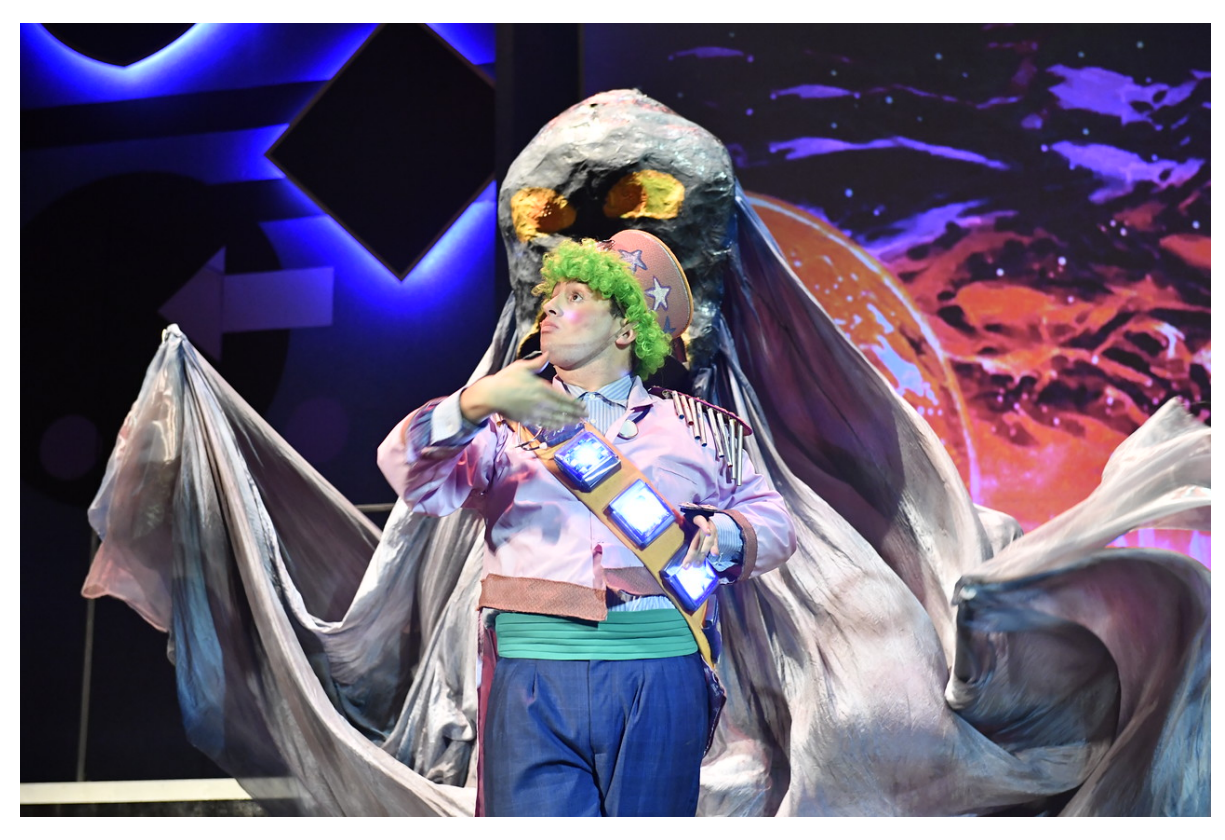

Figure 4.3: Kakafonous A. Discord. 


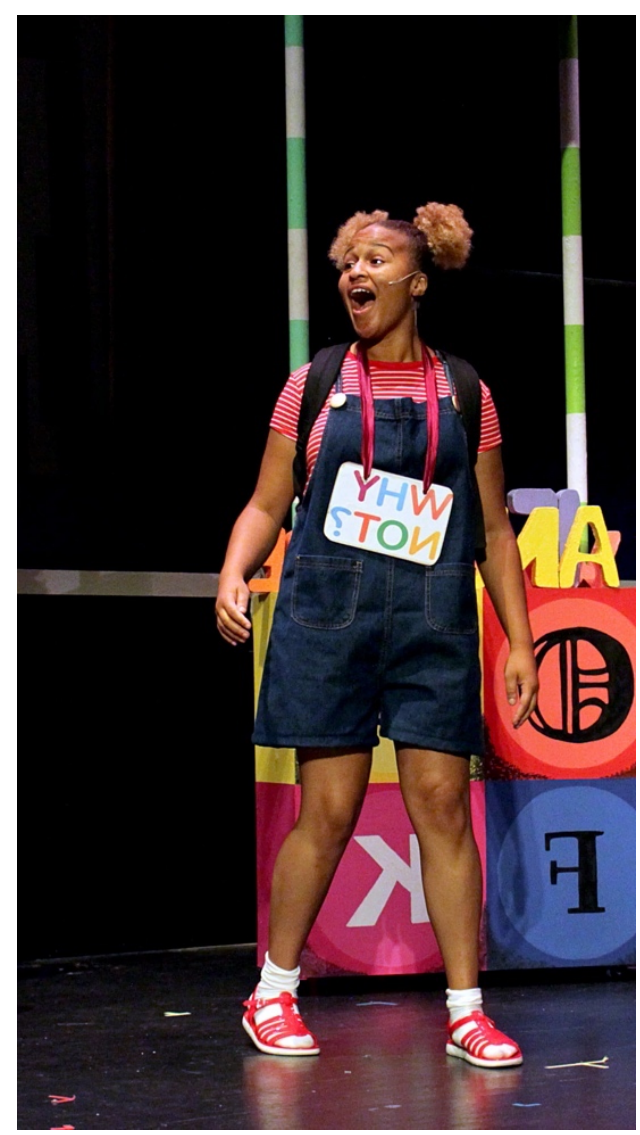

Figure 4.4: Mila in Dictionopolis.
In addition to issues with serving the play and communication, I also can now look back and see that there were some serious problems with casting delays. The director and I discussed very early on in the process that casting was open to any gender or race. In the Design Process Section, I explain the situation around casting of Sydney Miller as Milo. This matter caused a great amount of stress and delayed the process. This situation does beg the question: why does the gender of the lead character matter in this play? Nothing Milo experiences in the book or play relates to his gender. The expedition taken on in the show can be achieved in the same manner regardless of gender. Why should plays still be issued with these casting limitations on the rights? What purpose does it serve to not adapt that story to a modern audience? This situation brought forth the entire argument of relevancy. Presenting this story during the era of the \#metoo movement and "pay inequality", there is arguably more value in a female protagonist as opposed to a male. Choosing to represent this story of courage and heroism from the point of view of Sydney Miller, a woman of color, is exactly what I want to see in 2019. In this production that was the result. My hope for future productions is casting options retaining the status quo from twenty years prior is less of the perfunctory response.

When producing The Phantom Tollbooth, the sheer volume of enigmatic characters every other page is a hard task for any shop. This story is an adventure and some of the stress for the costume creation is that each character needs to be more brilliant than the last. It's very easy to 
get bogged down by the to-do list. For this production, the costume shop was in a transitional period of staffing. The costume shop manager took medical leave early in the fall semester and we were also understaffed by one graduate student. Several delays in the building process came from growing pains due to the responsibilities of these two positions being reallocated to the remaining staff. This dynamic change in the shop made build for this production feel very daunting. I believe that reevaluating the build list in late August when these staffing changes happened could have improved the costume shop's production. August would have been a better time to cut building and crafting projects to lighten the load on the shop.

The original budget for this production was not accurate to the final amount spent. This production went over-budget by $\$ 431.89$. First issues were shoes for the Lethargarians, I had originally planned for socks, but after watching the show the performers needed more traction against the floor. It suited the characters best to have slippers with a rubber sole. Also, Tock needed to change to cotton fabric used on his arms and legs that cost $\$ 48.50$. There was also around one hundred dollars spent during tech week for emergency items. To budget for these contingencies better, I would have needed to reduce the amount spent on raw materials at the beginning of the process. A large portion of my purchasing occurred over the summer before I had a cast list or definite sizes. This resulted in almost half of the budget being used before the fall semester started. Once the design presentation occurred and unexpected items like the Dynne were added to the budget, initial contingency predictions were no longer accurate.

Due to the budget allotted to costumes for the whole season the overage of \$431.89 was absorbed. The previous show in the season $M U D$ came in under-budget by approximately 500 dollars. This meant that the additional costs for The Phantom Tollbooth costumes didn't affect the subsequent productions in the season. 


\begin{tabular}{|c|c|c|c|c|c|}
\hline \\
\hline \# & Date & Description & Character & Retailer/ Location & Spent \\
\hline 1 & 7/21 & Fabric & Watchdog/Azaz & Ayaz moon Fabric (NY) & 303.50 \\
\hline 2 & 7/21 & Fabric & Bee/Watchdog & Diana Fabrics (NY) & 69.68 \\
\hline 3 & $8 / 3$ & Fabric & Bee/Math/Azaz & Gail K (GA) & 330.78 \\
\hline 4 & $8 / 3$ & Fabric & Azaz/others & Fine Fabrics (GA) & 166.24 \\
\hline 5 & $8 / 5$ & Fabric & Azaz, Math, Rhyme & Textile Fabric (TN) & 430.28 \\
\hline 6 & $8 / 13$ & Mask, Glue, bits & Bee/Cour/various & Amazon & 111.23 \\
\hline 7 & $8 / 13$ & Mask & Court & Amazon & 17.14 \\
\hline 8 & $8 / 28$ & Foam & So Many & Foam and More & 317.49 \\
\hline 9 & $8 / 12$ & Heat Foil & Mathmagician & Specialty Graphics & 45.99 \\
\hline 10 & $8 / 27$ & Fabric/Craft & Reason/Dyne/others & Dharma Trading & 507.07 \\
\hline 11 & $8 / 28$ & Fabric & Humbug & Etsy & 114.48 \\
\hline 12 & 9/10 & clothing/Acc. & Everyone & Amazon & 915.80 \\
\hline 13 & 9/10 & \begin{tabular}{|l} 
Detail supplies \\
\end{tabular} & cacophonous/whether & Amazon & 75.76 \\
\hline 14 & $9 / 10$ & barge glue & puppets and other & Amazon & 26.45 \\
\hline 15 & 9/10 & duct tape & \begin{tabular}{|l|} 
Whetherman \\
\end{tabular} & Amazon & 7.82 \\
\hline 16 & 9/11 & straws/beads & Princess Reason & Amazon & 38.13 \\
\hline 17 & 9/11 & prom dress & Princess Reason & Amazon & 48.75 \\
\hline 18 & 9/12 & crown & Azaz & Amazon & $\begin{array}{ll}43.47 \\
\quad 1\end{array}$ \\
\hline 19 & 9/22 & clothing/Acc. & Milo & Amazon & 155.07 \\
\hline 20 & 9/23 & Tights & Spelling Bee & Amazon & 20.24 \\
\hline 21 & 9/23 & running shoes & Milo & Amazon & 30.73 \\
\hline 22 & 9/23 & Wigs & Various & Amazon & 79.46 \\
\hline 23 & 9/23 & \begin{tabular}{|l|l|} 
Latex \\
\end{tabular} & Mathmagician & Amazon & 24.33 \\
\hline 24 & 9/24 & clothing/Acc. & Mila & Amazon & 168.18 \\
\hline
\end{tabular}

\begin{tabular}{|r|l|l|l|l|r|}
\hline$\#$ & Date & Description & Character & Retailer/ Location & \multicolumn{1}{l|}{ Spent } \\
\hline 25 & $9 / 25$ & Leather Jacket & Spelling Bee & Amazon & 42.38 \\
\hline 26 & $9 / 26$ & Aqua Socks & Tock & Amazon & 37.38 \\
\hline 27 & $10 / 1$ & RETURNS & Milo/other & Amazon & -379.42 \\
\hline 29 & $9 / 31$ & Wigs & Humbug/Mathmagician & Amazon & 86.00 \\
\hline 30 & $9 / 20$ & Canvas & Tock & Walmart & 17.91 \\
\hline 31 & $9 / 23$ & Shoes & Lethargarians & Amazon & 143.00 \\
\hline 32 & $9 / 25$ & knee/elbow pads & Lethargarians & Amazon & 105.90 \\
\hline 33 & $9 / 26$ & Cooling towels & Tock the watchdog & Amazon & 12.71 \\
\hline 34 & $9 / 26$ & shoes & Lethargarians & Amazon & 14.30 \\
\hline 35 & $9 / 23$ & Dance Rubber & Tock Word Snatch & Manhattan Wardrobe & 59.54 \\
\hline 36 & $9 / 15$ & Paint & Various & AC Moore & 48.36 \\
\hline 37 & $9 / 24$ & puppet blacks & Various & Walmart & 72.00 \\
\hline 38 & $9 / 25$ & Paint & Various & AC Moore & 86.60 \\
\hline 39 & $10 / 1$ & Emergency & Tock & Hobby Lobby & 48.56 \\
\hline 40 & $10 / 10$ & Fynne masks & Dyne & AC Moore & 29.67 \\
\hline 41 & $10 / 18$ & Dowel Rods & Dyne & Lowes & 15.96 \\
\hline 42 & $10 / 18$ & Tech notes & Mila & Target & 91.86 \\
\hline 43 & $12 / 11$ & FETURNS & Slippers/wig & Amazon & -107.59 \\
\hline 44 & $11 / 4$ & RETURNS & Milo watch & Target & -39.00 \\
\hline
\end{tabular}

Figure 4.5: Final costume budget for The Phantom Tollbooth . 


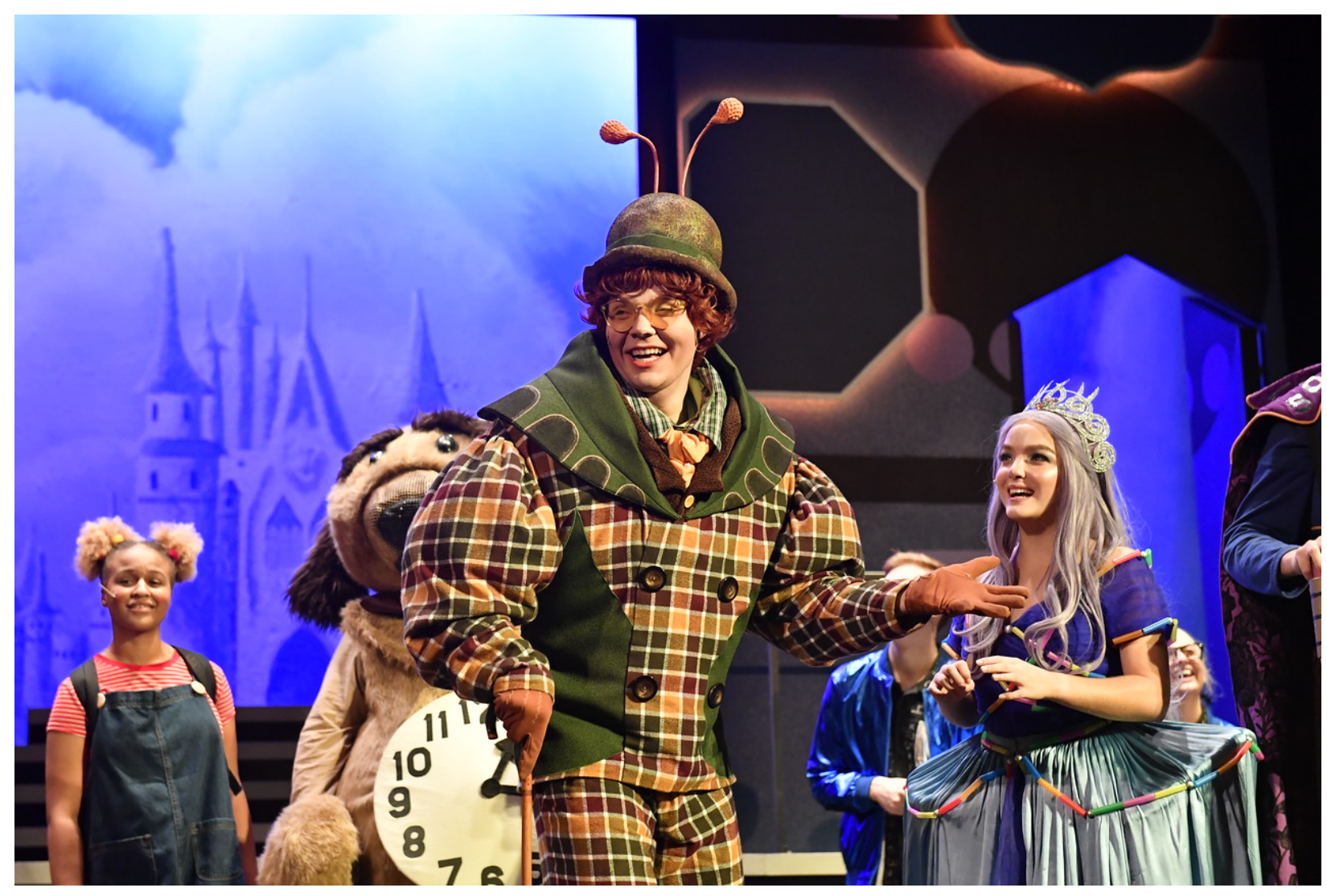

Figure 4.6: Humbug.

Overwhelmingly, the response to the costumes was positive. Audience members I knew talked a lot about the bright color palette and the reshaping of the performer's bodies. A welcome compliment even came from the President of West Virginia University Gordon Gee, he said, "I wanted to send you a note immediately after seeing The Phantom Tollbooth and congratulate you on the most fabulous costume designs. My significant other and I were so taken with the whole production, and we could not stop talking on the way home about the costumes that you designed." Perhaps my favorite compliment was from a student who said, "It's like illustrations come to life". 
APPENDIX

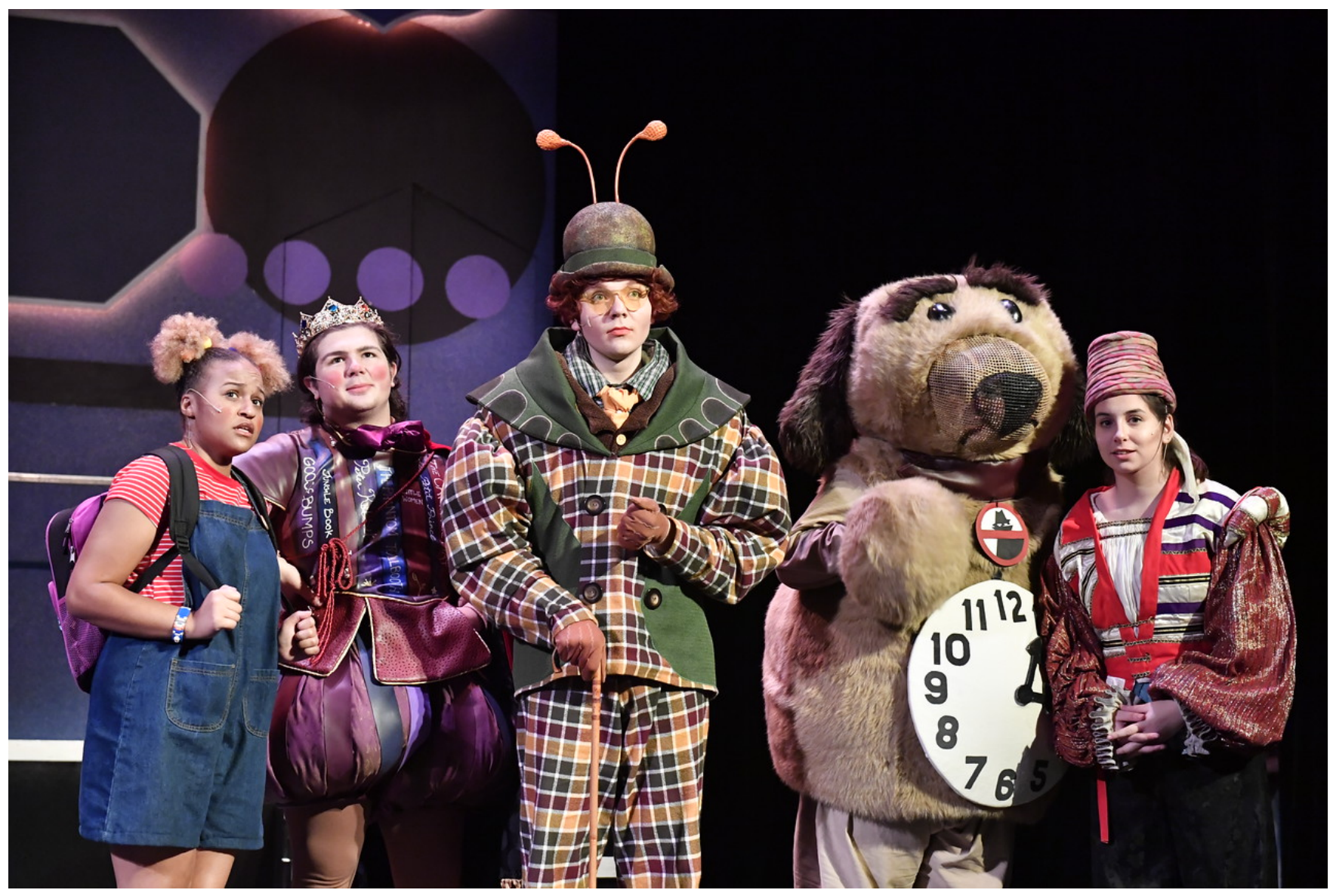

Figure 5.1: Mila, King Azaz, Humbug, Tock and Gatekeeper of Dictionopolis. 


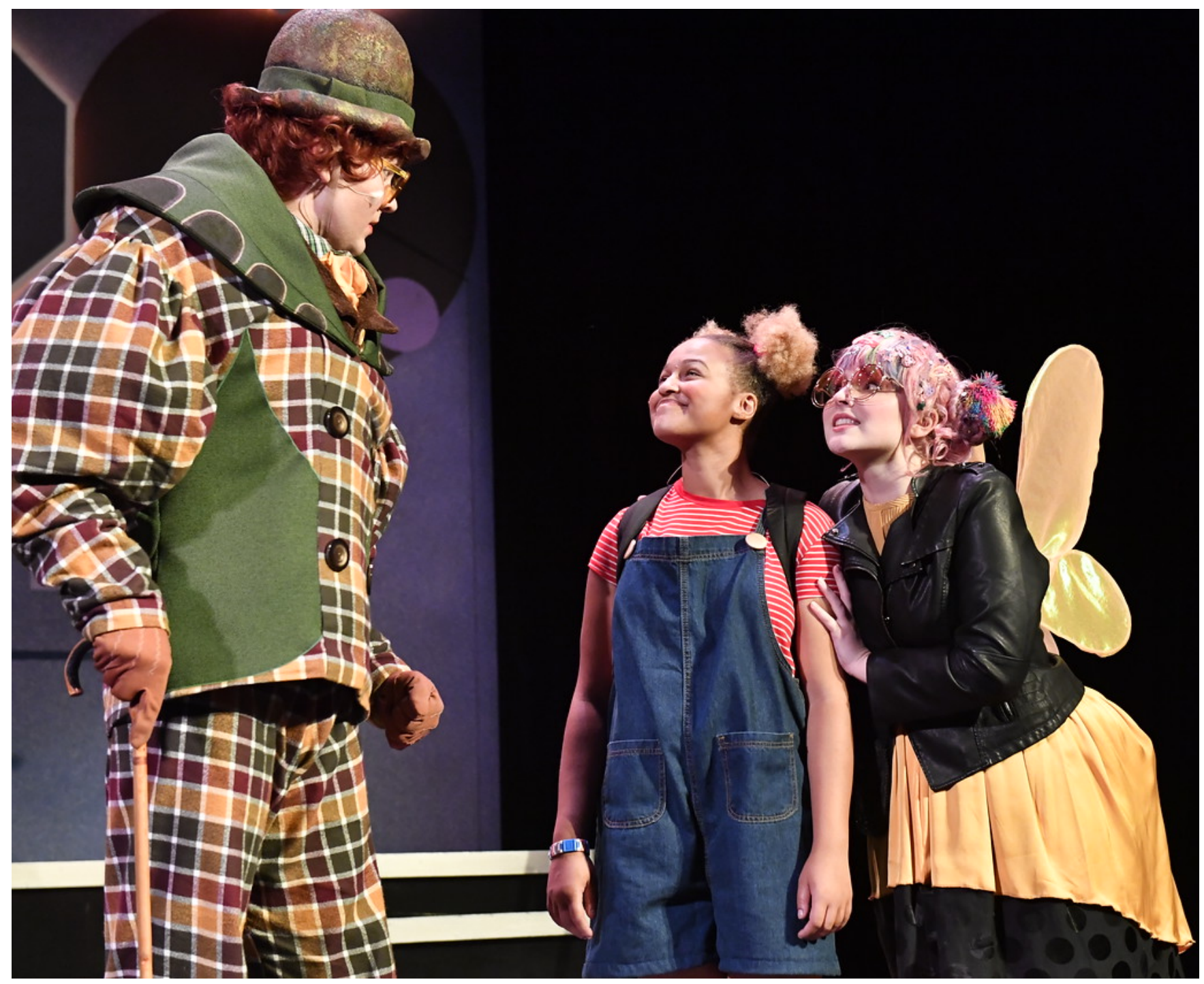

Figure 5.2: Humbug, Mila, and Spelling Bee. 


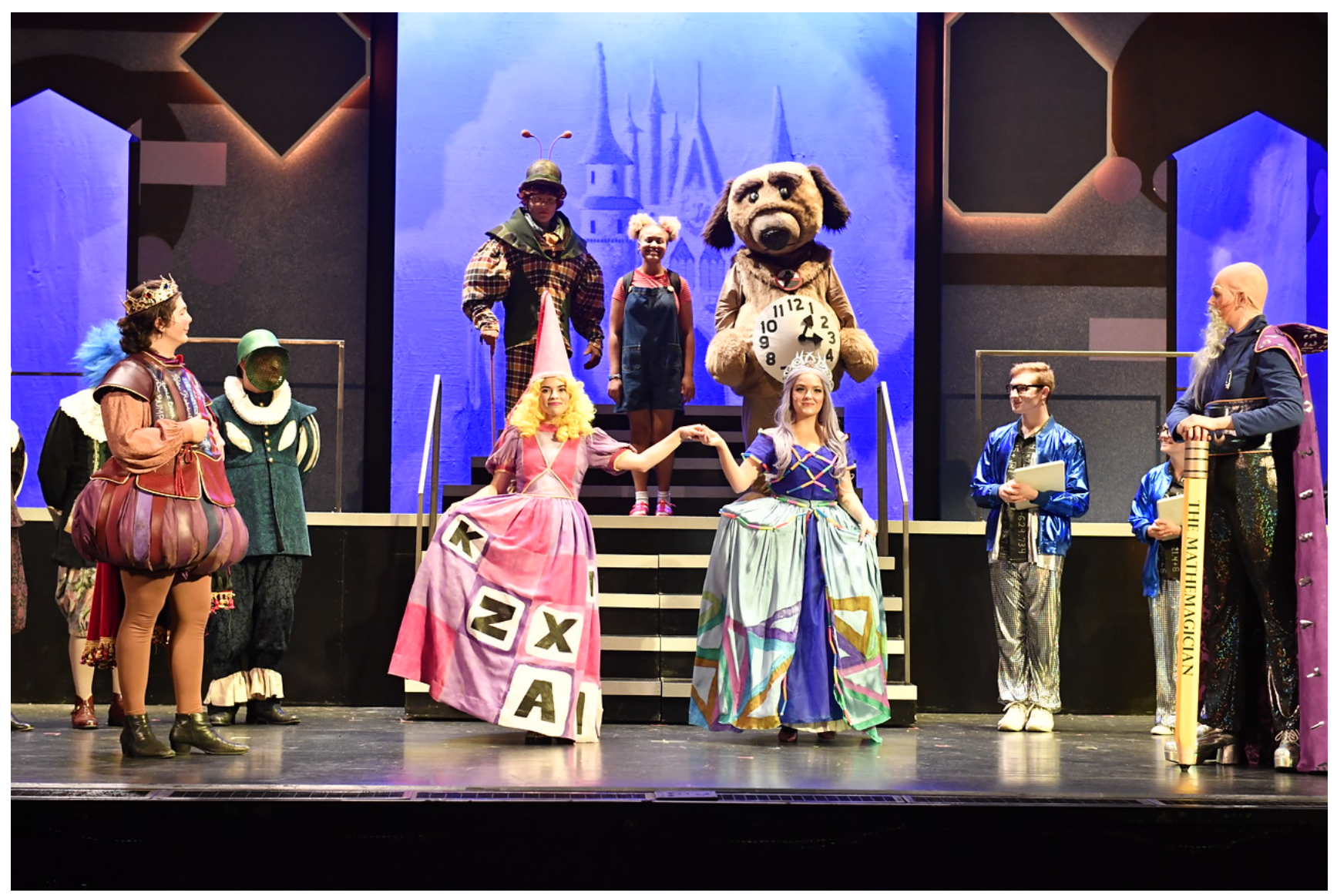

Figure 5.3: King Azaz, Princess Rhyme, Princess Reason, Mathemagician. 


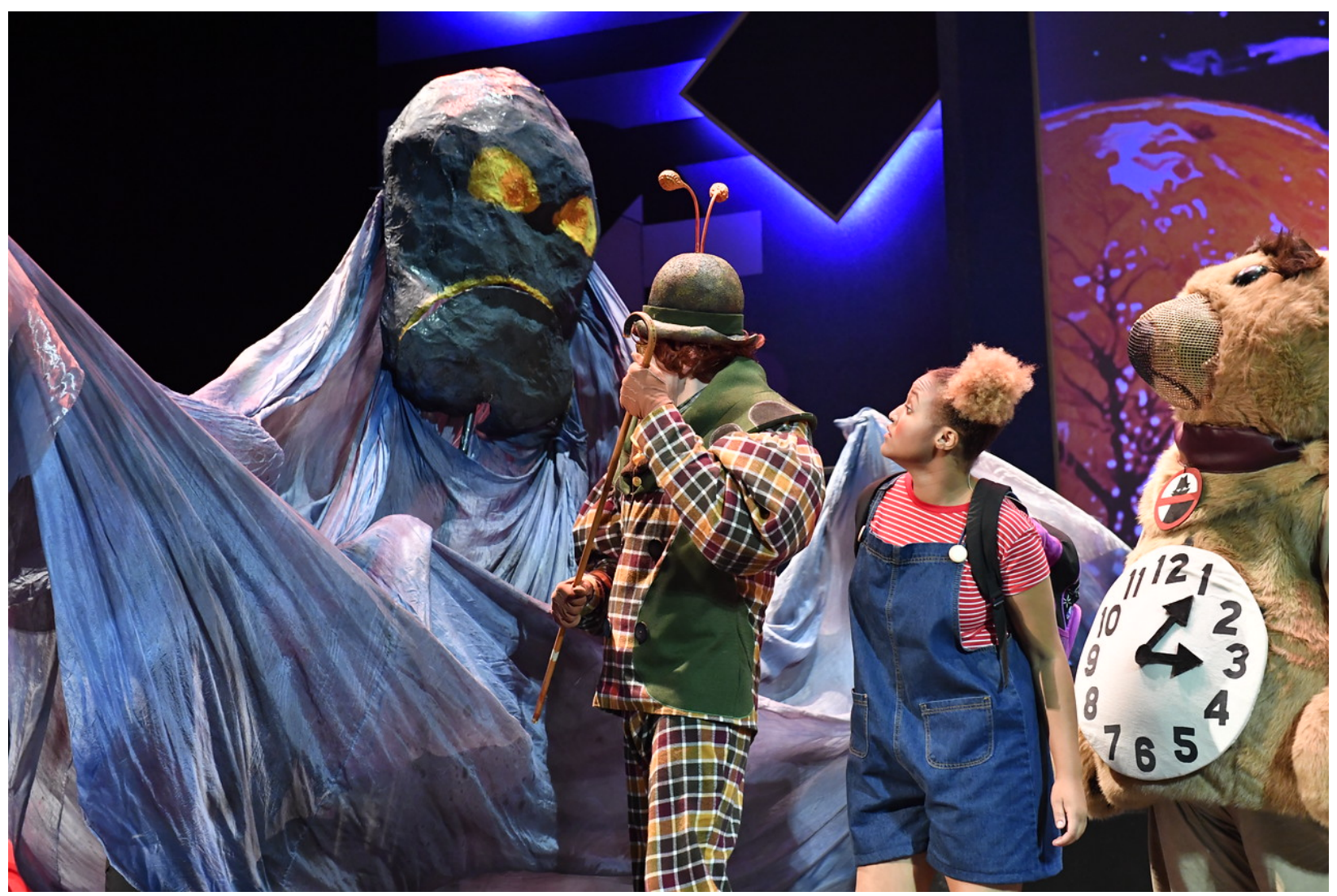

Figure 5.4: Dynne, Humbug, Mila, and Tock. 


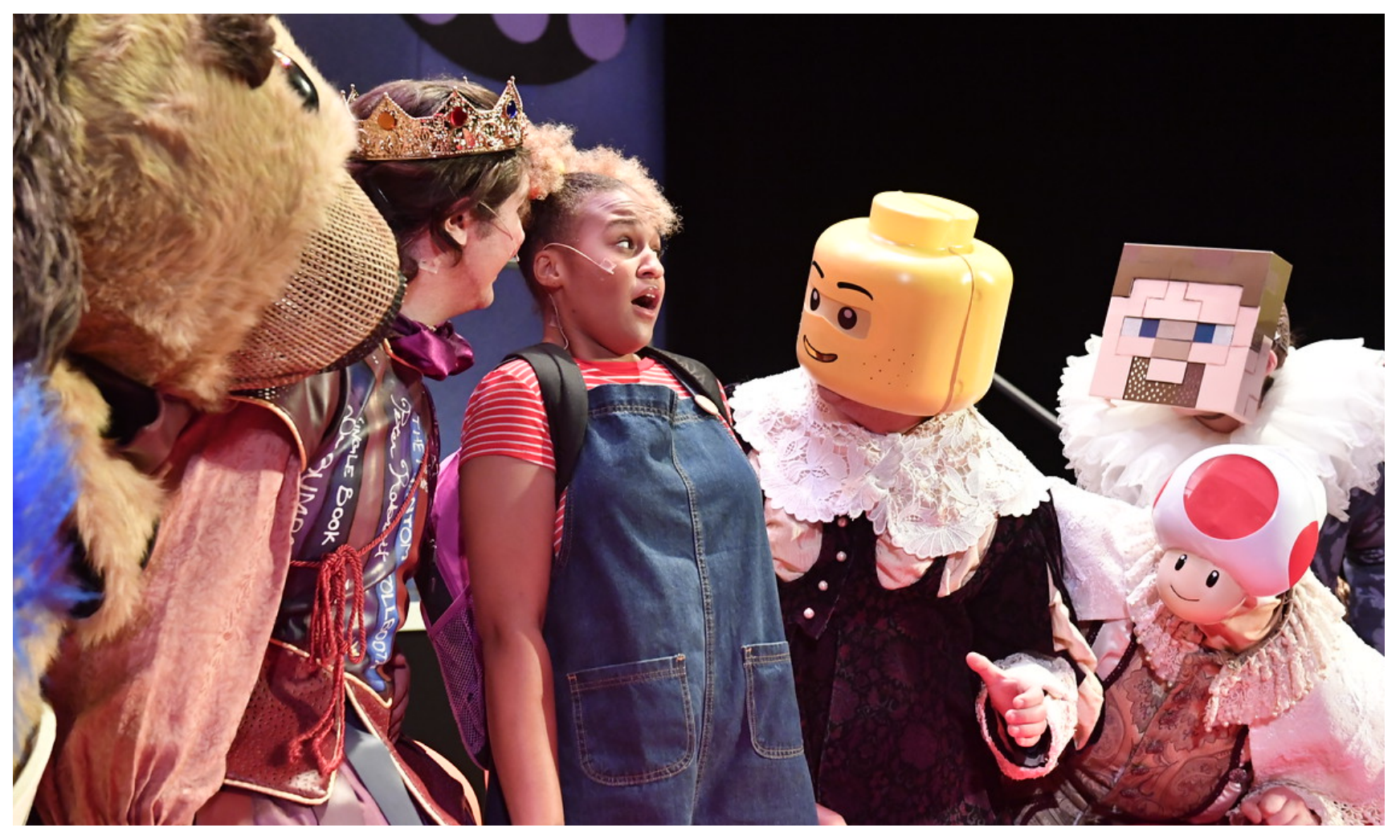

Figure 5.5: Tock, King Azaz, Mila, and Ministers of King Azaz's Court. 


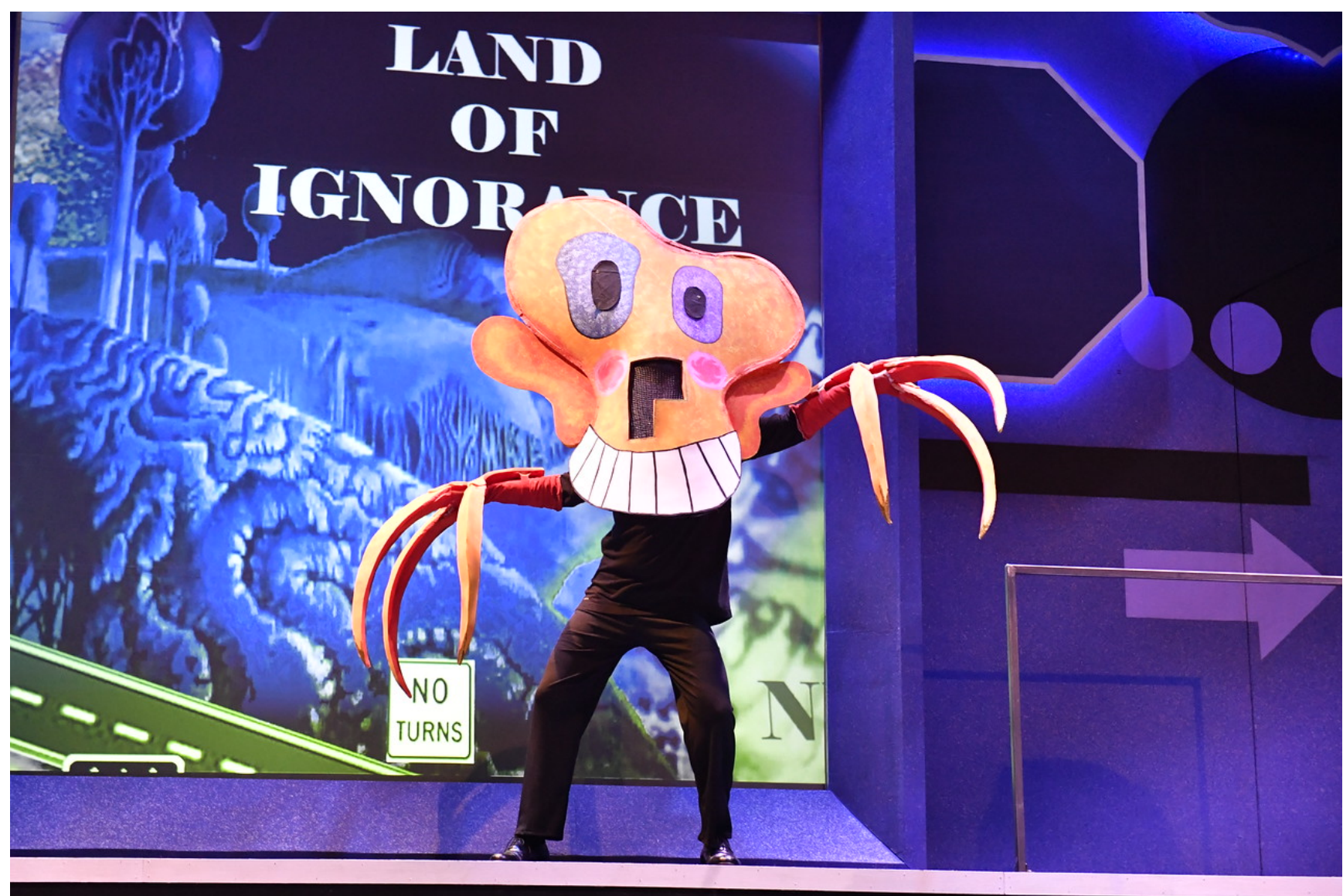

Figure 5.6: The Terrible Trivium 


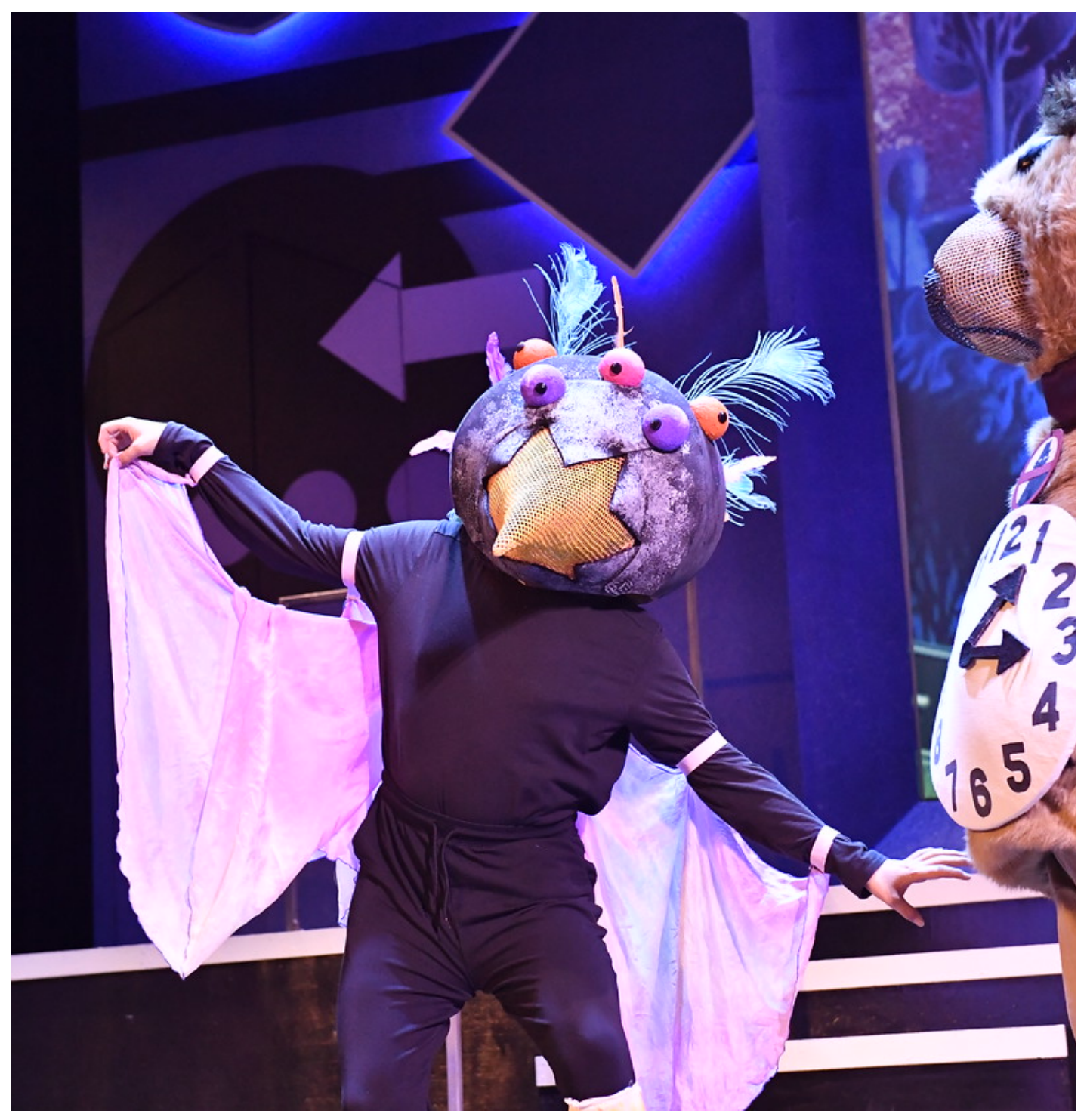

Figure 5.7: The Everpresent Wordsnatcher. 


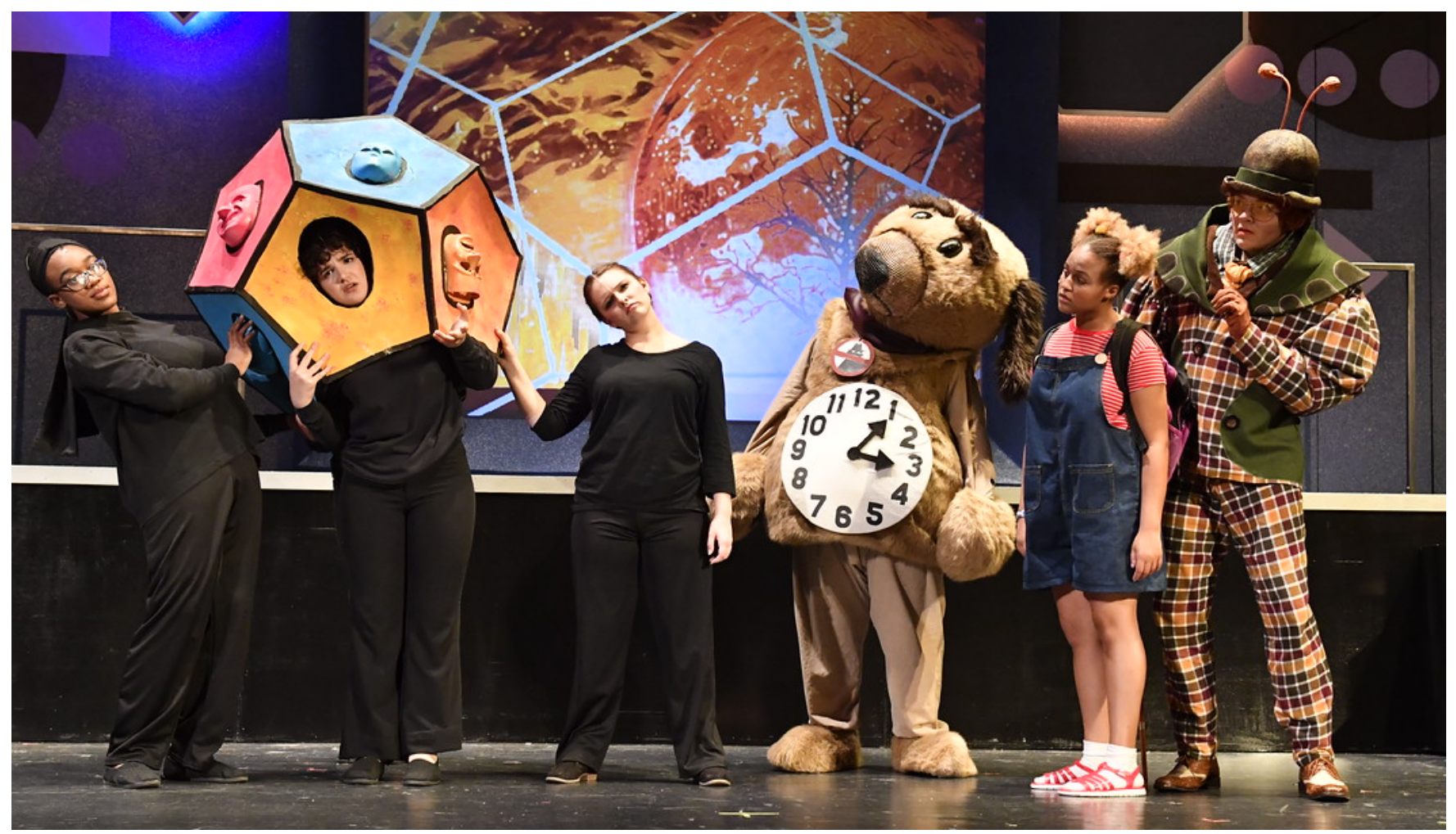

Figure 5.8: Dodecahedron Ensemble, Tock, Mila, and Humbug. 


\title{
The Phantom Tollbooth Piece List
}

\section{Sydnee MIller.}

Mlla

Jean overalls

Red shirt

socks

Red jelly shoes

\section{Joseph Kemproski}

\author{
Tock (aka Watchdog) \\ Belly understructure \\ Mascot head with Helmet \\ Tan Fur body suit \\ Multiple White t-shirts \\ Multiple White tank tops \\ Multiple leggings
}

\section{Alexander Evans}

\section{Whether Man}

Two Toned fringe covered rain coat

Two Toned fringe covered pants

Yellow undershirt

Tennis shoes

Yellow rain cap with propeller top

Number Miner of Digitopoljs

White undershirt (OR previous undershirt)

Orange toned Jumpsuit with infinity symbol on chest

boots

Hat

Handkerchief

\section{The Terrible Trivium}

Giant yellow painted mask

big painted yellow claws

Black pants

Black long sleeved shirt

Black shoes 


\title{
Eryk Bluto
}

\author{
Lethargarian \#1 \\ Hood painted \\ pajama onesie suit painted dot style \\ sock shoes
}

Shopper Servent \#1

breeches

Peasant shirt

waistcoat

Hat

Satchel

Boots

socks

White undershirt

The Three

Blue Shiny bomber jacket

Silver bowling shirt with number on front Holographic grid pants

White shoes

\section{Chidera Nwoko}

\section{Lethargarian \#2}

Hood painted

pajama onesie suit painted dot style

sock shoes

Word Merchant \#1

sleeved Bodice

Hat

Petticoat

peasant skirt

Apron

boots

Dodecahedron \#1

Black shirt

Black pants 
Black shoes

\section{Mackenzie Wolcott}

Word Merchant \#2

Bodice

Shirt

petticoat

skirt

Apron

Hat

Boots

Dodecahedron \# 2

Black long sleeve shirt

Black pants

Black shoes

\section{Carley Ward}

\section{Lethargarian \#4}

Hood painted

pajama onesie suit painted dot style

sock shoes

Word Merchant \#3

Bodice

Skirt

Petticoat

boots

blouse

apron

Hat

Belt

\section{The Three}

Metallic blue bomber jacket sliver bowling shirts with numbers holographic grid pants 
White tennis shoes

\section{Drew Gasemy.}

Lethargarian \#5

Hood painted

pajama onesie suit painted dot style

sock shoes

Shopper Servant \#2

bodice

Blouse

petticoat

skirt

shoes

apron

hat

shawl

Dodecahedron \#3

black long sleeved shirt

black pants

Black shoes

\section{Aliza Broder}

\section{Lethargarian \#3}

Hood painted

pajama onesie suit painted dot style

sock shoes

\section{Gate Keeper}

Doublet

Undershirt

Hat

breeches

boots

\section{Dodecahedron \#3}

Black pants 
black long sleeved shirt

black shoes

\title{
Megan Wright
}

Spelling bee

Pink space bun wig

leather jacket

black and yellow striped stockings

black boots

black and yellow layered skirt

butt pillow

yellow shirt

pink choker necklace

Dodecahedron \#4

long sleeve black shirt

black pants

black shoes

\section{Jacob Masters}

\section{Humbug}

Bowler hat with antenna

Yellow sunglasses

Dickie suit front

Large shouldered plaid suit jacket

Plaid suit pant

Boots

Socks

White undershirt

\section{Joseph Zecevic}

\author{
Azaz the Unabridged \\ Gold crown multi colored jewels \\ Doublet painted with book spines \\ Pumpkin Breeches painted with book spines \\ Red Velvet Cape with tassels \\ Black low boots with large ruffle bow \\ Tights \\ Socks \\ White undershirt
}




\title{
Riley Barringer
}

\author{
The Mathmagecian \\ Bald cap \\ Gray Beard \\ blue turtle neck \\ black holographic bellbottoms \\ silver platform shoes \\ Purple and foiled high collar cape \\ White undershirt (if needed) \\ Dance Belt
}

\section{Grace Alvarez}

Princess sweet Rhyme

Petticoat

Pink and gold gown

Pink steeple hat

Gold wig

Pink metallic shoes

\section{Dynne \#2}

Black long sleeved shirt

Black leggings

Black shoes

Black puppet hood

\section{Jordan Phillips}

\section{Princess Pure Reason}

Blue Gown

Blue Elizabethan overskirt

Purple kitten heels

Petticoat

Dynne \#3 
Black pants

Black long sleeved shirt

Black shoes

Black puppet hood

\title{
Adam Payne
}

Kakafonous A. Dischord

White and Purple lab coat with epaulets

Blue plaid pants

white undershirt

socks

piano spats

toy drum hat

Duke of Definition

blue doublet with split sleeves

blue breeches with white cuffs

black boots

white ruff

army helmet with face cover

\section{Caleb McClung}

\author{
Minister of Meaning \\ doublet \\ breeches \\ white undershirt \\ white ruff \\ troll mask \\ troll wig
}

The Everpresent Wordsnatcher

black long sleeved turtle neck

black pants

black shoes

yellow shoe spats

watercolor circle cape

bird head 


\title{
Noah Gross
}

\author{
Earl of Essence \\ doublet \\ breeches \\ boots \\ tights \\ lego mask \\ socks
}

\section{Miner \#3}

Orange jumpsuit

Bandana

Boots
Senses Taker
Blue polo shirt
painted tie
painted reflective vest
brown shoes
socks
visor

\section{Alexandra Ashworth}

Count of Connotation

Tan and cream doublet

Matching breeches

stockings

brown boots with bow

white head mask with red dots

toad mask

\section{Dynne \#1}

Black long sleeved shirt

Black pants

black socks

black low top shoes

bass drum overhead strap 
puppet hood

Demon of Insincerity

Same as Dynne

Black long sleeved shirt

Black pants

black socks

black low top shoes

puppet hood

\section{Rhowyn Saffel}

\section{Undersecretary of Understanding}

Blue doublet with gold trim

matching breeches

large ruff collar

minecraft mask

shoes

tights

\section{The Three}

Blue shiny bomber jacket

Silver bowling shirt

Grid holo silver pants

White keds

glasses

Figure 5.9: Pages 86-94 Costume Piece List . 


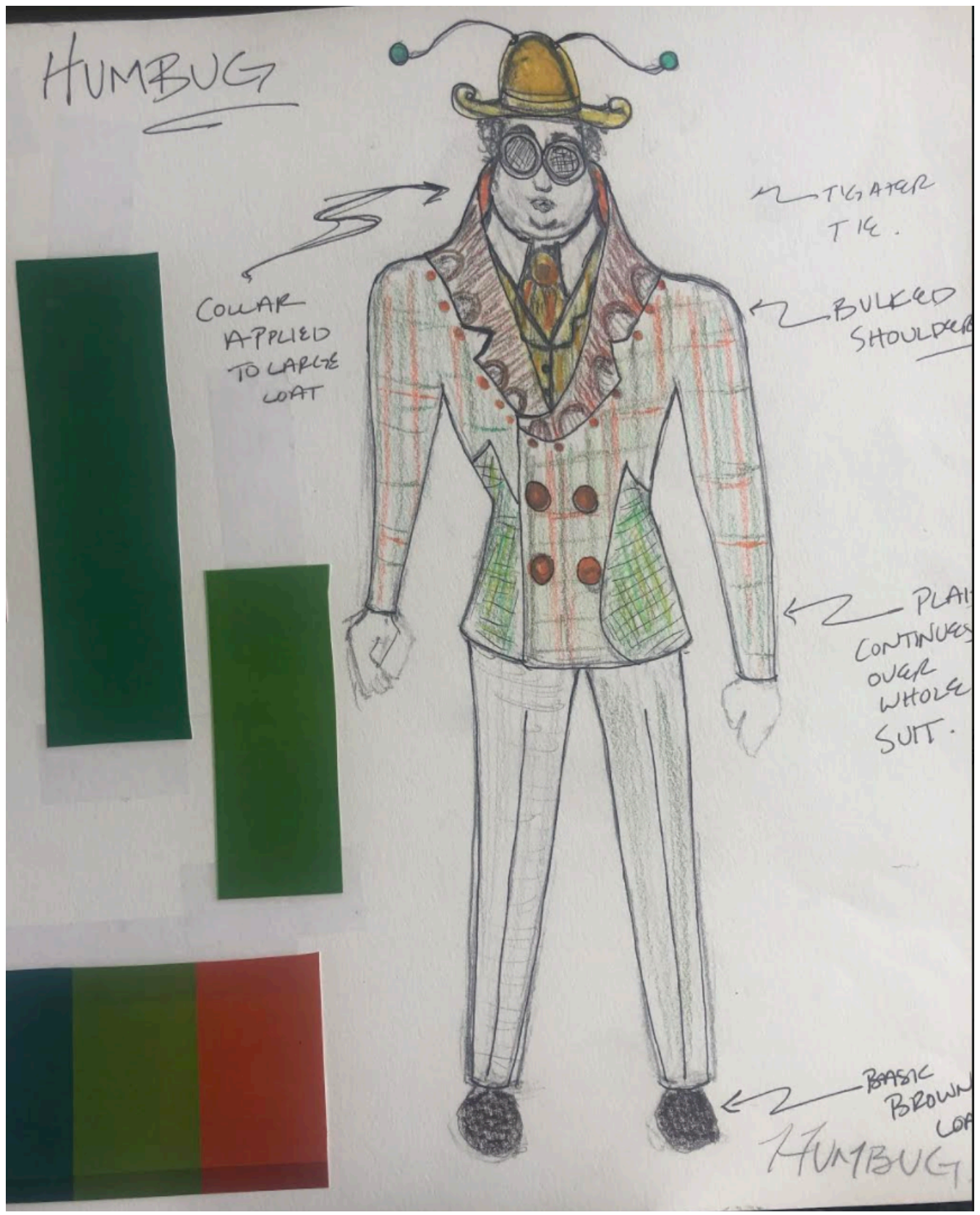

Figure 5.10: Humbug color sketch. 


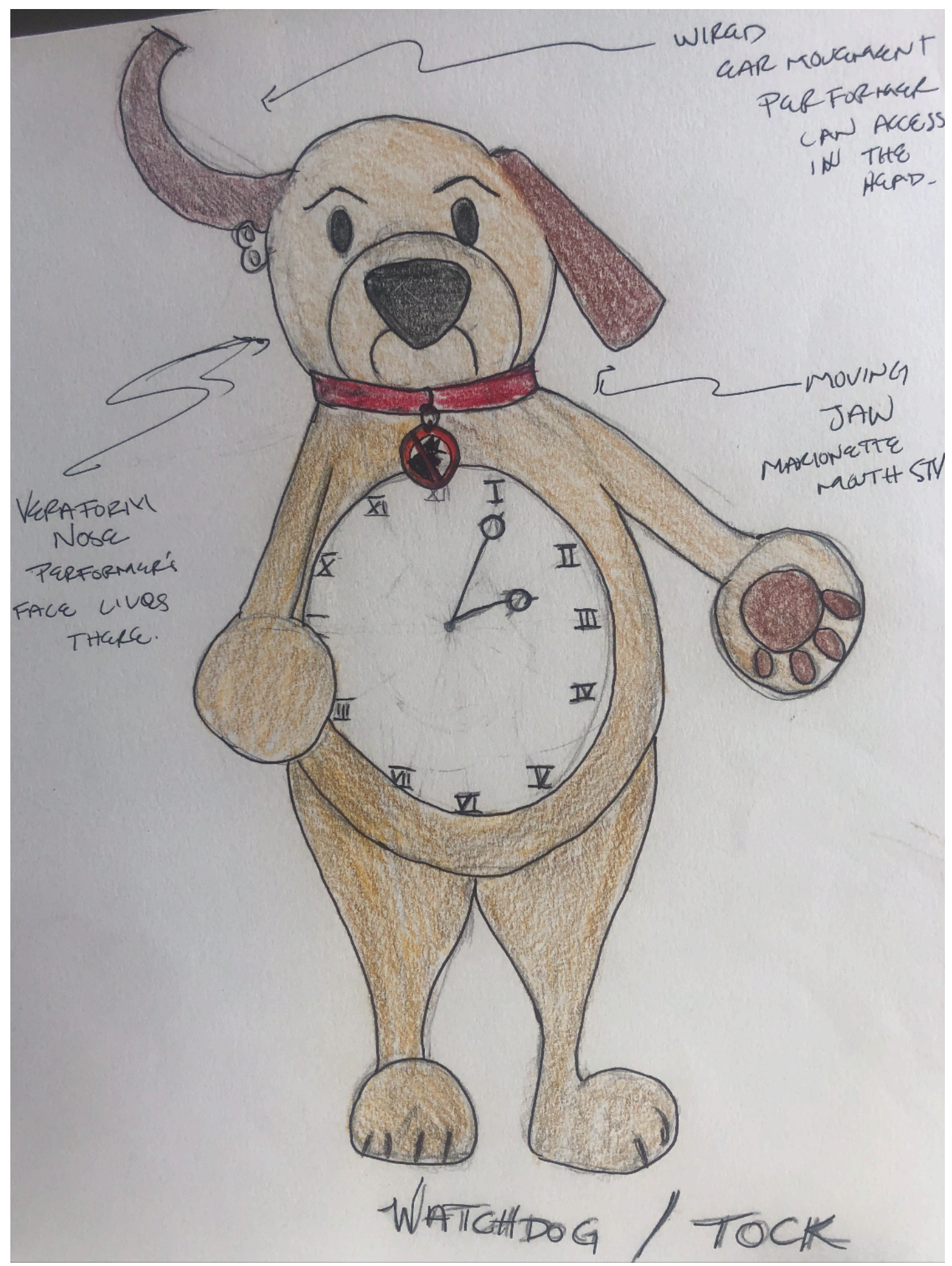

Figure 5.11: Tock color sketch. 


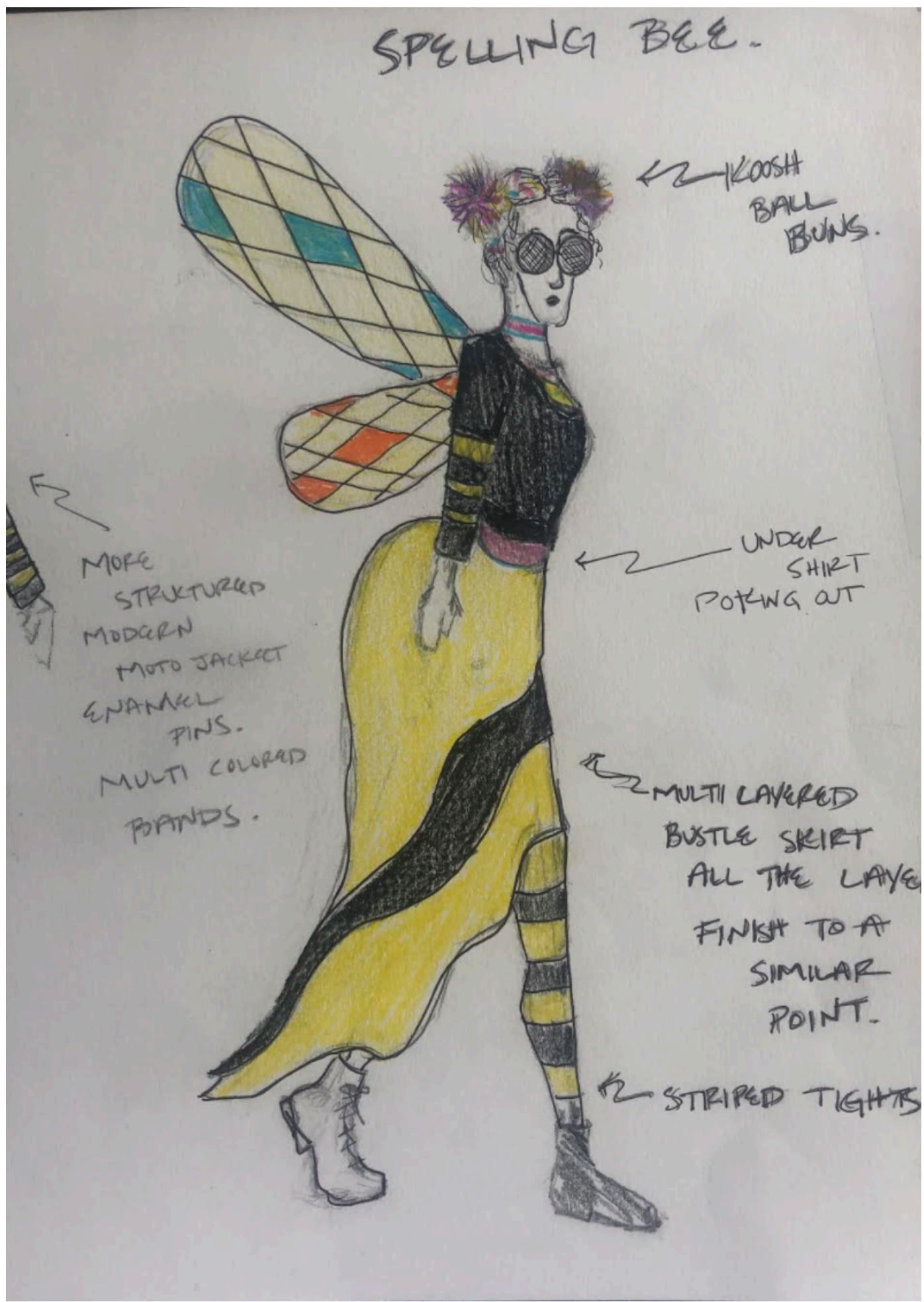

Figure 5.12: Spelling Bee colored sketch. 


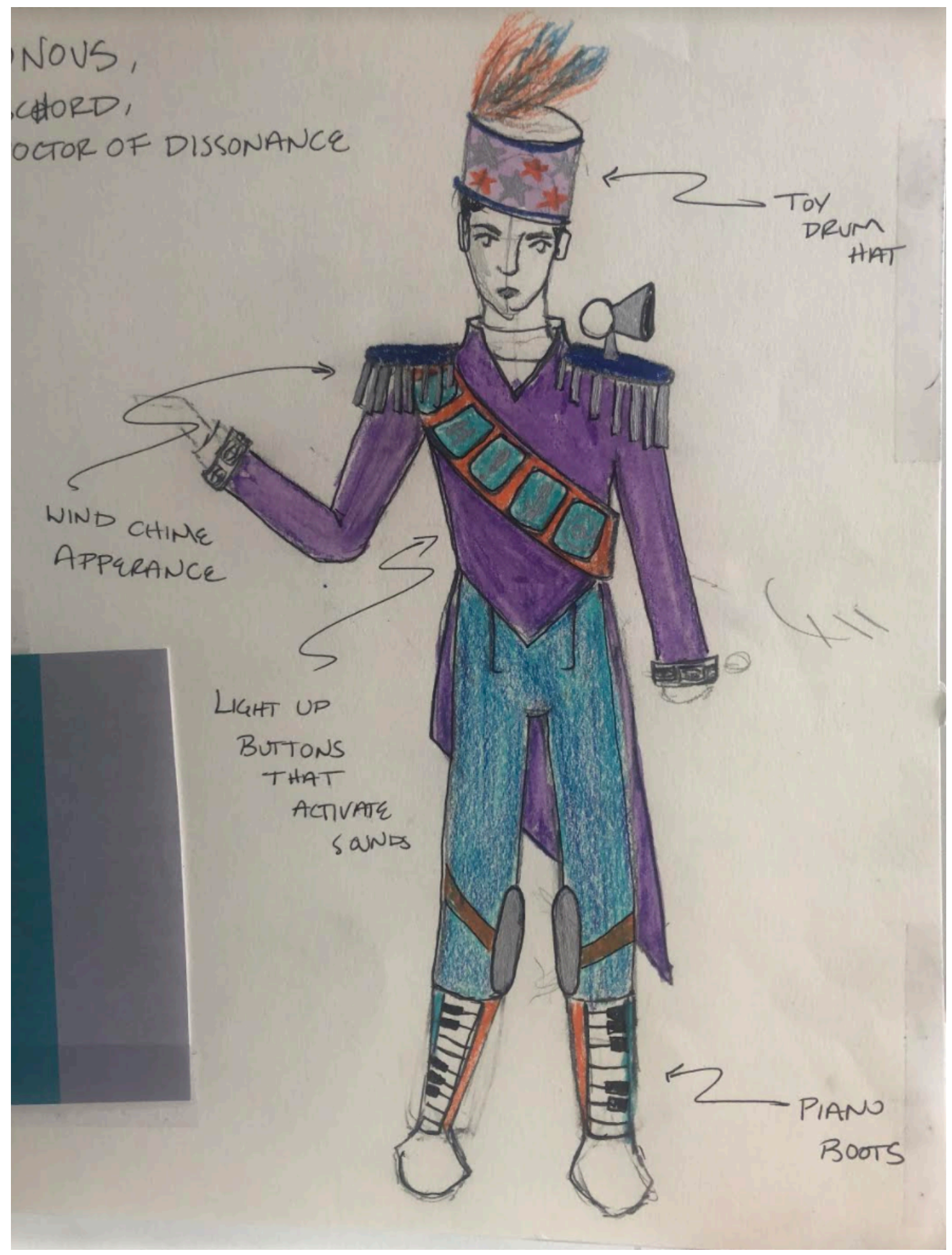

Figure 5.13: Kakafonous color sketch 


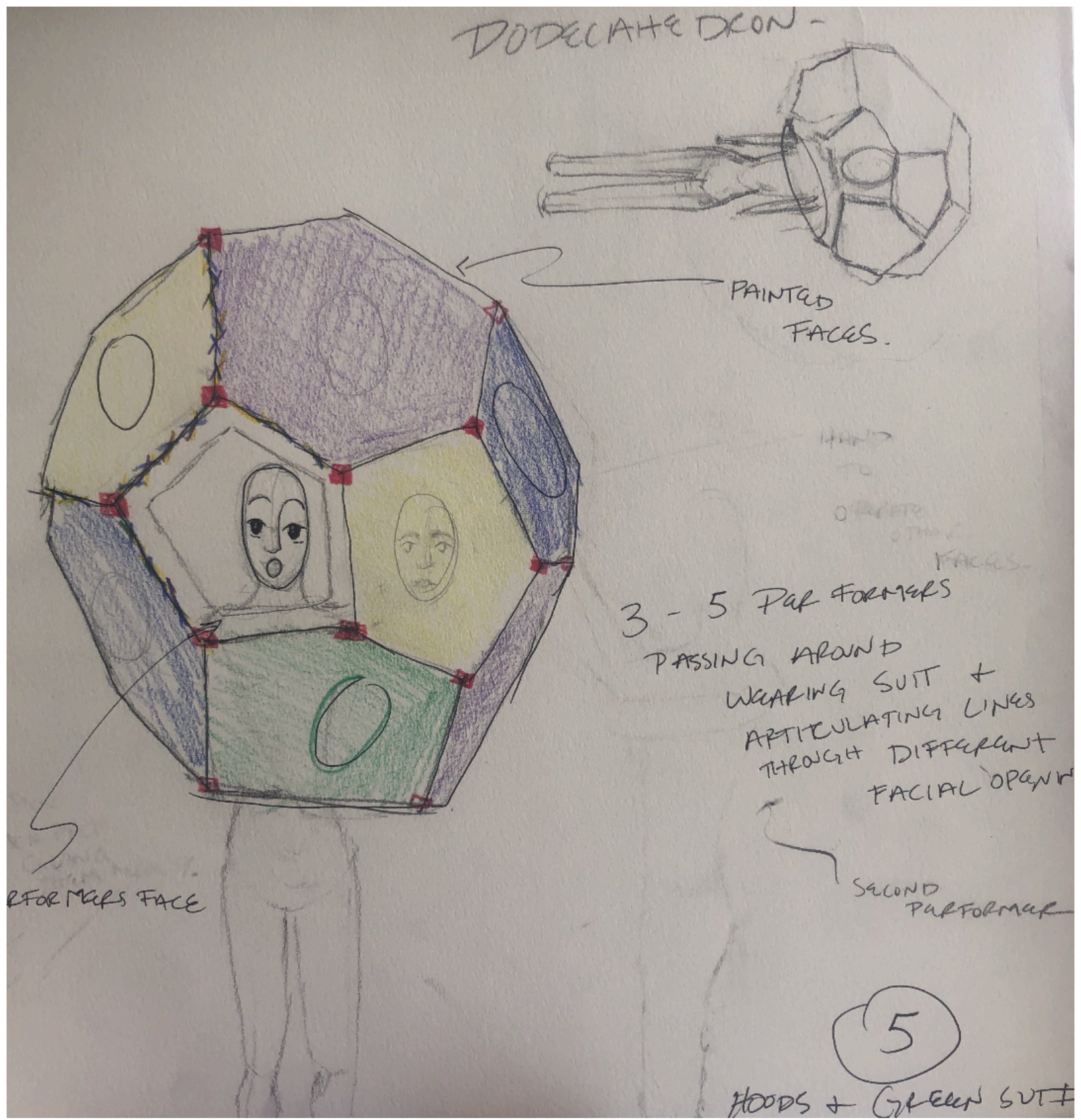

Figure 5.14: Dodecahedron color sketch. 


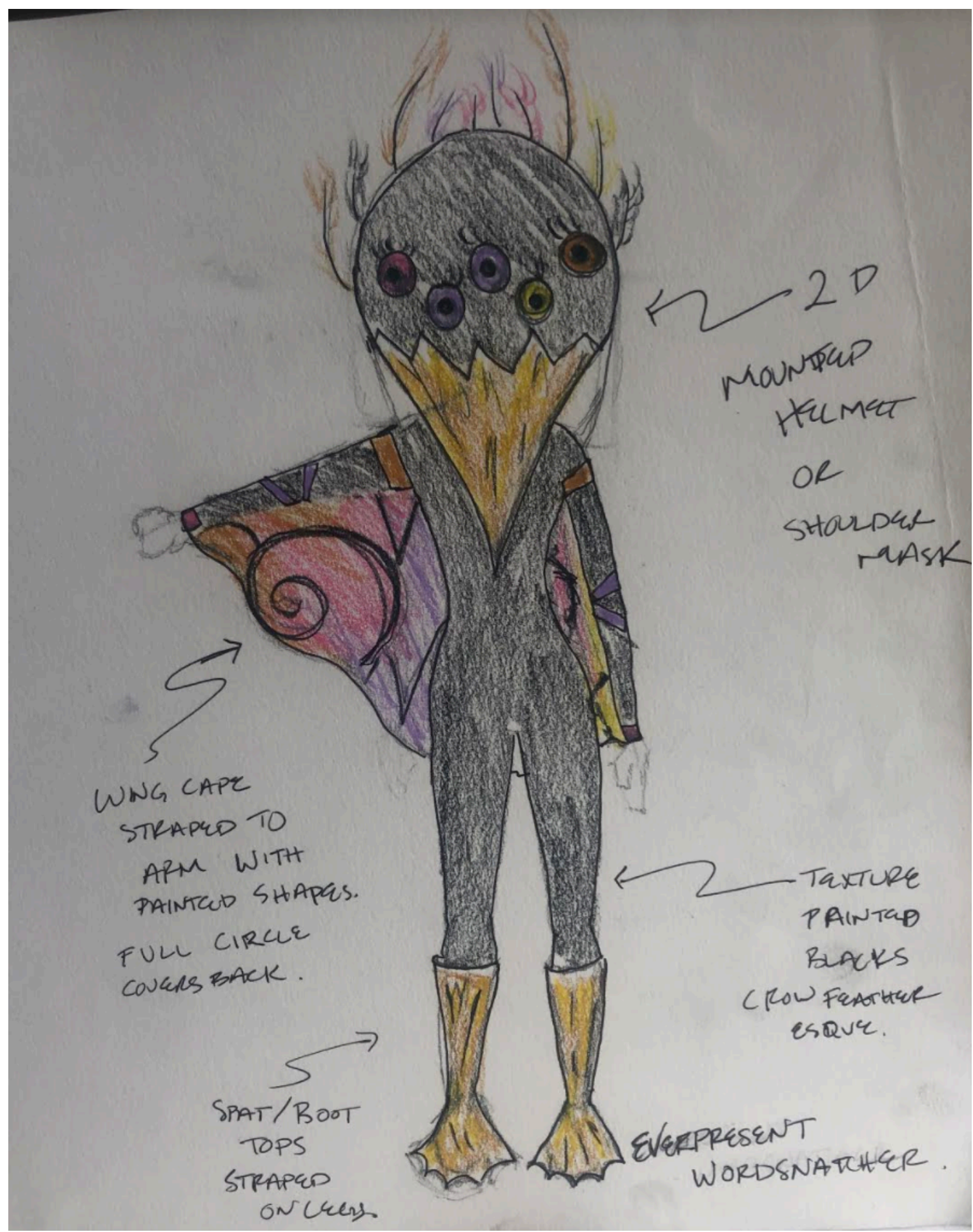

Figure 5.15: Everpresent Wordsnatcher color sketch. 


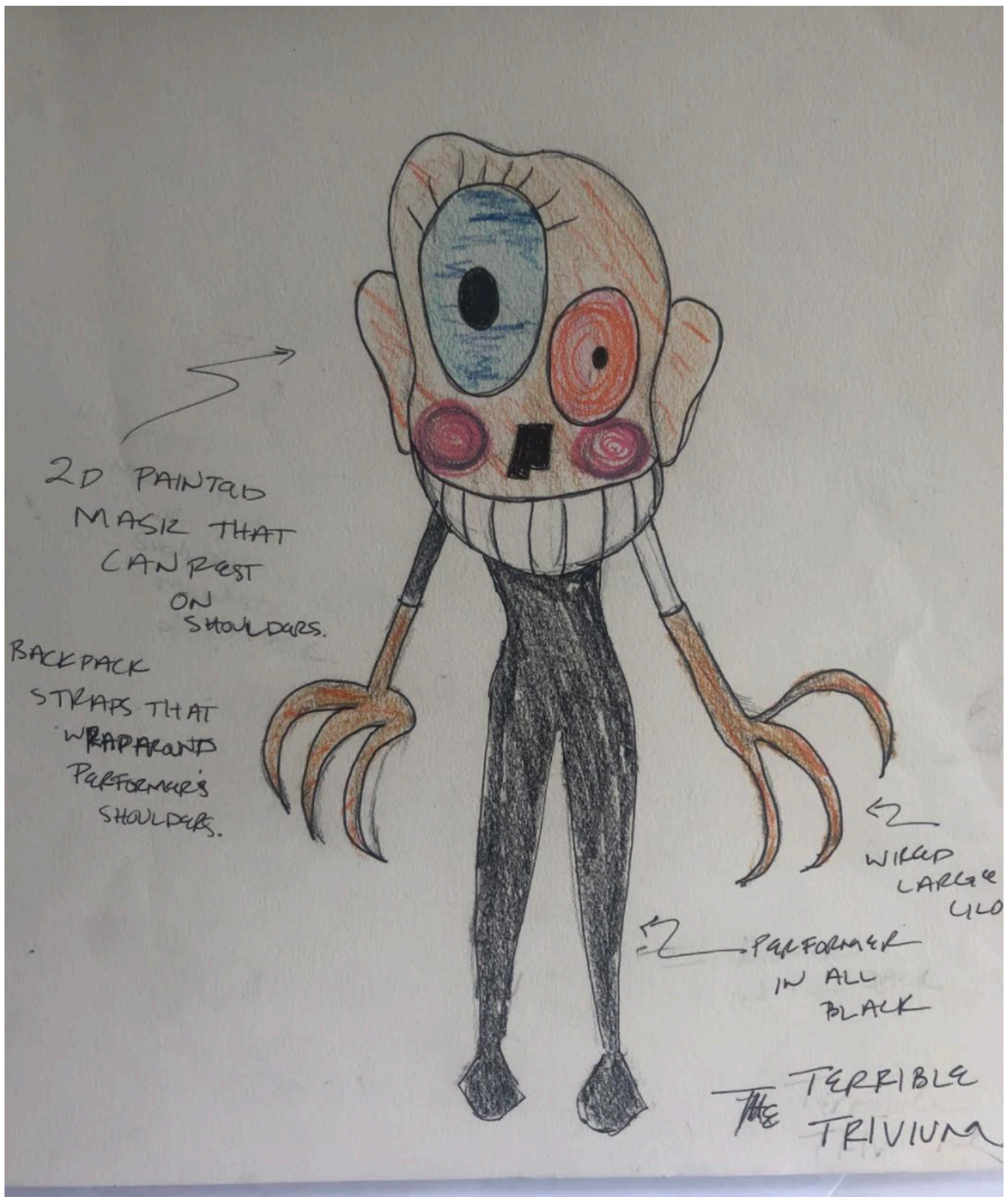

Figure 5.16: Terrible Trivium color sketch. 


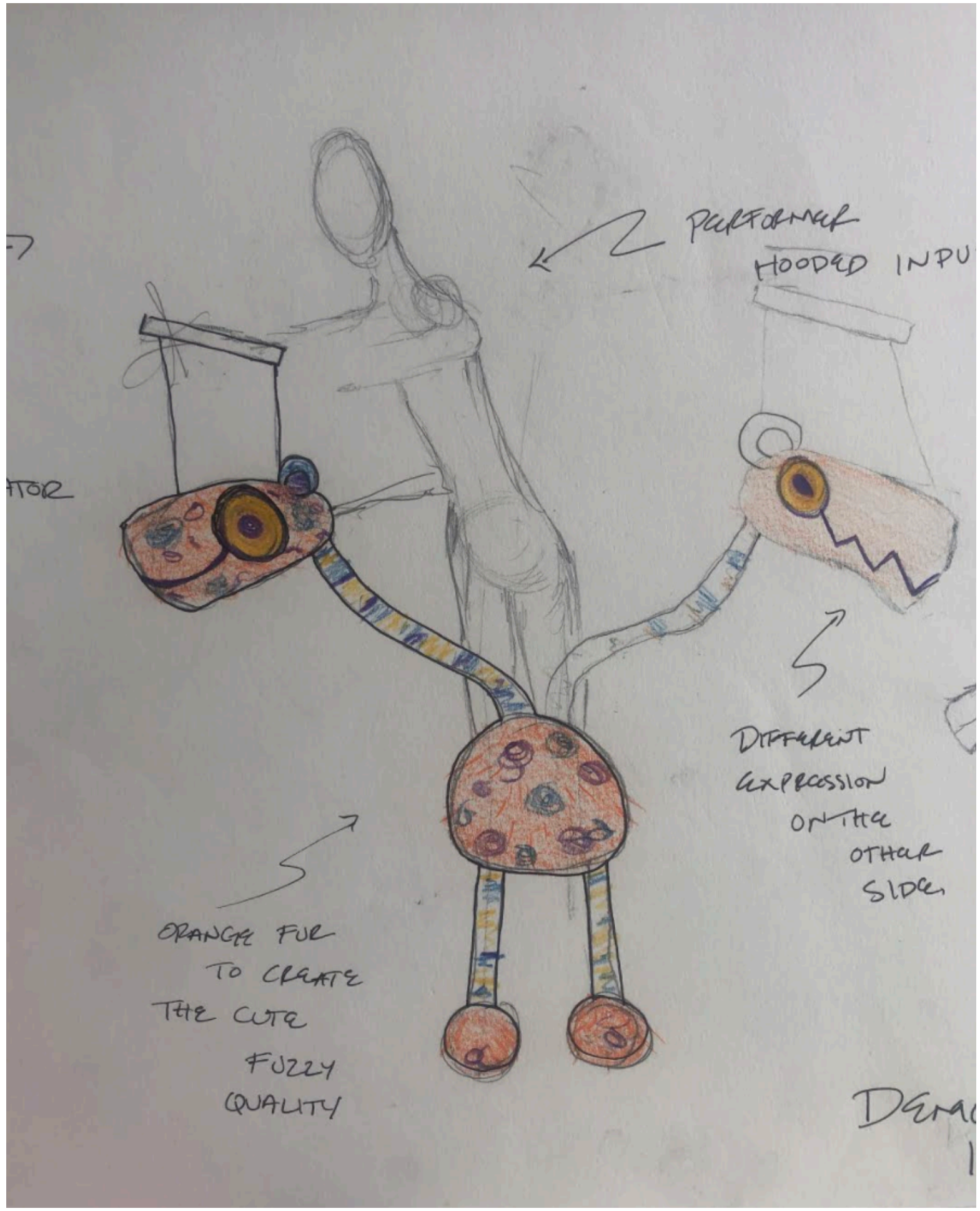

Figure 5.17: Demon on Insincerity color sketch. 


\section{BIBLIOGRAPHY}

Bateson, Patrick, and Paul Martin. Play, Playfulness, Creativity and Innovation. Cambridge University Press, 2013. ProQuest Ebook Central, http://ebookcentral.proquest.com/lib/wvu/detail.action?docID=1303631.

“Best Magnetic Toys for Kids to Buy 2020.” LittleOneMag, 10 June 2019, https://littleonemag.com/best-magnetic-toys-for-kids/.

CNN, By Jamie Gumbrecht. "Red Chair Interview: Norton Juster's Guide to Talking to Children.” CNN, https://www.cnn.com/2012/04/06/living/norton-juster-phantomtollbooth/index.html. Accessed 20 Jan. 2020.

“Cute Sitting Dog Plush Toy.” Stuffed Animal Manufacturers, Plush Toy Manufacturers, Custom Stuffed Animals Supplier Kaida, https://www.stuffedanimalmanufacturers.com/project/cute-sitting-dog-plush-toy/. Accessed 27 Jan. 2020.

“Dog Plush Toys Manufacturer.” Stuffed Animal Manufacturers, Plush Toy Manufacturers, Custom Stuffed Animals Supplier Kaida, https://www.stuffedanimalmanufacturers.com/dog/. Accessed 27 Jan. 2020.

Engin, Hande Bilsel. "Barbied Dreams, Barbied Lives: On Our Backs, in the Attics of Our Memories, on the Shelves." International Journal of Social Inquiry, vol. 6, no. 2, June 2013, pp. 18-37.

Fisher-Price US | Baby Gear and Toys | Home. https://www.fisher-price.com/en-us. Accessed 31 Jan. 2020.

“Interview with Author Norton Juster.” RIF.Org, 27 Aug. 2017, /literacycentral/material/interview-author-norton-juster. 
Nanus, Susan. The Phantom Tollbooth. Samuel French , 1977.

Saline, Sharon. “The Most Recent Dreams of Children Ages 8-11.” Dreaming, vol. 9, no. 2-3, June 1999, pp. 173-81. 1999-11074-005, EBSCOhost, doi:10.1023/A:1021345800325.

Singer, Dorothy G., and Jerome L. Singer. The House of Make-Believe: Children's Play and the Developing Imagination. Harvard University Press, 1992. ProQuest Ebook Central, http://ebookcentral.proquest.com/lib/wvu/detail.action?docID=3300254.

“Sleeping Beauty Doll - Princess Aurora Doll - Bendy Doll - Aurora Princess - Barker Toys Sleeping Beauty Toy - Disney Inspired Princess.” Etsy, https://www.etsy.com/listing/631583496/sleeping-beauty-doll-princessaurora?utm_source=OpenGraph\&utm_medium=PageTools\&utm_campaign=Share. Accessed 30 Jan. 2020.

Stephan, Julia, et al. "TV Viewing and Dreaming in Children: The UK Library Study." International Journal of Dream Research, Nov. 2012, pp. 130-33. journals.ub.uniheidelberg.de, doi:10.11588/ijodr.2012.2.9454.

“The Phantom Tollbooth by Norton Juster: 9780394820378 | PenguinRandomHouse.Com: Books." PenguinRandomhouse.Com, https:/www.penguinrandomhouse.com/books/89124/the-phantom-tollbooth-by-nortonjuster-illustrated-by-jules-feiffer/. Accessed 20 Jan. 2020.

Toys in the 90s - The Greatest Popular Toys from the 1990s. http://www.skooldays.com/blog/toys-in-the-90s/. Accessed 27 Jan. 2020. 